\title{
Review of Exemptions and General Licenses for Fissile Material in 10 CFR 71
}




\section{AVAILABILITY OF REFERENCE MATERIALS \\ IN NRC PUBLICATIONS}

\section{NRC Reference Material}

As of November 1999, you may electronically access NUREG-series publications and other NRC records at the NRC's Public Electronic Reading Room at http://www. nrc.gov/reading-rm. html. Publicly released records include, to name a few, NUREG-series publications; Federal Register notices; applicant, licensee, and vendor documents and correspondence; NRC correspondence and internal memoranda; bulletins and information notices; inspection and investigative reports; licensee event reports; and Commission papers and their attachments.

NRC publications in the NUREG series, NRC regulations, and Title 10, "Energy," in the Code of Federal Regulations may also be purchased from one of these two sources.

1. The Superintendent of Documents

U.S. Government Publishing Office

Washington, DC 20402-0001

Internet: http://bookstore.gpo.gov

Telephone: 1-866-512-1800

Fax: (202) 512-2104

2. The National Technical Information Service 5301 Shawnee Road

Alexandria, VA 22161-0002

http://www.ntis.gov

1-800-553-6847 or, locally, (703) 605-6000

A single copy of each NRC draft report for comment is available free, to the extent of supply, upon written request as follows:

\section{U.S. Nuclear Regulatory Commission \\ Office of Administration \\ Multimedia, Graphics, Storage, and \\ Distribution Branch \\ Washington, DC 20555-0001 \\ E-mail: distribution. resource@nrc.gov \\ Facsimile: (301) 415-2289}

Some publications in the NUREG series that are posted at the NRC's Web site address

http://www.nrc.gov/reading-rm/doc-collections/nuregs are updated periodically and may differ from the last printed version. Although references to material found on a Web site bear the date the material was accessed, the material available on the date cited may subsequently be removed from the site.

\section{Non-NRC Reference Material}

Documents available from public and special technical libraries include all open literature items, such as books, journal articles, transactions, Federal Register notices, Federal and State legislation, and congressional reports. Such documents as theses, dissertations, foreign reports and translations, and non-NRC conference proceedings may be purchased from their sponsoring organization.

Copies of industry codes and standards used in a substantive manner in the NRC regulatory process are maintained at-

\section{The NRC Technical Library \\ Two White Flint North \\ 11545 Rockville Pike \\ Rockville, MD 20852-2738}

These standards are available in the library for reference use by the public. Codes and standards are usually copyrighted and may be purchased from the originating organization or, if they are American National Standards, from-
American National
11 West 42 nd Street
New York, NY 10036-8002
http://www.ansi.org
(212) 642-4900

Legally binding regulatory requirements are stated only in laws; NRC regulations; licenses, including technical specifications; or orders, not in NUREG-series publications. The views expressed in contractorprepared publications in this series are not necessarily those of the NRC.

The NUREG series comprises (1) technical and administrative reports and books prepared by the staff (NUREG-XXXX) or agency contractors

(NUREG/CR-XXXX), (2) proceedings of conferences (NUREG/CP-XXXX), (3) reports resulting from international agreements (NUREG/IA-XXXX), (4) brochures (NUREG/BR-XXXX), and (5) compilations of legal decisions and orders of the Commission and Atomic and Safety Licensing Boards and of Directors' decisions under Section 2.206 of NRC's regulations (NUREG-0750).

DISCLAIMER: This report was prepared as an account of work sponsored by an agency of the U.S. Government. Neither the U.S. Government nor any agency thereof, nor any employee, makes any warranty, expressed or implied, or assumes any legal liability or responsibility for any third party's use, or the results of such use, of any information, apparatus, product, or process disclosed in this publication, or represents that its use by such third party would not infringe privately owned rights. 
United States Nuclear Regulatory Commission

Protecting People and the Environment

\section{Review of Exemptions and General Licenses for Fissile Material in 10 CFR 71}

Manuscript Completed: February 2017

Date Published: January 2018

Prepared by:

Douglas G. Bowen and Cecil V. Parks

Oak Ridge National Laboratory

Managed by UT-Battelle, LLC

Oak Ridge, TN 37831-6170

A. Barto, NRC Project Manager

NRC Job Code J5728 



\begin{abstract}
Title 10 of the United States (US) Code of Federal Regulations (CFR), Part 71, Packaging and Transportation of Radioactive Material, includes requirements for the transport of fissile material in packages. These regulations provide requirements for packages that are certified by the U.S. Nuclear Regulatory Commission (NRC) to transport fissile material. 10 CFR 71 also includes provisions for exemptions from classification as fissile material (10 CFR 71.15) and permits general licenses for limited quantities of fissile material and plutonium-beryllium special form sources (10 CFR 71.22 and 10 CFR 71.23, respectively). These provisions were extensively revised by the NRC as part of a broad rule-making effort in 2004. The exemption and general license provisions are used frequently for a wide-variety of fissile material shipping operations, and consignors must interpret the regulations for particular shipping situations. The purpose of this document is to provide explanatory information on the background, intent, and anticipated use of the provisions in an effort to assist fissile material licensees in their interpretation and application of the provisions such that criticality safety is ensured during transportation activities. A variety of examples are presented and discussed to illustrate how the regulations should be applied.
\end{abstract}





\section{TABLE OF CONTENTS}

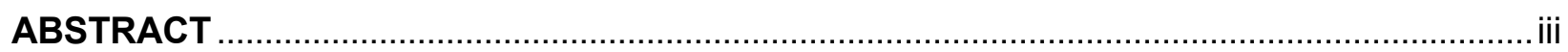

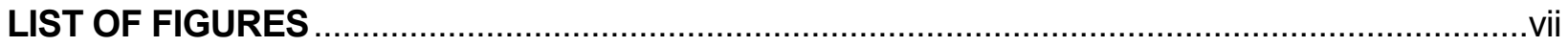

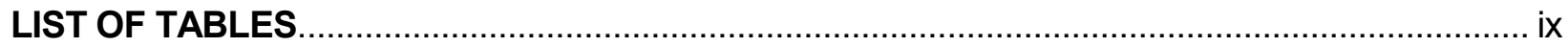

ACKNOWLEDGMENTS

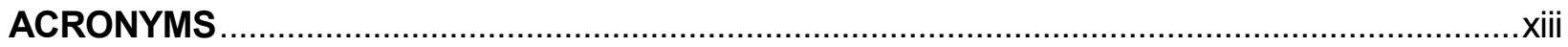

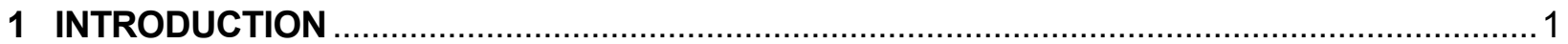

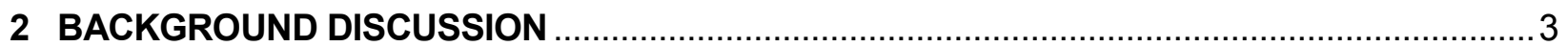

2.1 Parameters Controlling Criticality Safety ……..........................................................

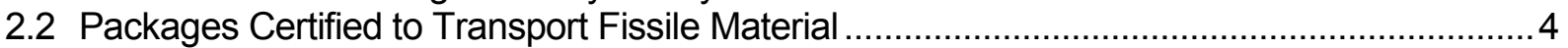

2.3 Exemptions from Classification as Fissile Material.............................................................

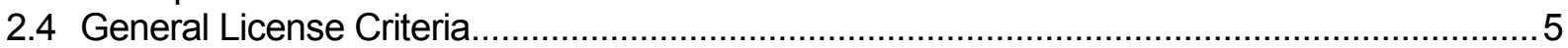

2.5 Packaging Requirements for Exemptions and General Licenses...................................... 6

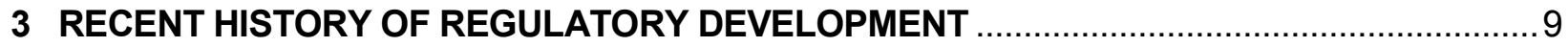

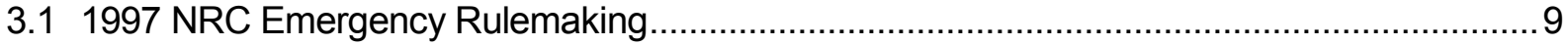

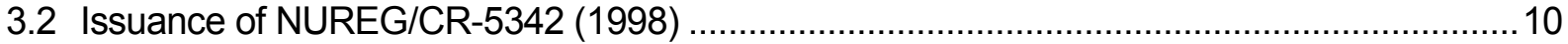

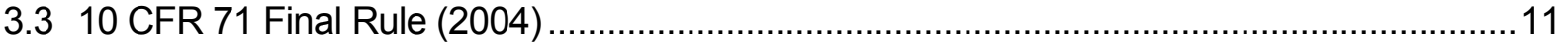

3.3.1 Exemptions from Classification as Fissile Material ..............................................11

3.3.2 General Licenses for Fissile Material..............................................................12

3.3.3 Plutonium-Beryllium Special Form Material General Licenses................................13

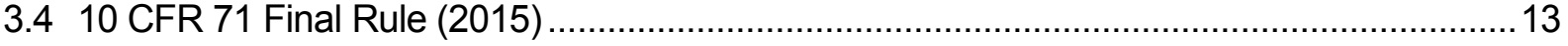

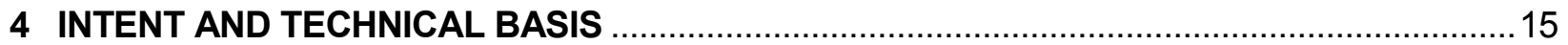

4.1 Exemptions from Classification as Fissile Material........................................................15

4.1.1 10 CFR 71.15(a): Individual Package Containing $2 \mathrm{~g}$ or Less Fissile Material...........16

4.1.2 10 CFR 71.15(b): Package Containing $15 \mathrm{~g}$ or Less Fissile Material .........................17

4.1.3 10 CFR 71.15(c) Low Concentrations of Solid Fissile Material Comingled with Solid Nonfissile Material .............................................................................19

4.1.4 10 CFR 71.15(d): Uranium Enriched in ${ }^{235} \mathrm{U}$ to a Maximum of 1 percent

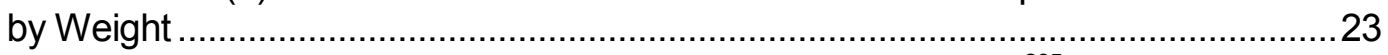

4.1.5 10 CFR 71.15(e): Liquid Solutions of Uranyl Nitrate Enriched in ${ }^{235} \mathrm{U}$ to a Maximum of 2 Percent....................................................................................26

4.1.6 10 CFR 71.15(f): Packages Containing Plutonium with a Large Percentage of

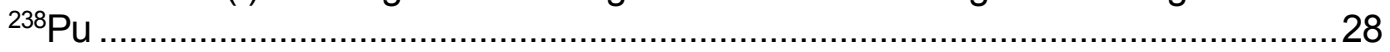

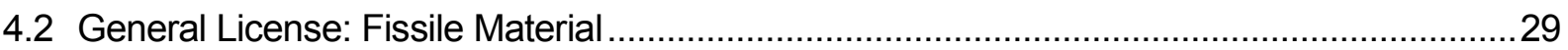

4.3 General License: Plutonium-Beryllium Special Form Material .............................................34

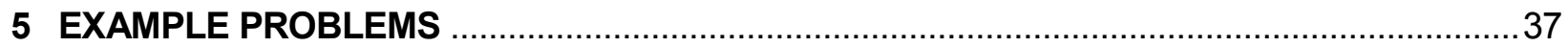

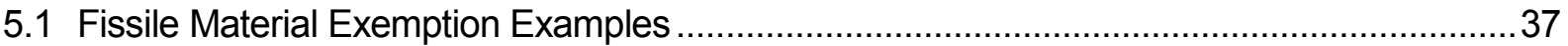

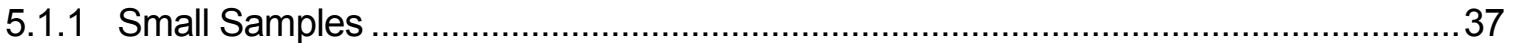

5.1.2 Plutonium-Contaminated Glove Box ……………................................................37

5.1.3 Uranium Contaminated Sludge ......................................................................38

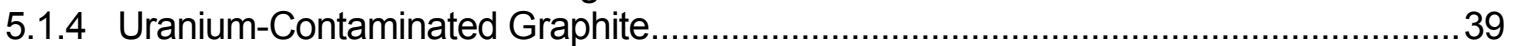

5.1.5 Soils Contaminated with Fissile Material ................................................................40

5.1.6 Contaminated Uranium Alumina Trap Contents ....................................................40

5.1.7 Uranium-Contaminated Process Equipment........................................................... 41 


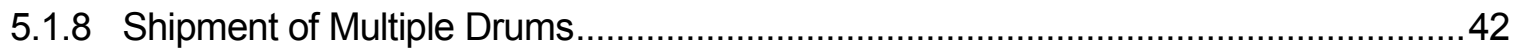

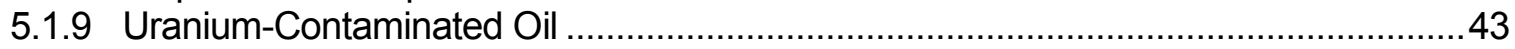

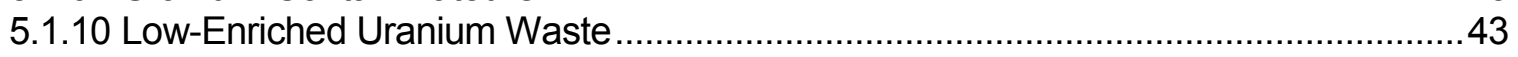

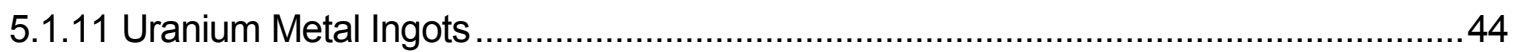

5.1.12 Uranyl Nitrate Solution from Spent Fuel Reprocessing .......................................44

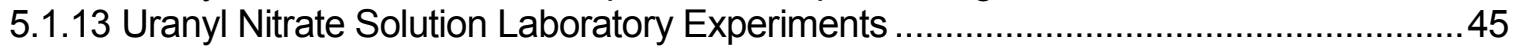

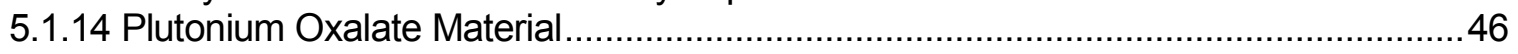

5.1.15 Plutonium-Contaminated Graphite Molds ....................................................... 46

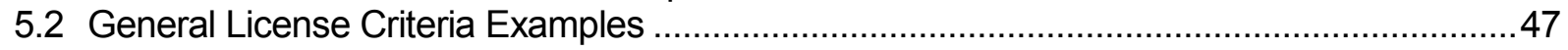

5.2.1 Uranyl Nitrate Solution Laboratory Experiments ............................................ 47

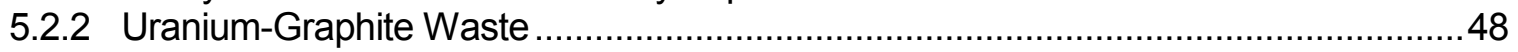

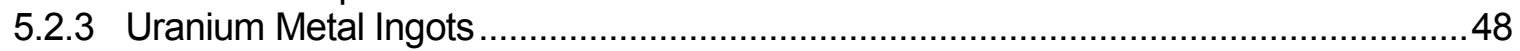

5.2.4 Sealed Sources for Gamma-Ray Measurements ................................................ 49

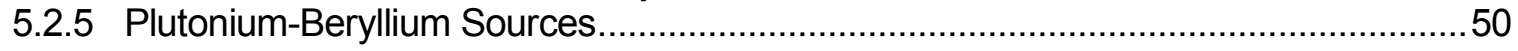

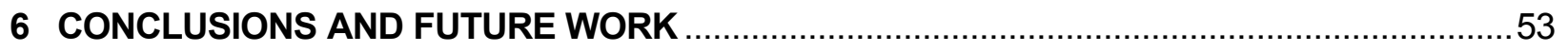

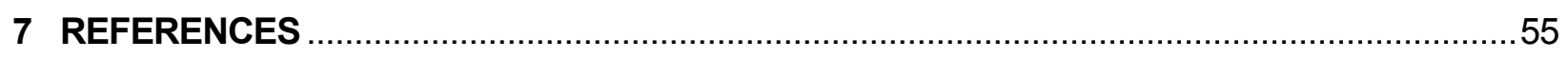

APPENDIX A BRIEF HISTORY OF 10 CFR 71 AND IAEA REGULATIONS FOR SAFE TRANSPORT OF RADIOACTIVE MATERIAL........................................ A-1

APPENDIX B DISCUSSION OF IAEA REGULATIONS ….......................................... 


\section{LIST OF FIGURES}

Figure 1 Spherical, Homogeneous Mixtures of ${ }^{235} \mathrm{U}$ and Various Nonfissile

Materials (30-cm Thick Water Reflection).

Figure 2 Infinite Homogeneous Mixture of ${ }^{235} \mathrm{U}$ Metal and Water with Aluminum

Present as a Diluent.

Figure 3 Infinite Homogeneous Mixture of ${ }^{235} \mathrm{U}$ Metal and Water with a Diluent-to- ${ }^{235}$ U Ratio of 2000.

Figure 4 Minimum Spherical Critical Masses as Functions of ${ }^{235} \mathrm{U}$ Enrichment in Homogeneous and Heterogeneous Hydrogen-Moderated Systems

(Ref. 21, Fig. 22).

Figure 5

Arrays of U(0.995)-Metal Units Immersed in Water.

Figure 6

$17 \times 17 \times 17$ Array of U(0.995)-Metal Units Immersed in Water.

Figure 9 Illustration of the HEU Sealed Source in 10 CFR 71.22 Example 4 (Figure Not to Scale). 



\section{LIST OF TABLES}

Table 1 Content in 10 CFR 71.15 "Exemption from the Classification as Fissile Material"...

Table 2

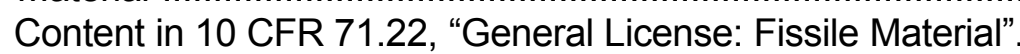

Table 3 10 CFR 71.22 Table 71-1-Mass Limits for General License Packages Containing Mixed Quantities of Fissile Material or ${ }^{235} \mathrm{U}$ of Unknown Enrichment per 71.22(e)...

Table 4 10 CFR 71.22 Table 71-2 Containing ${ }^{235} \mathrm{U}$ of Known Enrichment per 71.22(e)

Table 5 Content in 10 CFR 71.23 "General License: Plutonium-Beryllium Special Form Material"

Table 6 Isotopic Breakdown of Pu-Be Sources for 10 CFR 71.23 Example Problem 



\section{ACKNOWLEDGMENTS}

The authors would like to acknowledge the numerous sites throughout the U.S. Department of Energy (DOE) complex that provided perspective and feedback on the use of the regulations in 10 CFR 71 to support the content in this report. D. M. Willaford of the DOE Oak Ridge Office provided invaluable assistance with respect to discussing the end-user and the regulator perspective regarding the regulations. As the report was being developed the authors received invaluable direction and review by Andrew Barto of the U.S. Nuclear Regulatory Commission. The authors are also appreciative of the thorough technical reviews by C. M. Hopper, E. P. Elliott, B. Lee, E. Saylor, L. F. Gelder, and M. Conroy. The authors appreciate the technical editing by R. Raney. Kristin Ellestad provided administrative reviews of the document and final formatting. 



\section{ACRONYMS}

AEC U.S. Atomic Energy Commission

CFR Code of Federal Regulations

CSI Criticality Safety Index

DOE U.S. Department of Energy

DOT U.S. Department of Transportation

DU depleted uranium

HEU highly enriched uranium

IAEA International Atomic Energy Agency

ICC Interstate Commerce Commission

LLW low-level waste

NDA non-destructive assay

NRC U.S. Nuclear Regulatory Commission

ORNL Oak Ridge National Laboratory

QA quality assurance 



\section{INTRODUCTION}

Title 10 of the United States Code of Federal Regulations (CFR), Part 71 (Ref. 1), Packaging and Transportation of Radioactive Material, includes requirements for the transport of fissile material in packages. These regulations require analyses for single packages and arrays of packages under 10 CFR 71.55 and 71.59 , respectively, to demonstrate the package remains subcritical. These analyses must consider normal conditions of transport defined in 10 CFR 71.71 and hypothetical accident conditions as defined in 10 CFR 71.73. These analyses are approved by the U.S. Nuclear Regulatory Commission (NRC), which issues a certificate of compliance for the fissile material package.

The regulations also include provisions that allow for shipment of fissile material in packages that do not require NRC certification. These provisions include criteria for exemptions from classification as fissile material (10 CFR 71.15) and permit general licenses for limited quantities of fissile material and plutonium-beryllium special form sources (10 CFR 71.22 and 71.23, respectively).

The provisions in 10 CFR 71 were revised by the NRC in 2004 as part of a broad rulemaking effort that included extensive revision to the exemptions and general licenses for fissile material. The NRC has received many requests for interpretation of the exemptions from classification of fissile material and the general license provisions since the revisions were implemented. Consignors and shippers need to understand and correctly interpret and apply the regulations to ensure packages do not pose a criticality safety risk during transport. The consignor is responsible for verifying package contents and preparing a package for shipment under exclusive or nonexclusive use. The shipper is responsible for controlling the package consistent with the contents and the required shipping controls under exclusive or non-exclusive use.

Packages that might pose a criticality safety risk are those containing fissile nuclides, defined by 10 CFR 71 as ${ }^{233} \mathrm{U},{ }^{235} \mathrm{U},{ }^{239} \mathrm{Pu}$, and ${ }^{241} \mathrm{Pu}$ or any combination of these radionuclides. According to 10 CFR 71.4, Definitions, the definition of fissile material is meant to apply to the fissile nuclides themselves, not the bulk material containing fissile nuclides. The quantity of fissile material that presents a criticality safety risk depends upon the presence of other materials in the system that might absorb neutrons emitted from fission or moderate (slow) those neutrons to lower energies where the probability of them creating additional fission reactions is higher. Besides absorption and moderation of neutrons, other parameters that must be considered to ensure criticality safety are: the mass, concentration, or isotopic distribution of the fissile material and the system geometry and surrounding materials (reflectors) that might reflect neutrons back into the package. These parameters were carefully considered in developing the requirements for the exemptions from classification of fissile material and the requirements for general licenses for fissile material.

Thus, the purpose of this document is to provide explanatory information on the background, intent, and anticipated use of the provisions in an effort to assist fissile material licensees in their interpretation and application of the provisions such that criticality safety is ensured during transportation activities. Numerous example problems are provided in this report to illustrate the intent of the regulations and how they are applied to realistic transportation scenarios.

The International Atomic Energy Agency (IAEA) also issues regulations for the safe transport of radioactive material (Ref. 2), including fissile material, and both the U.S. and IAEA regulations governing safe transport domestically and internationally have evolved significantly over the past 50 years. 
Appendix A provides a brief discussion about the history of 10 CFR 71 and IAEA regulations for the safe transport of fissile material. Appendix $B$ provides additional information about the IAEA transportation regulations. 


\section{BACKGROUND DISCUSSION}

The objective of the fissile material exemptions in 10 CFR 71.15 and fissile material general licenses in 10 CFR 71.22 and 71.23 is to facilitate the safe transport of low-risk (e.g., small quantities or low concentrations) fissile material by exempting shipments of these materials from the packaging requirements and the criticality safety assessments required for fissile material transportation, and to allow the shipments to take place without specific Commission approval. The lower amount of regulatory oversight is acceptable for these shipments because the exemptions are established to ensure safety under all credible transportation conditions.

The exemption criteria in 10 CFR 71.15 provide criteria for the fissile material type, quantity, form, moderation, and mass concentration deemed adequate to ensure that there are no credible means to achieve a critical condition for a package or accumulation of packages under normal conditions of transport or hypothetical accident conditions. The type and quantity of fissile material (e.g., ${ }^{235} \mathrm{U}$ or ${ }^{239} \mathrm{Pu}$ ) are important because the mass required to achieve a critical condition (i.e., the critical mass) varies as a function of fissile nuclide. The critical mass for a fissile material can vary significantly when the fissile material is mixed with other types of material. Materials with a significant concentration of hydrogen or other moderating material (e.g., water, polyethylene) can thermalize neutrons in the system and significantly reduce the mass of fissile material necessary for criticality. Thus, the exemption criteria in 10 CFR 71.15 were established considering the potential for water to be present to an optimal extent; however, other moderators are also considered and limited as appropriate.

The general license criteria in 10 CFR 71.22 (fissile material) and 71.23 (Pu-Be special form material) are intended for the shipment of small quantities of fissile material per package with accumulation control provided by an assigned criticality safety index (CSI) for each package. However, the general license provision requires that the fissile material be contained in a Type A package that meets U.S. Department of Transportation (DOT) requirements of 49 CFR 173.417(a) ${ }^{1}$ applicable for "Authorized Fissile Material Packages," to ensure the package withstands normal conditions of transport without dispersing fissile material.

\subsection{Parameters Controlling Criticality Safety}

Nuclear Criticality Safety is defined as the "Protection against the consequences of a criticality accident, preferably by prevention of the accident" (Ref. 3). Ensuring criticality safety can be a complex process because it depends upon the direct or indirect control of many nuclear parameters ${ }^{2}$. The regulatory exemptions and general licenses for transport of fissile material establish criteria that, if followed, ensure that a package containing fissile radionuclides mixed with any type of material is incapable of inadvertent criticality during normal conditions of transport or hypothetical accident conditions. The NRC does not certify package designs or review shipments made in accordance with the criteria specified in 10 CFR 71 for exemption from fissile material classification or fissile material general licenses. To ensure that a transportation package

1 This section of 49 CFR 173.417(a) provides the packaging requirements for fissile materials (less than $A_{1}$ or $A_{2}$ quantities).

2 The nuclear parameters of interest to nuclear criticality safety are fissile mass, neutron absorption, fissile material geometry, and interaction between fissile material units, fissile concentration, neutron moderation, fissile nuclide enrichment, neutron reflection, and fissile material volume. 
containing fissile nuclides is incapable of inadvertent criticality (i.e., the package is subcritical ${ }^{3}$ ), criteria for the principal parameters of concern to nuclear criticality safety must be specified. These parameters of concern are: (Ref. 4)

- Type, mass, and form of the fissile material;

- Moderator-to-fissile material ratio (degree of moderation);

- Amount and distribution of moderator and absorber materials;

- Package geometry - internal and external; and

- Reflector effectiveness.

Since the 10 CFR 71 exemptions and general licenses for fissile material do not require a criticality safety evaluation for the actual packaging that is used for transport, the content configuration that might be held in place by the packaging cannot be relied on for criticality safety control. The specification within the general licenses for use of a Type A package does provide assurance that the package geometry should remain intact during normal conditions of transport. However, in general, to establish the criteria for the exemptions and general licenses, the parameters of concern for criticality safety were considered within the context of the hypothetical accident conditions of 10 CFR 71 and the ability of the consignor to confirm the contents of the package. The consignor should have knowledge of, or control over, the type, form, and mass of the fissile material; thus the specifications for these parameters were selected such that, when optimally configured and moderated, the package would remain in a subcritical condition at all times by assuming the worst-case abnormal conditions to account for any package alterations during shipment.

\subsection{Packages Certified to Transport Fissile Material}

Packages certified to transport fissile material are subject to rigorous criteria to ensure safety during transportation operations. Unless packages containing fissile material meet the exemption criteria in Part 71, Subpart B, "Exemptions," or Part 71, Subpart C, "General Licenses," they are subject to the requirements of Part 71, Subpart D, "Application for Package Approval," which requires applicants to provide a thorough package description (10 CFR 71.33), safety evaluation (10 CFR 71.35), and description of the applicant's quality assurance program (10 CFR 71.37). The packaging evaluation required by 10 CFR 71.35 includes provisions for the general requirements for individual packages containing fissile material and standards for arrays of such packages. These requirements are meant to ensure both individual packages and arrays of packages containing fissile material will be subcritical if subjected to normal conditions of transport and hypothetical accident conditions. Package accumulation on a conveyance is controlled by the CSI, which is defined in the regulations by 10 CFR 71.59(a) such that $2 \mathrm{~N}$ packages will remain subcritical under hypothetical accident conditions and $5 \mathrm{~N}$ packages will remain subcritical under normal conditions of transport. The number 50 divided by the limiting (lowest) $\mathrm{N}$ from the normal conditions of transport and hypothetical accident conditions array evaluations, rounded up to the

3 A fissionable material system is considered to be subcritical if the system effective neutron multiplication factor, $k$ eff, is less than one. Ref. 3 defines the effective multiplication factor as the ratio of the total number of neutrons produced during a time interval to the total number of neutrons lost by absorption and leakage during the same time interval. This definition excludes neutrons produced by sources whose strengths are not a function of the fission rate. 
nearest tenth, is the CSI. The CSI limit on a conveyance is 50 for shipment under nonexclusive use, and 100 for an exclusive-use shipment.

As discussed in the introduction to 10 CFR 71.15, fissile material meeting the criteria in 10 CFR 71.15 are exempt from the classification as fissile material and from the rigorous packaging standards in 10 CFR 71.55 and 71.59 .

\subsection{Exemptions from Classification as Fissile Material}

The criteria for exemption from classification as fissile material are designed to maintain the fissile concentration, fissile mass, and/or fissile enrichment sufficiently low that accidental criticality is not credible under normal conditions of transport or hypothetical accident conditions, as defined in 10 CFR 71. Under normal conditions of transport, a single package could easily be shown to remain subcritical; however, the fissile exemptions also consider the accumulation of fissile mass as a result of the commingling of multiple packages. Thus, the fissile mass or mass concentration must be sufficiently low, based on conservative assumptions, to assure a subcritical arrangement for transport of individual or multiple packages. The exemption criteria are based on worst-case or optimal conditions, including: unlimited accumulation; optimum moderation by water; presence of low-neutron-absorbing moderators such as beryllium, graphite, or hydrogenous material enriched in deuterium; spherical geometry; and pure fissile content (i.e., ${ }^{239} \mathrm{Pu},{ }^{241} \mathrm{Pu}$, ${ }^{235} \mathrm{U}$, or ${ }^{233} \mathrm{U}$, without nonfissile uranium and plutonium nuclides). The bases for each of the exemption criteria will be discussed later in this report. The exemption criteria also consider the rearrangement or reconfiguration of fissile material during transport to ensure that all realistic and foreseen arrangements will remain in a subcritical state during the transport operations. The exemption criteria in 10 CFR 71.15 do not take credit for packaging materials or packing geometry since there are no packaging requirements listed with the provisions. Thus, reconfiguration of the contents during hypothetical accident conditions must be considered. The technical bases for the criteria to exempt material from classification as fissile material assumes limited preferential fissile material redistribution based on a risk-based assessment of normal conditions of transport and hypothetical accident conditions.

\subsection{General License Criteria}

A general license for fissile material applies to the shipment of a Type A quantity ${ }^{4}$ of radioactive material in a Type A package or fissile material in the form of plutonium-beryllium ( $\mathrm{Pu}-\mathrm{Be}$ ) special form sealed sources. The quantity of fissile material $\left({ }^{235} \mathrm{U},{ }^{233} \mathrm{U},{ }^{239} \mathrm{Pu}\right.$ and ${ }^{241} \mathrm{Pu}$ ) and moderating materials, such as beryllium, graphite, or hydrogenous material enriched in deuterium is limited. The quantity of fissile material in sealed special form ${ }^{5}$ source capsules $\left({ }^{239} \mathrm{Pu}\right.$ and $\left.{ }^{241} \mathrm{Pu}\right)$ is also limited to preclude criticality. A Type A package is required to prevent the loss or dispersal of the radioactive contents and to maintain its shielding properties for all normal conditions of

4 Per the provisions in 10 CFR $§ 71.4$, "Definitions," a Type A quantity means a quantity of radioactive material, the aggregate radioactivity of which does not exceed the $A_{1}$ quantity for special form radioactive material, or $A_{2}$, for normal form radioactive material, where $A_{1}$ and $A_{2}$ are given in Table $A-1$ of this part, or may be determined by procedures described in Appendix A to Part 71. A Type A package is assumed to meet normal conditions of transport as prescribed in 10 CFR 71.

5 See 10 CFR 71.4, "Definitions," for the definition of special form radioactive material. 
transportation. As discussed in Ref. 5, a Type A package must withstand normal conditions of transport including:

1. Changing climate conditions: humidity, temperature, pressure, solar heating, and precipitation.

2. Dynamic and static mechanical effects: limited shock, repeated bumping, and vibration.

3. Compressive forces due to stacking or load movement.

The provisions in the general license criteria ensure that the fissile material configuration (fissile material mass mixed with other materials or Pu-Be sealed sources) present in a shipment will remain below the mass needed to achieve criticality for water-reflected, water-moderated systems. The quantity of fissile material in a single package is limited to a CSI of 10 for the general license in 10 CFR 71.22. Packages containing Pu-Be special form material under the general license of 10 CFR 71.23 are allowed to have a maximum CSI of 100 . For the shipment of multiple packages on a nonexclusive use conveyance, the CSI may be $\leq 50$. For the shipment of multiple packages on an exclusive use conveyance, the CSI must be $\leq \overline{100}$, because more control is required during the shipping process.

\subsection{Packaging Requirements for Exemptions and General Licenses}

The provisions of 10 CFR 71.15 provide exemptions from classification as fissile material and eliminate the need for the fissile material to be shipped in packages subject to the provisions of 10 CFR 71.55, "General Requirements for Fissile Material Packages," and 71.59, "Standards for Arrays of Fissile Material Packages." Radioactive material exempted from classification as fissile material must, however, still meet the same requirements as nonfissile radioactive material. The packaging chosen for material exempted from fissile material classification must be consistent with the type and amount of radioactive material present. The requirements in 10 CFR 71.15(a)(d) and (f), provide no specific packaging provisions. Uranyl nitrate solution shipped under 10 CFR 71.15(e) requires the liquid to be contained in at least a DOT Type A package.

The exemption in 10 CFR 71.15(a) requires that the mass of fissile material be limited to $\leq 2 \mathrm{~g}$ in an individual package. There are no packaging requirements as long as the quantity of fissile material present does not exceed the radionuclide exemption values in Table A-2, "Exempt Material Activity Concentrations and Exempt Consignment Activity Limits for Radionuclides." If the exemption values are exceeded for a particular radionuclide, a Type A package meeting the DOT requirements of 49 CFR $173.417(a)^{6}$ would have to be used. A Type B package would be required if the fissile material or nonfissile radioactivity exceeds the $A_{1}$ or $A_{2}$ values. For example, there are no packaging requirements for ${ }^{235} \mathrm{U}$ with up to $2 \mathrm{~g}$ per package because the $A_{1}$ and $A_{2}$ values are unlimited, whereas a Type $B$ package would be required for shipping more than $0.435 \mathrm{~g}$ of ${ }^{239} \mathrm{Pu}$ or $0.016 \mathrm{~g}$ of ${ }^{241} \mathrm{Pu}$ because the Type A quantity limit has been exceeded (Ref. 6). The provisions in 10 CFR 71.15(b) and (c) are similar in that packaging requirements are dictated by the total amount of fissile and nonfissile radioactive material in the package. However, those provisions also contain limitations on lead, beryllium, graphite and hydrogenous materials enriched in deuterium.

649 CFR 173.417, titled, "Authorized Fissile Material Packages," provides the packaging requirements for fissile material containing less than $A_{1}$ or $A_{2}$ quantities. 
For 10 CFR 71.15(e), the regulation states that liquid solutions of uranyl nitrate solutions must be contained within a DOT Type A package that meets the Type A standards in 71.43, "General Standards for All Packages." This requirement was established to ensure the liquid solutions present in the package were protected from any adverse conditions that could affect nuclear criticality safety during transport operations (e.g., redistribution, dilution, low temperatures that could affect fissile concentration, or collection into an unfavorable geometry). The exemption provisions in 10 CFR 71.15(f) provide exemption limits for plutonium isotopes (e.g., total Pu mass less than $1000 \mathrm{~g}$ with less than $20 \%$ by mass being ${ }^{239} \mathrm{Pu}$ or ${ }^{241} \mathrm{Pu}$ ). This provision allows a variety of nonfissile $\mathrm{Pu}$ isotopes (e.g., ${ }^{238} \mathrm{Pu}$ heat sources) to be shipped without packaging requirements or criticality safety assessment. It is recognized that Pu quantities shipped under this exemption will likely exceed a Type A quantity and require shipment in a Type B package.

The provisions of 10 CFR 71.22 and 71.23 both require the use of Type A packages. The fissile material is not required to be packaged in a container that meets the requirements of 10 CFR 71 Subpart E and F. A Type A package must meet the DOT requirements of 49 CFR 173.417(a) and cannot contain more than a Type A quantity of nonfissile radioactive material based on the $A_{1}$ and $A_{2}$ values in Table A-1 of Part 71. Quantities of radioactive material greater than a Type A quantity will require a certified Type $B$ package and cannot be shipped under a general license. Any Type A package required to ship fissile material with a general license must be able to withstand testing consistent with the normal conditions of transport such as a water spray test, $4 \mathrm{ft}$ drop test, penetration test, and stacking test. Documentation of the package's ability to withstand these conditions must be maintained to meet the requirements of 49 CFR 173.415. The use of a Type A package for the general license provisions represents more control over the shipment than is typically required for the exemptions from classification as fissile material, and, thus, allows for somewhat higher fissile mass limits to be shipped with little or no NRC oversight. 



\section{RECENT HISTORY OF REGULATORY DEVELOPMENT}

Since the inception of 10 CFR 71, provisions were included to allow exemption from classification as fissile material and fissile material general licenses. Prior to 1997, the following six exemptions from classification as fissile material were contained in 10 CFR 71.53:

- packages with $15 \mathrm{~g}$ or less of fissile material;

- select homogeneous hydrogenous solutions or mixtures of fissile material with limits specified on combinations of mass, ${ }^{235} \mathrm{U}$ enrichment, hydrogen content, and/or solution concentration;

- packages that can be demonstrated to have less than $5 \mathrm{~g}$ of fissile material in any $10 \mathrm{~L}$ volume;

- $\quad$ packages containing uranium enriched in ${ }^{235} \mathrm{U}$ to a maximum of $1 \mathrm{wt} \%$;

- packages containing liquid solutions of uranyl nitrate enriched in uranium to a maximum of 2 wt $\%{ }^{235} \mathrm{U}$; and

- $\quad$ packages with less than $1 \mathrm{~kg}$ of plutonium if the combined mass of ${ }^{239} \mathrm{Pu}$ and ${ }^{241} \mathrm{Pu}$ is less than $20 \%$ of the total plutonium mass.

As will be discussed further in this report, the last three exemptions cited above are largely retained in the current provisions of 10 CFR 71.15(d), 10 CFR 71.15(e), and 10 CFR 71.15(f). The criteria for the first exemption were originally justified based on a maximum shipment of 250 packages, with minimal consideration of hypothetical accident conditions. Criteria for the next two exemptions were specified with parameter values that ensured subcriticality under controlled conditions, but there was little consideration regarding how normal conditions of transport or hypothetical accident conditions might impact the as-loaded parameter values. These concerns, together with concerns regarding low neutron absorbing moderators, created extensive discussion at the IAEA in the decade prior to the issuance of the 1996 edition of the IAEA Regulations in which revisions to the exemptions were made to address the concerns.

The general licenses for fissile material prior to 1997 existed as four separate provisions: (1) limited quantity per package; (2) limited moderator per package; (3) limited quantity, controlled shipment; and (4) limited moderator, controlled shipment. Both the general license provisions and the exemptions from classification as fissile material have been significantly revised since the 10 CFR 71 versions that existed prior to 1997. The details of these revisions will be discussed in the following sections.

\subsection{NRC Emergency Rulemaking}

In September 1996, the NRC was notified by one of its licensees about use of the volume-based concentration criteria within the fissile material exemption provided at the time as 10 CFR 71.53(d). This provision exempted the material from classification as fissile material provided there were less than $5 \mathrm{~g}$ of fissile radionuclides in a $10 \mathrm{~L}$ volume and the material was packaged such that this concentration was maintained during normal conditions of transport (Ref. 7). The licensee was planning to ship significant quantities of material containing enriched uranium and beryllium oxide (uranium-beryllium filter cake) that was the waste product of a process involving highly enriched uranium materials. Based on licensee calculations, (Ref. 8) the potential for criticality in a large volume system (e.g., greater than 2000 L) could be realized even with adherence to the volume concentration limits specified for exemption in 10 CFR 71.53(d). This potential for criticality was possible because the exemption limits at the time assumed that water is the most limiting moderator and reflector material that can be credibly present in a 
package. Although hydrogen, which is abundant in water, is the optimal moderator to obtain the minimum fissile mass that can achieve criticality, other moderators with absorption cross-sections smaller than hydrogen enable criticality with a lower mass concentration than that provided by hydrogen. Thus, the fissile mass to achieve criticality would be higher in a beryllium-moderated system than in a hydrogen-moderated system. However, if the beryllium-moderated system is large enough, a critical configuration can be achieved with a fissile-to-moderator concentration that is lower than that for a hydrogen-moderated system.

As determined by the licensee and by Oak Ridge National Laboratory (ORNL), (Ref. 4) other lowneutron-absorbing moderator materials such as beryllium, graphite, and heavy water $\left(D_{2} O\right)$ could be present in transportation packages, but their presence is expected to be far less frequent than water or other materials commonly used in the nuclear industry or found in the environment. Based on licensee calculations, the NRC declared 10 CFR 71.53 deficient (Ref. 9) and decided that the regulations should be changed to ensure that materials that have neutron absorption cross-sections less than that of water (e.g., beryllium, graphite and heavy water) were sufficiently limited to ensure subcriticality even for large volume systems.

Also, the fissile material exemptions that existed at the time in 10 CFR 71.53 provided limits on the quantity of fissile materials that could be shipped in individual packages; however, the regulations did not limit the total amount of fissile material in a consignment or on a conveyance. There was a recognized concern for criticality safety given the possibility for accumulation of large numbers of packages in a consignment, even though the single package limits might be compliant.

To address the concerns with (a) low neutron absorbing moderators, (b) moderators with hydrogen densities greater than water, and (c) uncontrolled mass accumulation, the NRC issued an emergency rulemaking in 1997 to revise 10 CFR 71 to be consistent with the fissile exception ${ }^{1}$ criteria developed by the IAEA (Ref. 10). This revision to 10 CFR 71 limited the quantity of beryllium, hydrogenous material enriched in deuterium, and graphite ${ }^{2}$ that could be present in packages that were to be shipped under a general license or handled as exempt from certification by the NRC to contain fissile material. The revised regulations allowed use of the exemptions or general licenses only when these moderating materials were not present in quantities exceeding 0.1 percent of the fissile material mass (Ref. 11). In Ref. 10, accumulation of packages classified as exempt was addressed by providing limits on the fissile mass in a consignment and providing additional (lower) limits for systems where moderators with hydrogen density greater than water might exist. These limits on the fissile mass in a consignment were assumed by the IAEA to provide a conservative level of control from a criticality safety perspective during transportation.

\subsection{Issuance of NUREG/CR-5342 (1998)}

The emergency rule issued by the NRC in 1997 resulted in numerous public concerns and comments because the rule was initially issued without a public comment period. Based on these issues and NRC staff concerns regarding potential deficiencies and inconsistencies in the regulations, the NRC decided to further assess the 10 CFR 71 provisions related to exemptions

1 The IAEA uses the phrase "fissile material exception" in SSR-6 whereas the United States uses the phrase "fissile material exemption" in 10 CFR 71.

2 Graphite has not been listed as a special moderator in IAEA SSR-6. 
and general licenses for fissile material (Ref. 4). The NRC requested that ORNL assess the 1997 revision of 10 CFR 71 with the following objectives in mind:

1. Document perceived deficiencies in the technical or licensing bases that might be averse to maintaining adequate subcriticality under normal conditions of transport and hypothetical accident conditions;

2. Identify areas where regulatory wording could cause confusion among licensees and potentially lead to subsequent safety concerns;

3. Study and identify the practical aspects of transportation or licensing that could mitigate, justify, or provide a historical basis for any identified potential deficiencies; and

4. Develop recommendations for revising the current regulations to minimize operational and economic impacts on licensees while maintaining safe practices and correcting identified deficiencies.

The assessment details and resulting recommendations can be found in Ref. 4 . This report concluded that there were "no significant or immediate criticality safety hazards associated with the practical applications of the general licenses and exemptions. The reason for this conclusion is that the typical qualifying fissile material matrix in a general license or exempt consignment is relatively stable as a dry activated waste or in a nearly noncombustible form". The report also noted that the consignment mass limits provided for the fissile material exemptions enhance the safety margin. However, the report concluded that consignors could misinterpret the fissile material exemption and general license requirements in the 1997 version of 10 CFR 71 and that the requirements could be applied inconsistently based on this misinterpretation. For example, limiting the fissile mass in a consignment did not appear to be effective considering some consignor's misinterpretation of the regulations as only administrative requirements, maintaining the consignment mass limit but accumulating multiple consignments on a conveyance (Ref. 3). Further, the report provided recommendations aimed at clarifying and simplifying the regulations and enhancing the flexibility of use (e.g., suggestions that would allow removal of the consignment limit for certain exemptions) while still maintaining assurance of criticality safety (Ref. 4). The NRC considered the ORNL recommendations (Ref. 4) in the proposed revision to 10 CFR 71 issued in 2002 (Ref. 12). The NRC allowed opportunities for the public to provide comments (Refs. 13-15) prior to the issuance of a final 10 CFR 71 rule that was effective in October 2004.

\subsection{CFR 71 Final Rule (2004)}

The final rule for a revision to 10 CFR 71 was effective on October 1, 2004 (Ref. 16). This rule revised the regulations to be generally more consistent with the 1996 revision of the IAEA regulations for the safe transport of radioactive material (Ref. 17). However, the exemptions from classification of fissile material are different than those found in Ref. 17. The final rule also considered changes in the exemption criteria for fissile material as a result of public comments that indicated some changes made during the 1997 emergency rulemaking were an economic burden for licensees with no gain in safety benefit. The intention behind the revised criteria was that they be practical for consignors to evaluate and be straightforward to implement. The criteria were subject to a public comment period during the rulemaking process.

\subsubsection{Exemptions from Classification as Fissile Material}

The existing six exemptions for fissile material were re-designated in the 2004 rulemaking as 10 CFR 71.15, "Exemption from classification as fissile material," under Subpart B, "Exemptions." Criteria for three new exemptions were included in this revision: (a) $2 \mathrm{~g}$ of fissile material per 
package; (b) $15 \mathrm{~g}$ of fissile material with a mass ratio of nonfissile to fissile material of 200:1; and (c) fissile material with a mass ratio of nonfissile to fissile material of 2000:1, with a requirement that there may be no more than $180 \mathrm{~g}$ of fissile material distributed within any $360 \mathrm{~kg}$ of contiguous nonfissile material. These new provisions allowed for the presence of lead, beryllium, graphite, and hydrogenous material enriched in deuterium, provided these materials are not designated as solid nonfissile material mass for ratio determination. The exemption for ${ }^{235} \mathrm{U}$ enriched up to $1 \mathrm{wt} \%$ was modified to replace the requirement for limiting heterogeneity and lattice arrangement within the package with a restriction on the quantities of beryllium, graphite, hydrogenous material enriched in deuterium of less than $5 \%$ of the uranium mass. The exemption for liquid solutions of uranyl nitrate was modified with the 2004 rulemaking to require the material be present in at least a DOT Type A package. Finally, the exemption for plutonium, $10 \mathrm{CFR}$ 71.15(f) (previously $10 \mathrm{CFR} 71.53[\mathrm{e}]$ ), was modified slightly to note that the requirement is applicable to individual packages only. Exemptions that set criteria based on mass per unit volume had been used in previous versions of 10 CFR 71 but were removed from 10 CFR 71 based on the recommendations in Ref. 4.

\subsubsection{General Licenses for Fissile Material}

In the 2004 rulemaking, the previous general license requirements from 10 CFR 71.18, "General license: Fissile material, limited quantity per package," 10 CFR 71.20, "General license: Fissile material, limited moderator per package," 10 CFR 71.22, "General license: Fissile material, limited quantity, controlled shipment," and 10 CFR 71.24, "General license: Fissile material, limited moderator, controlled shipment," were simplified and combined under a single section, 10 CFR 71.22, "General license: Fissile Material." This section contains a formula to determine the CSI for each package based on the fissile material mass in the package. The CSI is limited to 10 for any individual package, and the CSI formula is constructed to ensure that the fissile material mass on any conveyance is no more than half of the safe subcritical mass limit for a nonexclusive use shipment.

This revised general license for fissile material includes a new requirement, 10 CFR 71.22(a), that directs licensees to ship fissile material under a general license in a Type A package to ensure the requirements of 49 CFR 173.417 (a) are met. Prior versions of the regulations required only that the package contents are limited to no more than a Type A quantity of radioactive material, and did not contain packaging requirements. The revised regulation in 10 CFR 71.22(b) states that the general license provisions only apply to those licensees that have an NRC-approved quality assurance program that satisfies the requirements of 10 CFR 71, Subpart H, "Quality Assurance." The general license criteria under 10 CFR 71.22(c)(1) and (c)(2) limit the package contents to no more than a Type A quantity of radioactive material and less than 500 total grams of beryllium, graphite, or hydrogenous materials enriched in deuterium. These criteria for beryllium, graphite, and deuteriumbased materials replace the earlier provision to limit them to $0.1 \%$ of the fissile material mass and should be more convenient from a licensee compliance perspective because the content quantities (e.g., fissile material and moderating material mass) are generally easier to determine.

The revised general license criteria under 10 CFR 71.22(d) provide the requirements for calculating the CSI of a package and limit the CSI for a shipment depending on whether the conveyance is exclusive use $(\mathrm{CSI} \leq 100)$ or nonexclusive use $(\mathrm{CSI} \leq 50)$. The CSI is calculated with the formula provided in 10 CFR 71.22(e)(1) along with the appropriate fissile material mass limits listed in Tables 71-1 and 71-2. Table 71-1 is a listing of mass limits for general license packages containing mixed quantities of fissile material $\left({ }^{235} \mathrm{U},{ }^{233} \mathrm{U},{ }^{239} \mathrm{Pu}\right.$, and $\left.{ }^{241} \mathrm{Pu}\right)$ or ${ }^{235} \mathrm{U}$ of unknown enrichment. The table provides separate mass limits for packages that might have fissile material mixed with moderating substances with hydrogen densities that are greater than that of 
water. Table $71-2$ is a listing of mass limits for general license packages containing ${ }^{235} \mathrm{U}$ of known enrichment, up to $24 \mathrm{wt} \%$.

\subsubsection{Plutonium-Beryllium Special Form Material General Licenses}

A new provision was added to the 2004 revision of 10 CFR 71 for the shipment of Pu-Be specialform fissile material. This new provision consolidates general license provisions on the shipment of $\mathrm{Pu}$-Be special form sources as contained in various portions (i.e., $10 \mathrm{CFR} 71.18$ and 10 CFR 71.22) of the earlier regulations. The new provisions in 10 CFR 71.23 reduce the maximum quantity of fissile Pu-Be special form sources that can be shipped on a single conveyance through changes in the mass limits and calculation of the CSI (Ref. 15). As is the case for the fissile material general licenses, the revised regulations in 10 CFR 71.23 require licensees to have an NRC-approved quality assurance program that satisfies the requirements of 10 CFR 71, Subpart H, "Quality Assurance." The Pu-Be special form sources must be contained within a Type A package that meets the requirements of 49 CFR 173.417(a). These provisions require the package to contain no more than a Type A quantity of fissile material and less than $1000 \mathrm{~g}$ of plutonium provided that ${ }^{239} \mathrm{Pu},{ }^{241} \mathrm{Pu}$ or any combination of these radionuclides constitutes less than $240 \mathrm{~g}$ of the total quantity of plutonium in the package. This general license applies to a package that is labeled with a CSI calculated using the formula of 10 CFR 71.23(e). The total CSI must be less than or equal to 50 for a non-exclusive use conveyance and less than or equal to 100 for an exclusive use conveyance.

\subsection{CFR 71 Final Rule (2015)}

The 2004 rulemaking described above changed the provisions of 10 CFR 71.15(d) to remove the restriction that uranium enriched to $1 \mathrm{wt} \%$ or less in ${ }^{235} \mathrm{U}$ must be distributed homogeneously and not form a lattice arrangement within the package. The terms homogeneity and lattice arrangement were not clearly defined, and a restriction on beryllium, graphite, and hydrogenous material enriched in deuterium would be sufficient to prevent criticality in all but a very large system that includes a repeating array of low-enriched uranium particles. These large systems were judged to be impractical for transport scenarios.

Subsequent to the 2004 rulemaking, DOE identified a planned shipment of large quantities of lowenriched fissile material that would qualify for the exemption at 10 CFR 71.15(d). Analyses performed by DOE indicated that large arrays (i.e., multiple conveyances) of heterogeneous uranium with enrichment of one percent by weight of ${ }^{235} \mathrm{U}$ could exceed an effective multiplication factor (Ref. 3), $k_{\text {eff, of }} 0.95$ when optimally moderated by water. Because such a shipment, as analyzed, could both qualify for the fissile material exemption for low-enriched uranium and have a $k_{\text {eff }}$ greater than 0.95 , the NRC decided that additional restrictions on low-enriched fissile material shipped under the fissile material exemption at 10 CFR 71.15(d) were warranted to provide similar safety equivalence provided by certified packages per the criteria of 10 CFR 71.55 and 71.59 .

The NRC has restored former lattice arrangement and homogeneous distribution provisions in the revised 10 CFR 71.15(d) exemption requirement (Ref. 18). The revised provision excludes from the exemption's scope situations where fissile "lumps" or lattice arrangements of fissile material are present within the package. The 10 CFR 71.15(d) exemption language continues to exclude large quantities (less than $5 \%$ of the uranium mass) of low-absorbing moderators (beryllium, graphite, or hydrogenous material enriched in deuterium). These restrictions will preclude fissile material arrangements in packages that can potentially result in criticality at ${ }^{235} \mathrm{U}$ enrichments less than $1 \mathrm{wt} \%$. 



\section{INTENT AND TECHNICAL BASIS}

The exemptions from classification as fissile material and general licenses for fissile material and plutonium-beryllium special form sources are provided in the regulations without specifying the intent of the provision or the technical bases for the limitations in the provisions (e.g., fissionable material mass limits). The following sections provide this information to assist end users in effectively applying the fissile exemption and general license provisions.

\subsection{Exemptions from Classification as Fissile Material}

Fissile material is defined in 10 CFR 71.4 as the radionuclides ${ }^{233} \mathrm{U},{ }^{235} \mathrm{U},{ }^{239} \mathrm{Pu}$, and ${ }^{241} \mathrm{Pu}$, and refers to the nuclides themselves, not material containing these nuclides. Unirradiated natural uranium and depleted uranium, and natural uranium or depleted uranium that has been irradiated in thermal reactors only, are not included in this definition. Material that meets the definition of fissile material but that also meets one of the six exemption criteria in 10 CFR 71.15 can be transported in packages that do not meet the fissile material transportation requirements of 10 CFR 71.55 or 71.59 for packages certified to contain fissile material. For purposes of ensuring criticality safety, the exemptions consider that the material can be released from any packaging during transport, may reconfigure into a worst-case geometric arrangement, may combine with material from other transport vehicles, and may be subject to the fire and water immersion conditions assumed as part of the criticality safety assessment for package designs approved to transport fissile material. The exemptions are subject to all other requirements of $10 \mathrm{CFR} 71$ except as noted in the exemption criteria.

\section{Table 1 Content in 10 CFR 71.15 "Exemption from the Classification as Fissile Material”}

\section{CFR 71.15 Exemption from Classification as Fissile Material}

Fissile material meeting the requirements of at least one of the paragraphs (a) through (f) of this section are exempt from classification as fissile material and from the fissile material package standards of $\S \S 71.55$ and 71.59 , but are subject to all other requirements of this part, except as noted.

(a) Individual package containing 2 grams or less fissile material.

(b) Individual or bulk packaging containing 15 grams or less of fissile material provided the package has at least $\mathbf{2 0 0}$ grams of solid nonfissile material for every gram of fissile material. Lead, beryllium, graphite, and hydrogenous material enriched in deuterium may be present in the package but must not be included in determining the required mass for solid nonfissile material.

(c)(1) Low concentrations of solid fissile material commingled with solid nonfissile material, provided that:

(i) There is at least 2000 grams of solid nonfissile material for every gram of fissile material, and

(ii) There is no more than 180 grams of fissile material distributed within $360 \mathrm{~kg}$ of contiguous nonfissile material.

(c)(2) Lead, beryllium, graphite, and hydrogenous material enriched in deuterium may be present in the package but must not be included in determining the required mass of solid nonfissile material.

(d) Uranium enriched in uranium-235 to a maximum of 1 percent by weight, and with total plutonium and uranium-233 content of up to 1 percent of the mass of uranium-235, provided that the mass of any beryllium, graphite, and hydrogenous material enriched in deuterium constitutes less than 5 percent of the uranium mass, and that the fissile material is distributed homogeneously and does not form a lattice arrangement within the package. 
(e) Liquid solutions of uranyl nitrate enriched in uranium-235 to a maximum of 2 percent by mass, with a total plutonium and uranium-233 content not exceeding 0.002 percent of the mass of uranium, and with a minimum nitrogen to uranium atomic ratio $(\mathrm{N} / \mathrm{U})$ of 2 . The material must be contained in at least a DOT Type A package.

(f) Packages containing, individually, a total plutonium mass of not more than 1000 grams, of which not more than 20 percent by mass may consist of plutonium-239, plutonium-241, or any combination of these radionuclides.

The provisions for the exemption from classification as fissile material are currently present in the Code of Federal Regulations in two locations: 10 CFR 71.15 and 49 CFR 173.453. The intent and content of these regulations are identical. The current exemptions as taken from 10 CFR 71.15 are listed in Table 1.

The intent of including exemptions from classification as fissile material in the regulations is to reduce the burden and cost imposed for packages that contain quantities and concentrations of fissile material that are low risk in terms of potential for inadvertent criticality in transport. These packages can be shipped without a packaging assessment for criticality safety purposes and require little or no regulatory oversight. The exemption criteria in 10 CFR 71.15 provide limits on the fissile material type, quantity, form, moderation, and mass concentration under which there are no credible means to achieve a critical condition under normal conditions of transport or hypothetical accident conditions. Thus, the fissile exemption criteria in 10 CFR 71.15 limit the quantity of fissile material in a package while considering the presence of potential moderators.

\subsubsection{CFR 71.15(a): Individual Package Containing $2 \mathrm{~g}$ or Less Fissile Material}

$$
\text { 71.15(a) - Individual package containing } 2 \text { grams or less fissile material. }
$$

Exempting a small fissile material mass from classification as fissile material removes extensive regulatory and economic burden on what the NRC rulemaking process has deemed to be a low risk transportation activity. During the comment period after the NRC emergency rule was issued in 1997, there were nuclear industry concerns that, without a small mass exemption (there has previously been an exemption for $15 \mathrm{~g}$ of fissile material per package with no accumulation control), there would be a significant impact on commerce with respect to frequent shipments of very small quantities of fissile material such as environmental samples (Ref. 15). Individual packages containing less than $2 \mathrm{~g}$ of ${ }^{233} \mathrm{U},{ }^{235} \mathrm{U},{ }^{239} \mathrm{Pu}$, or ${ }^{241} \mathrm{Pu}$ contain such a low quantity of fissile materials that the risk of accumulating the number and type of packages needed to present a potential criticality hazard was judged to be inconsequential (Refs. 15 and 16).

Stated in Ref. 6, the intent of 10 CFR 71.15(a) is to limit a single package within a consignment to a de minimis value of two total grams of ${ }^{233} \mathrm{U},{ }^{235} \mathrm{U},{ }^{239} \mathrm{Pu}$, or ${ }^{241} \mathrm{Pu}$. This exemption does not limit the accumulation of $2 \mathrm{~g}$ packages because it was judged that shipment in sufficient numbers to pose a potential for criticality would be incredible based on practical and economic considerations. Unlimited quantities of ${ }^{235} \mathrm{U}$ samples could be shipped without any package requirements as a result of the $A_{1}$ and $A_{2}$ values being unlimited (10 CFR 71, Table A-1). For other fissile nuclides, the samples would have to be shipped in a Type A package if the quantities of radioactive material exceed the exempted quantities. Furthermore, a Type $B$ package is required if the quantity of radioactive material present exceeds the $A_{1}$ or $A_{2}$ values shown in Table $A-1$ (e.g., $>0.435 \mathrm{~g}$ for ${ }^{239} \mathrm{Pu}$ or $>0.016 \mathrm{~g}$ for ${ }^{241} \mathrm{Pu}$ for normal form material). 
The accumulation of a large number of these packages for this exemption does not appear to be credible, based on the number and volume of packages required to approach criticality. Ref. 15 discusses a series of calculations performed to determine the number of $1 \mathrm{~L}$ containers containing $2 \mathrm{~g}$ of fissile material required to achieve criticality under optimal conditions [i.e., pure ${ }^{235} \mathrm{U}$ (fully enriched uranium)], optimum moderation, optimum geometry (spherical units/cubic array), and full water reflected array. No packaging material is credited in these calculations. A cubic array of $84,8531 \mathrm{~L}$ packages was required at near-optimal moderation (hydrogen-to-uranium ratio of approximately 1200) for criticality to be possible. The size of the array in the calculation model was roughly $4.4 \mathrm{~m}(>14 \mathrm{ft})$ on a side. The results of these calculations demonstrate that it would be impractical or uneconomical to accumulate such a large number of such packages, especially considering that under realistic conditions (e.g., neutron absorption by package material and nonfissile uranium isotopes) a critical array would be much larger. Thus, the $2 \mathrm{~g}$ limit was added to the final rule issued in 2004.

\subsubsection{CFR 71.15(b): Package Containing $15 \mathrm{~g}$ or Less Fissile Material}

71.15(b) - Individual or bulk packaging containing 15 grams or less of fissile material provided the package has at least 200 grams of solid nonfissile material for every gram of fissile material. Lead, beryllium, graphite, and hydrogenous material enriched in deuterium may be present in the package but must not be included in determining the required mass for solid nonfissile material.

The intent of this fissile material exemption is to allow up to $15 \mathrm{~g}$ of fissile material in a package that has at least $200 \mathrm{~g}$ of solid nonfissile material present per gram of fissile material. The distribution of small quantities of fissile material in a matrix of nonfissile material will ensure that accidental criticality is precluded. According to Ref. 16, the nonfissile mass can include the packaging mass. Common nonfissile materials include concrete, aluminum, steel, and other packaging or waste materials. Lead, beryllium, graphite and hydrogenous materials enriched in deuterium may be present, but cannot be counted as nonfissile material in complying with the 1:200 mass ratio. The exemption was designed to allow industry to continue to use the $15 \mathrm{~g}$ limit historically used in the exemptions while addressing concerns related to package accumulation and low-absorbing non-hydrogenous moderators.

This exemption requirement would allow for consignors to prepare a package to ship small quantities of fissile material in such a way that nuclear criticality safety concerns related to the accumulation of a large number of fissile material packages are precluded. Consignors can meet this exemption requirement based on using the mass quantities of fissile and solid nonfissile materials present to prepare packages instead of using volume-based concentration limits that are difficult to verify. The ratio of $200 \mathrm{~g}$ of nonfissile material (excluding select moderating and reflecting materials) for every gram of fissile material is judged to provide adequate assurance that the accumulation of large numbers of packages will remain subcritical. The reduction in density significantly increases the minimum critical mass and eliminating nonfissile mass credit for moderating or reflecting materials - lead, beryllium, graphite, and hydrogenous materials enriched in deuterium - will prevent critical concentrations of fissile material. The quantity of these nonhydrogenous moderating and reflector materials cannot be included in the nonfissile material quantity, although they can be present in the package. The mass of lead is also not allowed to be credited as a nonfissile material in the package because, as an abundant and high-density $\left(11.4 \mathrm{~g} / \mathrm{cm}^{3}\right)$ material with an extremely low neutron absorption cross section, the presence of lead may not provide sufficient dilution and density reduction if a large number of packages are accumulated. 
Ref. 16 states that many other nonfissile materials such as iron, generic steels, and concretes have sufficient neutron absorption for them to be considered as the nonfissile mass to mix with up to 15 grams of fissile material, in a mass ratio of at least $200: 1$, to ensure the overall system is subcritical. Aluminum is also a common nonfissile material included in a package design because of its material properties and availability (Ref. 16). However, aluminum has a smaller neutron absorption cross-section at thermal energies than hydrogen, which makes it more of a diluent to this fissile material system than a significant neutron absorber. A series of KENO V.a calculations using ENDF/B-VII neutron cross sections were performed to estimate the effective multiplication factor, $k_{\text {eff, }}$ for a mixture of ${ }^{235} \mathrm{U}$ metal and various nonfissile materials. The solid nonfissile materials considered include aluminum (Al), Regulatory concrete, Rocky Flats concrete, Oak Ridge concrete, and carbon steel. ${ }^{1}$ The calculations consider an initial, maximum, spherical volume of $584 \mathrm{~m}^{3}$ that is representative of the maximum available volume in five public highway transport vehicles, e.g., two tandem trailers pulled by a single tractor (Ref. 4). This volume was reduced in the calculations, as necessary, to determine the critical volume, and, subsequently, the number of $15 \mathrm{~g}^{235} \mathrm{U}$ packages required for criticality $\left(k_{\text {eff }}=1.0\right)$. Two spherical configurations are considered in the calculations to directly determine the dilution effect of the $k_{\text {eff }}$ on the quantity of nonfissile materials present in the mixture: a dry ${ }^{235} \mathrm{U}$ metal-nonfissile mixture, and a flooded system that approximates an immersed package with the same ${ }^{235} \mathrm{U}$ metal-nonfissile mixture. Both configurations consider a spherical $30 \mathrm{~cm}$ thick water reflector. As a starting point for an immersed package, the water-moderated system assumes an $\mathrm{H} /{ }^{235} \mathrm{U}$ ratio of about 100 , corresponding, approximately, to an optimally moderated system for an infinite ${ }^{235} \mathrm{U}$-water mixture. The nonfissile material is then added to the dry and optimally-moderated configurations to examine the diluent effect. The results for a nonfissile-to-fissile mass ratio of 200 are then used to estimate the number of $15 \mathrm{~g}^{235} \mathrm{U}$ packages that will remain subcritical $\left(k_{\text {eff }}<1.0\right)$.

The results in Fig. 1 illustrate the significant effect of adding nonfissile materials to ${ }^{235} \mathrm{U}$ metal for both dry (unmoderated) and moderated configurations. It is clear from these results that only the carbon steel and ${ }^{235} \mathrm{U}$ mixtures will remain subcritical for an unlimited number of $15 \mathrm{~g}^{235} \mathrm{U}$ packages. For the rest of the nonfissile materials considered in these calculations, subcriticality can only be assured for a finite number of $15 \mathrm{~g}^{235} \mathrm{U}$ packages. The number of packages that remain subcritical for the dry configuration is approximately $250,850,1100$, and 500,000 for Regulatory concrete, Oak Ridge concrete, Rocky Flats concrete, and Aluminum, respectively. The number of $15 \mathrm{~g}^{235} \mathrm{U}$ packages that remain subcritical for the moderated (immersed) configuration is approximately $600,800,1100$, and 20,000 for Regulatory concrete, Oak Ridge Concrete, Rocky Flats concrete, and Aluminum, respectively. The Regulatory concrete results indicate the smallest number of $15 \mathrm{~g}^{235} \mathrm{U}$ packages that remain subcritical for both dry and moderated configurations, but is a hypothetical concrete mixture. The Oak Ridge and Rocky Flats concrete mixtures, which are typical concrete mixtures, require additional $15 \mathrm{~g}^{235} \mathrm{U}$ packages, 850 and 1100 for the dry configuration and 800 and 1100 for the moderated configuration, respectively, to achieve criticality. The Al results show much more Al can be added to $15 \mathrm{~g}^{235} \mathrm{U}$ packages as a diluent than the concrete configurations. These extremely conservative calculations demonstrate a large number of packages can be combined and shipped safely with a 200 nonfissile-to-fissile mass

\footnotetext{
${ }^{1} \mathrm{NRC}$ regulatory concrete, developed for the $\mathrm{NRC}$, is a mixture (density is $2.3 \mathrm{~g} / \mathrm{cm}^{3}$ ) comprised of $1.4 \mathrm{wt} . \% \mathrm{Fe}, 1.0 \mathrm{wt} \% \mathrm{H}$, 3.4 wt. \% Al, 4.4 wt. \% Ca, 53.2 wt. \% O, 33.7 wt. \% Si, and 2.9 wt. \% Na. Rocky Flats concrete is a mixture (density is 2.321 $\mathrm{g} / \mathrm{cm}^{3}$ ) comprised of 1.01 wt. \% Fe, 0.75 wt. \% H, 5.52 wt. \% C, 0.02 wt. \% N, 48.49 wt. \% O, 0.63 wt. \% Na, 1.25 wt. \% Mg, 2.17 wt. \% Al, 15.5 wt. \% Si, 0.19 wt. \% S, 1.37 wt. \% K, 23.0 wt. \% Ca, and 0.1 wt. \% Ti. Oak Ridge concrete is a mixture (density is $2.2994 \mathrm{~g} / \mathrm{cm}^{3}$ ) comprised of 0.7784 wt. \% Fe, 0.6187 wt. \% H, 17.52 wt. \% C, 41.02 wt. \% O, 0.0271 wt. \% Na, 3.265 wt. \% Mg, 1.083 wt. \% Al, 3.448 wt. \% Si, 0.1138 wt. \% K, and 32.13 wt. \% Ca. Carbon Steel (density is 7.8212 g/cm ${ }^{3}$ ) is comprised of 1.0 wt. \% C and 99.0 wt. \% Fe. Aluminum has a density of $2.702 \mathrm{~g} / \mathrm{cm}^{3}$. These composition and density data are taken from Ref. 19.
} 
ratio to dilute and to provide neutron absorption to the fissile material present. The calculations consider all the fissile and nonfissile material commingled in a single, spherical, package with a thick water reflector. Typical packages are assembled individually up to the $15 \mathrm{~g}^{235} \mathrm{U}$ limit and, although there is neutron reflection present from packaging materials, adjacent packages and structure, the reflection is typically less than the tight-fitting, thick water reflected configurations assumed in the calculations. This significantly increases the mass required for criticality, even when multiple packages are commingled. Thus, the number of packages that would remain subcritical is realistically much greater than the values estimated from the conservative calculations summarized in Fig. 1.

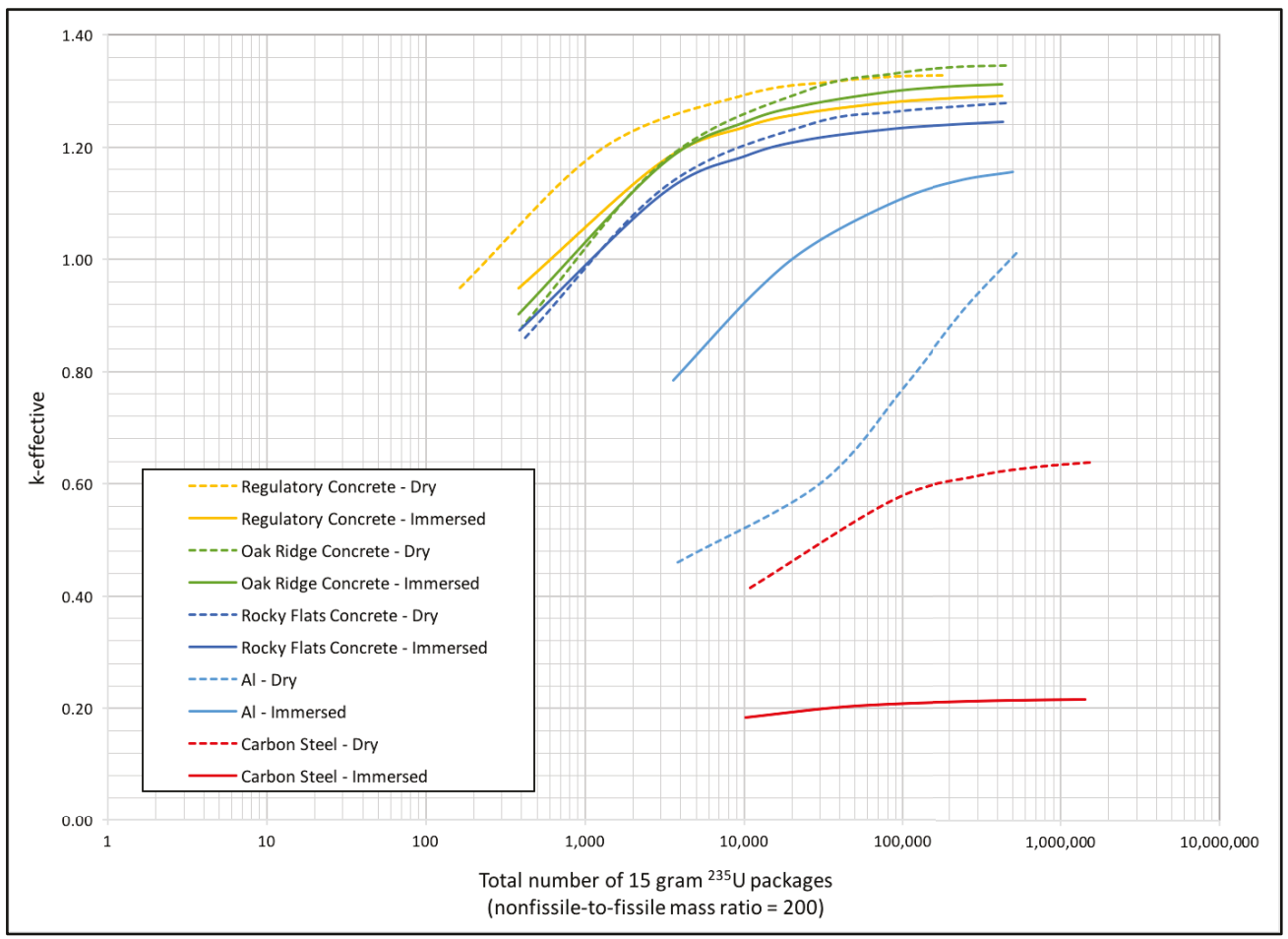

Figure 1 Spherical, Homogeneous Mixtures of ${ }^{235} \mathrm{U}$ and Various Nonfissile Materials (30-cm Thick Water Reflection)

\subsubsection{CFR 71.15(c) Low Concentrations of Solid Fissile Material Comingled with Solid Nonfissile Material}

71.15(c) - (1) Low concentrations of solid fissile material commingled with solid nonfissile material, provided that:

(i) There is at least 2000 grams of solid nonfissile material for every gram of fissile material, and

(ii) There is no more than 180 grams of fissile material distributed within $360 \mathrm{~kg}$ of contiguous nonfissile material.

(2) Lead, beryllium, graphite, and hydrogenous material enriched in deuterium may be present in the package but must not be included in determining the required mass of solid nonfissile material.

The intent of this fissile material exemption is to allow large volumes of waste material containing low concentrations of solid fissile material, commingled with a large amount of solid nonfissile 
material. The mass of solid nonfissile material required by the provision cannot include the mass of lead, beryllium, graphite, and hydrogenous material enriched in deuterium although these materials can be present in the package. The quantity of fissile material in this provision is not limited, but it must be commingled such that no more than $180 \mathrm{~g}$ is distributed within $360 \mathrm{~kg}$ $(360,000 \mathrm{~g})$ of solid nonfissile material. The intent is to have package contents that have an essentially homogeneous mixture of fissile and nonfissile material. According to the provision, the fissile material must be distributed within contiguous nonfissile material, which will ensure the fissile material will not form any heterogeneous arrangements within the waste matrix during normal conditions of transport and hypothetical accident conditions.

This exemption could be applied to transporting large volumes of soil contaminated with fissile materials or uranium-contaminated alumina trap mix where the fissile material is essentially homogeneously distributed throughout the waste matrix, for example. This particular fissile material exemption would not apply to surface contaminated equipment or piping, for example, where the fissile material may exist in localized sections within the equipment or where the surface of the equipment is contaminated with fissile material because the fissile material is not commingled with the solid nonfissile material.

This exemption requirement precludes nuclear criticality safety concerns by limiting the mass concentration and requiring a nearly uniform mixture of fissile and nonfissile materials. Lead, beryllium, graphite and hydrogenous material enriched in deuterium can be present in the package but not included in the determination of the nonfissile material present. The material should be well mixed and homogeneous.

According to Ref. 15, the technical basis for the 2000:1 ratio of solid nonfissile material to fissile material in 10 CFR 71.15 (c)(1) is that this concentration represents approximately $60 \%$ of the minimum critical fissile material concentration of $1.33 \mathrm{~g}{ }^{235} \mathrm{U} / \mathrm{L}$ in a $1600-\mathrm{g}-\mathrm{SiO}_{2} / \mathrm{L}$ matrix. The $60 \%$ value is judged to be a reasonably conservative decrease in the minimum critical concentration to accommodate nonfissile materials other than $\mathrm{SiO}_{2}$. Calculations in Ref. 20 were performed to compare mixtures of fissile materials (e.g., ${ }^{235} \mathrm{U},{ }^{239} \mathrm{Pu}$, and ${ }^{233} \mathrm{U}$ ) with various moderators: beryllium, graphite, deuterium, and $\mathrm{SiO}_{2}$. Based on the results of these calculations, $\mathrm{SiO}_{2}$ was chosen as the matrix of interest for deriving the fissile exemptions because it is judged to be the most representative and limiting matrix associated with the transport of waste material contaminated with small quantities of fissile materials, such as construction debris or contaminated soils (Ref. 20). $\mathrm{SiO}_{2}$ has a large abundance in nature and has a low tendency for absorbing neutrons, which is conservative from a criticality safety standpoint. Except for beryllium, graphite, and deuterium and pure forms of magnesium and bismuth, silicon or $\mathrm{SiO}_{2}$ is the most reactive diluent for fissile materials (Ref. 15). Furthermore, the density assumed for $\mathrm{SiO}_{2}(1.6$ $\mathrm{g} / \mathrm{cm}^{3}$ ) is representative of dry bulk mean world soil density (Ref. 20).

With respect to the fissile mass limitation of $180 \mathrm{~g}$ per $360 \mathrm{~kg}$ of solid nonfissile material, computations were performed for ${ }^{239} \mathrm{Pu}^{2}$ and $\mathrm{SiO}_{2}$-water matrix to determine the minimum critical mass under optimum conditions of moderation and reflection. According to the calculation results (Ref. 20) for these systems, the minimum critical mass of ${ }^{239} \mathrm{Pu}$ in an $\mathrm{SiO}_{2}$-water matrix is approximately $920 \mathrm{~g}^{3}$. Because of heterogeneity concerns, (i.e., lumps of fissile material in the

2 These computations assume the ratio of ${ }^{240} \mathrm{Pu}$ to ${ }^{241} \mathrm{Pu}$ is greater than 1 and the ${ }^{241} \mathrm{Pu}$ present in mixture is assumed to be ${ }^{239} \mathrm{Pu}$. This assumption would result in a bounding critical mass value for use in the derivation of a fissile material exemption value.

3 This critical mass value occurs at $0.01 \mathrm{~g}^{239} \mathrm{Pu} / \mathrm{g} \mathrm{SiO} 2$ and $0.25 \mathrm{~g} \mathrm{H}_{2} \mathrm{O} / \mathrm{g} \mathrm{SiO}_{2}$. 
nonfissile matrix), the $920 \mathrm{~g}$ minimum critical mass was reduced by a factor of five (to $180 \mathrm{~g}$ ) to ensure subcriticality under normal conditions of transport and hypothetical accident conditions, where it is possible for some of the fissile material to redistribute in the matrix. Thus, to maintain the 2000:1 ratio of nonfissile to fissile material in the package requires $180 \mathrm{~g}$ of fissile material to be distributed within a minimum of $360,000 \mathrm{~g}(360 \mathrm{~kg})$ of contiguous nonfissile material.

A series of KENO V.a calculations using ENDF/B-VII neutron cross sections were performed to estimate the infinite multiplication factor, $k_{\text {inf }}$, for a mixture of ${ }^{235} \mathrm{U}$ metal and aluminum to determine the effect of adding diluent to the system. The calculations with the diluent present are compared to a ${ }^{235} \mathrm{U}$ metal-water system. $k_{\text {inf, }}$ the ratio of the number of neutrons resulting from fission in the current generation to the number absorbed in the preceding generation in a system of infinite size, does not consider neutron leakage because the size of the homogeneous ${ }^{235} \mathrm{U}$ metal, water, and aluminum system is infinite. The $k_{\text {inf }}$ for a ${ }^{235} \mathrm{U}$ metal-water system was first calculated to compare to the cases where the quantity of aluminum is increased in the U-water mixture (zero to 2000 grams of diluent per gram of ${ }^{235} \mathrm{U}$ present). These calculations consider hydrogen-to- ${ }^{235} \mathrm{U}\left(\mathrm{H} /{ }^{235} \mathrm{U}\right)$ ratios that range from a dry system $\left(\mathrm{H} /{ }^{235} \mathrm{U}=10\right)$ to an over-moderated system $\left(\mathrm{H} /{ }^{235} \mathrm{U}=4000\right)$ that corresponds to a much lower concentration than the limiting critical density for a ${ }^{235} \mathrm{U}$ metal-water system $(\sim 12 \mathrm{~g} / \mathrm{L})$. The results in Fig. 2 indicate the $k_{\text {inf }}$ is less than 1.0 , regardless of the level of moderation, for a system with an Al-to- ${ }^{235} \mathrm{U}$ ratio of 500 or greater. This indicates that aluminum is an effective diluent for this type of system.

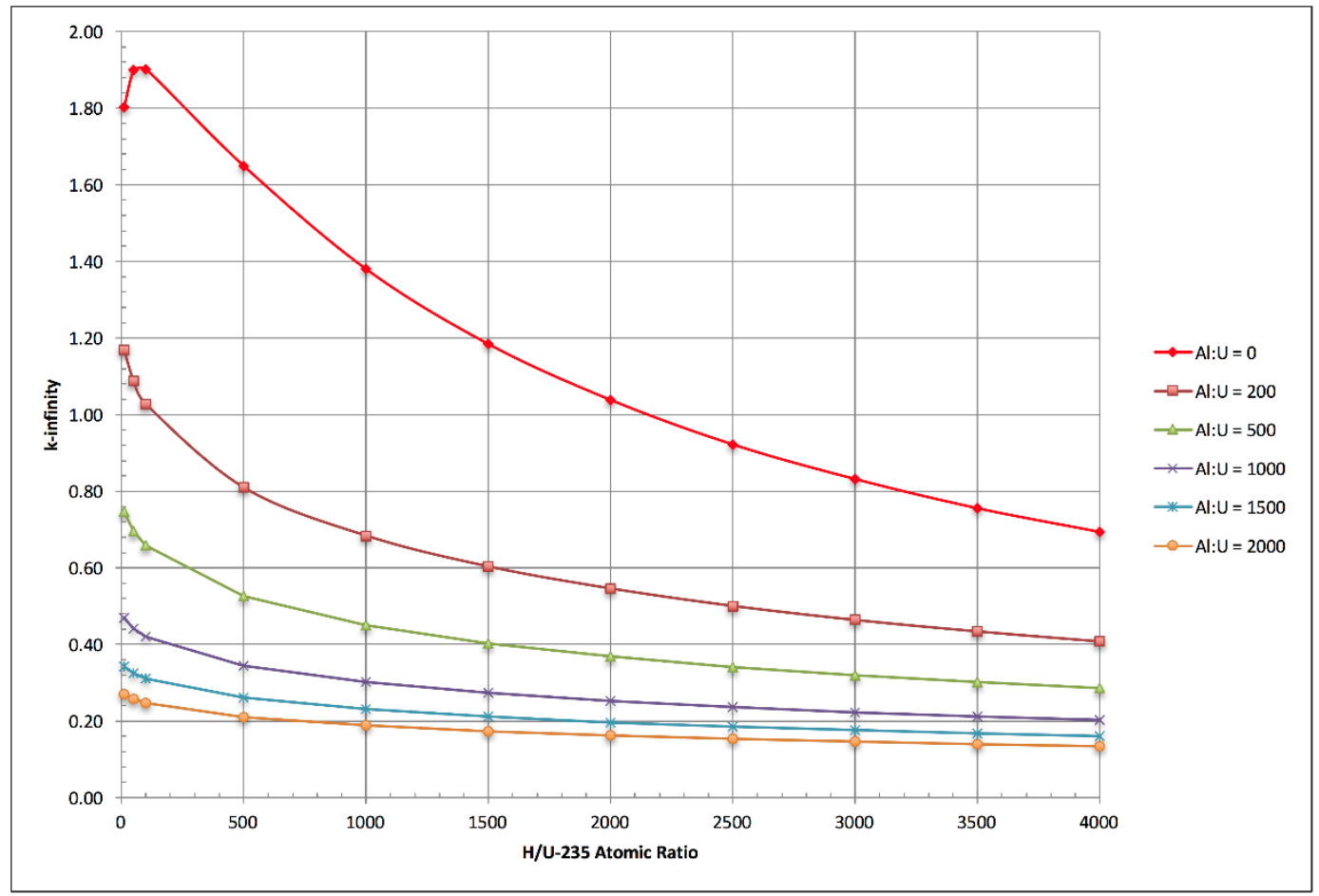

\section{Figure 2 Infinite Homogeneous Mixture of ${ }^{235} \mathrm{U}$ Metal and Water with Aluminum Present as a Diluent}

To expand on the aluminum, ${ }^{235} \mathrm{U}$, and water mixture analysis, the SCALE calculations were expanded to consider additional diluents of interest (beryllium [Be], graphite, bismuth [Bi], lead [Pb], magnesium oxide $\left[\mathrm{MgO}_{2}\right]$, magnesium fluoride $\left[\mathrm{MgF}_{2}\right]$, silicon oxide $\left[\mathrm{SiO}_{2}\right]$, and hydrogenous materials enriched with deuterium) in place of the aluminum in the infinite homogeneous ${ }^{235} \mathrm{U}$ and water system. As stated in 71.15(b), beryllium, graphite, hydrogenous materials enriched with 
deuterium, and lead are excluded as solid nonfissile material intended as a diluent. These are provided simply for comparison with the other results. The other diluents listed $\left(\mathrm{MgO}_{2}, \mathrm{Bi}\right.$, and $\mathrm{MgF}_{2}$ ) are considered exotic in the sense that they have a very low probability of absorbing neutrons, but are not commonly available in large, pure quantities for use as a filler material in a package. Silicon oxide may be present in significant quantities as a constituent of soil (Ref. 20). Magnesium compounds are also not expected to be available as package filling material in large quantities, although magnesium fluoride, for example, may be present in the waste matrix itself rather than as a component of soil.

The results, shown in Fig. 3, conclude that all diluents of interest considered in the calculations reduce the $k_{\text {inf }}$ for the system below that of a ${ }^{235} \mathrm{U}$ metal-water system, regardless of the quantity of the diluent and moderation (water) present in the system. In other words, the ${ }^{235} \mathrm{U}$ metal-water mixture is more reactive without the diluents present in the system. A key point is that the configurations considered in the calculations do not represent realistic matrices commonly found in the industry. Systems are not infinite in extent nor optimally constructed. Realistic matrices of fissile and nonfissile materials will contain a wide variety of neutron absorbing materials or diluents in the system. The results in Fig. 3 demonstrate the $k_{\text {inf }}$ is less than 1.0 for the entire $\mathrm{H} /{ }^{235} \mathrm{U}$ range for aluminum, $\mathrm{SiO}_{2}$, and $\mathrm{MgO}_{2}$ but greater than 1.0 for those constituents that have a reduced tendency of absorbing neutrons from the system $\left(\mathrm{D}_{2} \mathrm{O}, \mathrm{Bi}, \mathrm{MgF}_{2}\right.$, Graphite, $\mathrm{Be}$, and $\left.\mathrm{Pb}\right)$, which occurs in dry, low-moderated, systems. The results demonstrate the $k_{\text {inf }}$ is reduced below 1.0 as the $\mathrm{H}^{235} \mathrm{U}$ ratio is greater than 100 for an Al-to ${ }^{235} \mathrm{U}$ ratio of 2000 (Fig. 3). Again, $\mathrm{MgO}_{2}, \mathrm{MgF}_{2}$ and $\mathrm{Bi}$ are not expected in large quantities as a package filler material and the other diluents considered, deuterium, lead, beryllium and graphite, are excluded by the 10 CFR 71.15(c) as acceptable nonfissile material to mix with fissile material.

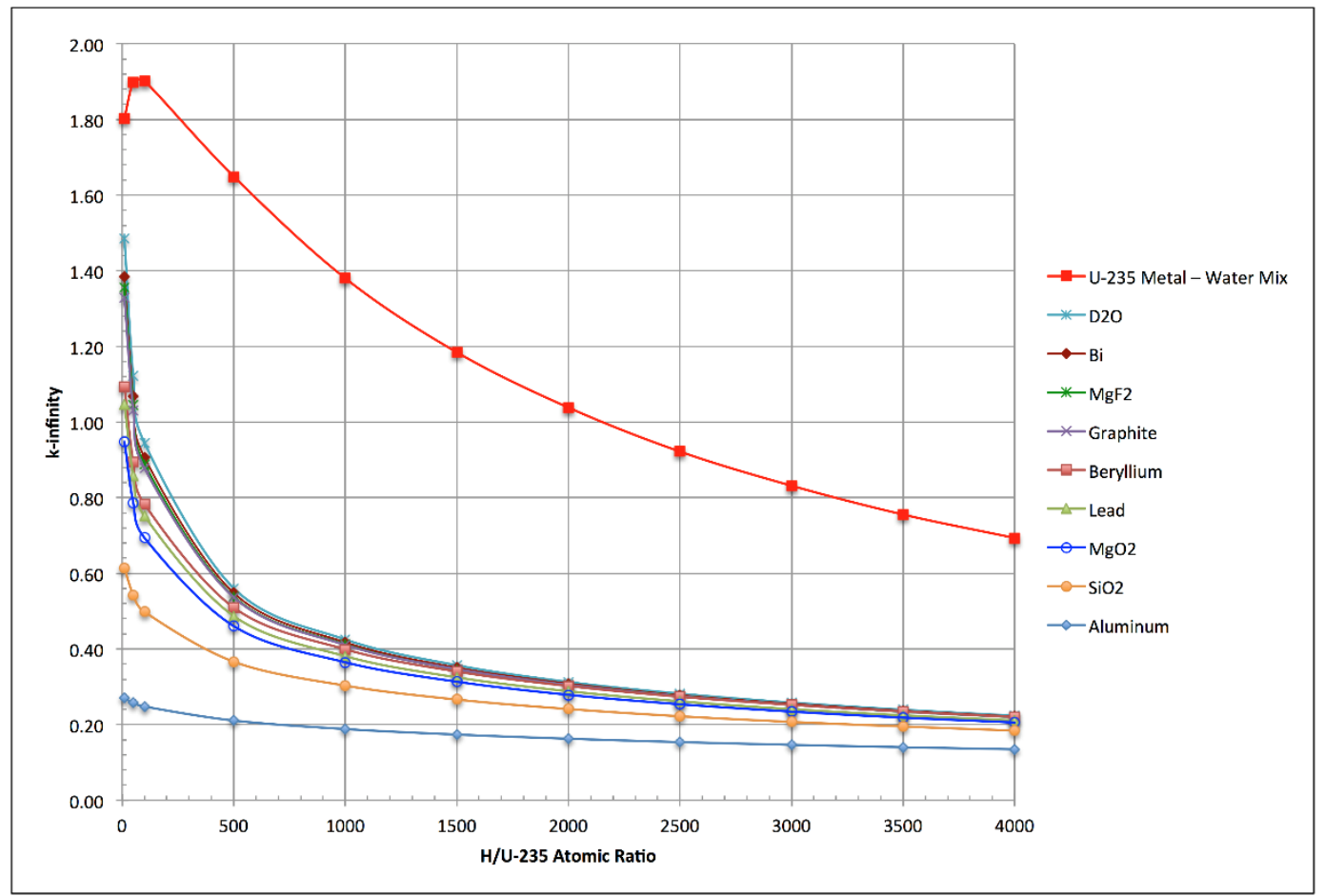

Figure 3 Infinite Homogeneous Mixture of ${ }^{235} \mathrm{U}$ Metal and Water with a Diluent-to- ${ }^{235} \mathrm{U}$ Ratio of 2000 


\subsubsection{CFR 71.15(d): Uranium Enriched in ${ }^{235} \mathrm{U}$ to a Maximum of 1 percent by Weight}

71.15(d) - Uranium enriched in uranium-235 to a maximum of 1 percent by weight, and with total plutonium and uranium-233 content of up to 1 percent of the mass of uranium-235, provided that the mass of any beryllium, graphite, and hydrogenous material enriched in deuterium constitutes less than 5 percent of the uranium mass, and that the fissile material is distributed homogeneously and does not form a lattice arrangement within the package.

This fissile provision exempts low-enriched uranium from classification as fissile material assuming the uranium has a ${ }^{235} \mathrm{U}$ enrichment of $1 \mathrm{wt} \%$ or less. To ensure subcriticality below this enrichment, the package must not contain plutonium or ${ }^{23} \mathrm{U}$ content in excess of $1 \%$ of the ${ }^{235} \mathrm{U}$ mass, and it must not contain low-neutron-absorbing moderator materials (beryllium, graphite, and hydrogenous material enriched in deuterium) with a mass greater than $5 \%$ of the ${ }^{235} \mathrm{U}$ mass. The mass of ${ }^{235} \mathrm{U}$ is unlimited in this provision; however, if ${ }^{233} \mathrm{U}$, plutonium, or low-absorbing moderators are present, the mass of the uranium must be known. For example, if ${ }^{233} \mathrm{U}$ and beryllium are present in a package and the mass of uranium in the package is known to be $100 \mathrm{~g}$, the ${ }^{233} \mathrm{U}$ content is limited to $1 \mathrm{~g}$, and the quantity of beryllium must be limited to $5 \mathrm{~g}$ or less in the waste matrix. The fissile material present must be essentially homogeneously distributed throughout the package since it is possible for heterogeneous configurations to be more reactive than homogeneous distributions of low-enriched fissile material. Small disparate volumes of heterogeneity may exist provided that a significant fraction of fissile material is homogeneous and mixed with nonfissile material. Heterogeneous effects in a package due to large fissile material lumps/particles or lattice arrangements of fissile material would only affect criticality safety for a lattice configuration over a large volume. Large quantities of fissile material (kilograms of ${ }^{235} U$ ) and regions of heterogeneity on the order of a cubic meter in size are necessary before a system could adversely affect the validity of the $1 \mathrm{wt} \%{ }^{235} \mathrm{U}$ enrichment limit for this fissile exemption. Heterogeneous configurations of concern would consist of large, fixed, repeating arrays of separate fissile material lumps.

The technical basis of this fissile material exemption is based on experimental data for spherical homogeneous mixtures of ${ }^{235} \mathrm{U}$ and water. Fig. 4 illustrates the results of experimental data for spherical homogeneous and heterogeneous systems of ${ }^{235} \mathrm{U}$ and water (Ref. 21, Fig. 22). Both unreflected and water-reflected data are presented. The figure shows that for homogeneous unreflected and water-reflected systems, the critical limit (the limit below which criticality is not possible) for a homogeneous system is approximately $1 \mathrm{wt} \%{ }^{235} \mathrm{U}$ enrichment. The corresponding critical limit for a heterogeneous system is approximately $0.7 \mathrm{wt} \%{ }^{235} \mathrm{U}$ (i.e., natural uranium). Further, Fig. 4 indicates the critical masses for heterogeneous systems are smaller than the corresponding values for homogeneous systems when the enrichment values are below about $10 \mathrm{wt} \%{ }^{235} \mathrm{U}$. Since this fissile material exemption considers practical conditions during transportation operations, it was judged that geometric arrangements of such low-enriched fissile material shipped in commerce would not present a realistic challenge to criticality safety.

Beryllium, graphite, and hydrogenous materials enriched in deuterium would have to be present in large quantities in order to provide conditions (low neutron absorbing moderator) with a potential for criticality; thus, these materials are excluded. 


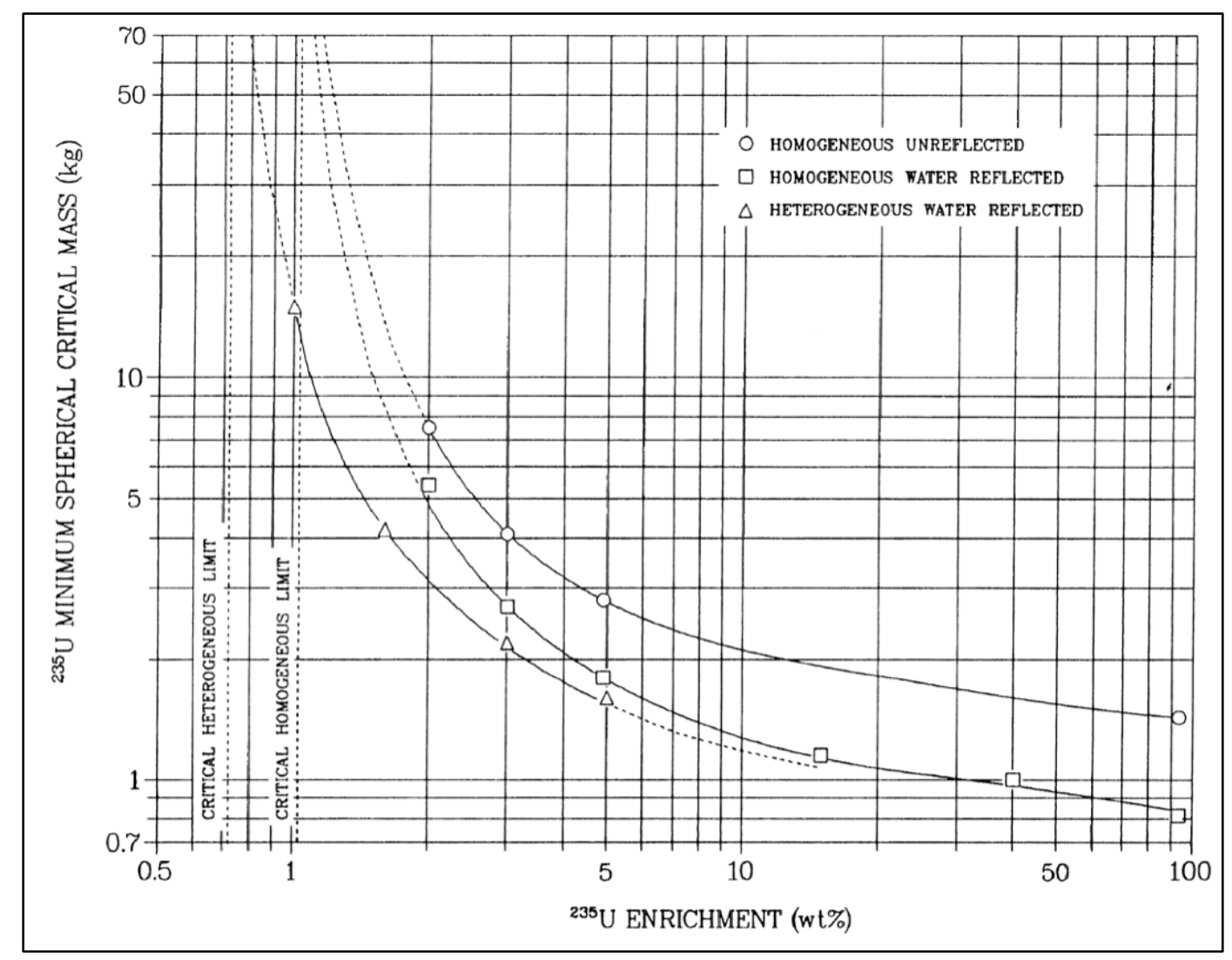

Figure 4 Minimum Spherical Critical Masses as Functions of ${ }^{235} \mathrm{U}$ Enrichment in Homogeneous and Heterogeneous Hydrogen-Moderated Systems (Ref. 21, Fig. 22)

The exemption criterion requires the quantity of these low-neutron-absorbing moderators to be limited in the waste matrix to a maximum of $5 \%$ of the uranium mass. According to Ref. 15, calculations of infinite heterogeneous systems of uranium plates enriched to $1 \mathrm{wt} \%{ }^{235} \mathrm{U}$ and moderated with heavy water $\left(\mathrm{D}_{2} \mathrm{O}\right.$, the limiting special moderator) indicate that a moderator mass of at least $15 \%$ of the uranium mass is necessary to result in a critical configuration. Based on these calculation results, restricting the mass of the low-absorbing special moderators to $5 \%$ of the moderator mass will ensure that all types of heterogeneous systems are bounded from a criticality safety perspective.

The intention of this requirement is that the waste matrix should stay essentially homogeneous and that significant heterogeneous lumps or volumes of lattice arrangements should be precluded because of the increased potential for criticality during transportation conditions. The effect of lumps or heterogeneities in a uranium-water system with an enrichment of $0.995 \mathrm{wt} \%{ }^{235} \mathrm{U}$ was studied using the KENO V.a sequence in the SCALE code system (Ref. 19). A series of $k_{\text {eff }}$ calculations with finite cubic arrangements of uranium metal units immersed in water was performed. The uranium metal array size and pitch ${ }^{4}$ was varied to determine the ${ }^{235} \mathrm{U}$ mass and volume necessary to result in a $k_{\text {eff }}$ of 1.0. The results are shown in Fig. 5 . The results show that a

4 The pitch was used to determine the $\mathrm{H} / \mathrm{X}$ ratio in the unit cell modeled in Keno V.a based on the fissile unit dimensions and fissile unit edge-to-edge spacing. 
uranium metal unit diameter of approximately $5 \mathrm{~cm}$ at an edge-to-edge unit spacing of about $0.37 \mathrm{~cm}(\mathrm{H} / \mathrm{X} \approx 240)$ is required for a $k_{\text {eff }}$ of 1.0 . The uranium mass per unit is about $1,246 \mathrm{~g} \mathrm{U}$ (12.4 $\mathrm{g}^{235} \mathrm{U}$ at $0.995 \mathrm{wt} \%$ enrichment) and the volume is approximately $65.5 \mathrm{~mL}$ per unit. Fig. 5 shows that $4,9135 \mathrm{~cm}$-diameter spherical uranium metal units $(17 \times 17 \times 17$ array $)$ at theoretical density $\left(19.05 \mathrm{~g} / \mathrm{cm}^{3}\right)$ are necessary at an optimum pitch $(\mathrm{H} / 235 \mathrm{U})$ for a heterogeneous arrangement of lumps to result in a critical configuration immersed in water. The results for an infinite array of units at an optimum pitch are plotted alongside the other array results. The $17 \times 17 \times 17$ array was more closely examined to determine the optimum uranium unit size in the array. The results of this array in Fig. 6 show the fissile unit size is nearly optimized at a diameter of about $8 \mathrm{~cm}\left(50.8 \mathrm{~g}^{235} \mathrm{U}\right.$ per unit). Thus, uranium units larger and smaller than about $8 \mathrm{~cm}$ in diameter are less reactive in the modeled array configuration.

Small volumes of heterogeneity may exist in a large shipment of fissile-contaminated waste that could be transported per this exemption, but it would not be credible for these shipments to exist as optimal arrangements of fissile material in heterogeneous lumps or arrangements that could achieve a critical state. Any heterogeneous regions of fissile material in this case would have a smaller effective density than would be present in an optimized configuration. Furthermore, the limitation on the uranium enrichment to less than $1.0 \mathrm{wt} \%{ }^{235} \mathrm{U}$, the limitation on the presence of other fissile isotopes to less than $1.0 \%$ of the ${ }^{235} \mathrm{U}$ mass, and the limitation on low neutron absorbing moderators to less than $5 \%$ of the ${ }^{235} \mathrm{U}$ mass will ensure subcriticality under normal conditions of transport and hypothetical accident conditions.

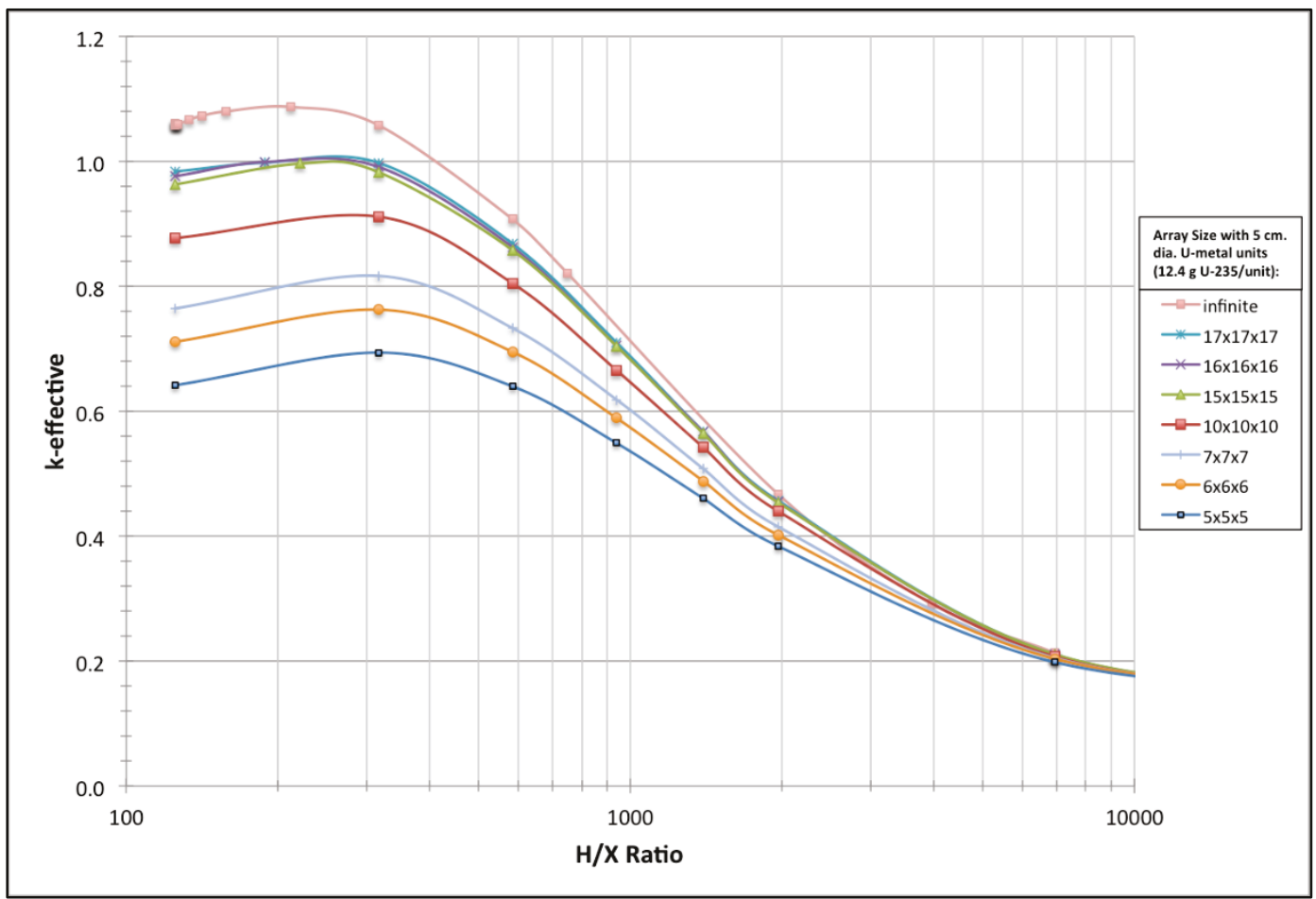

Figure 5 Arrays of U(0.995)-Metal Units Immersed in Water 


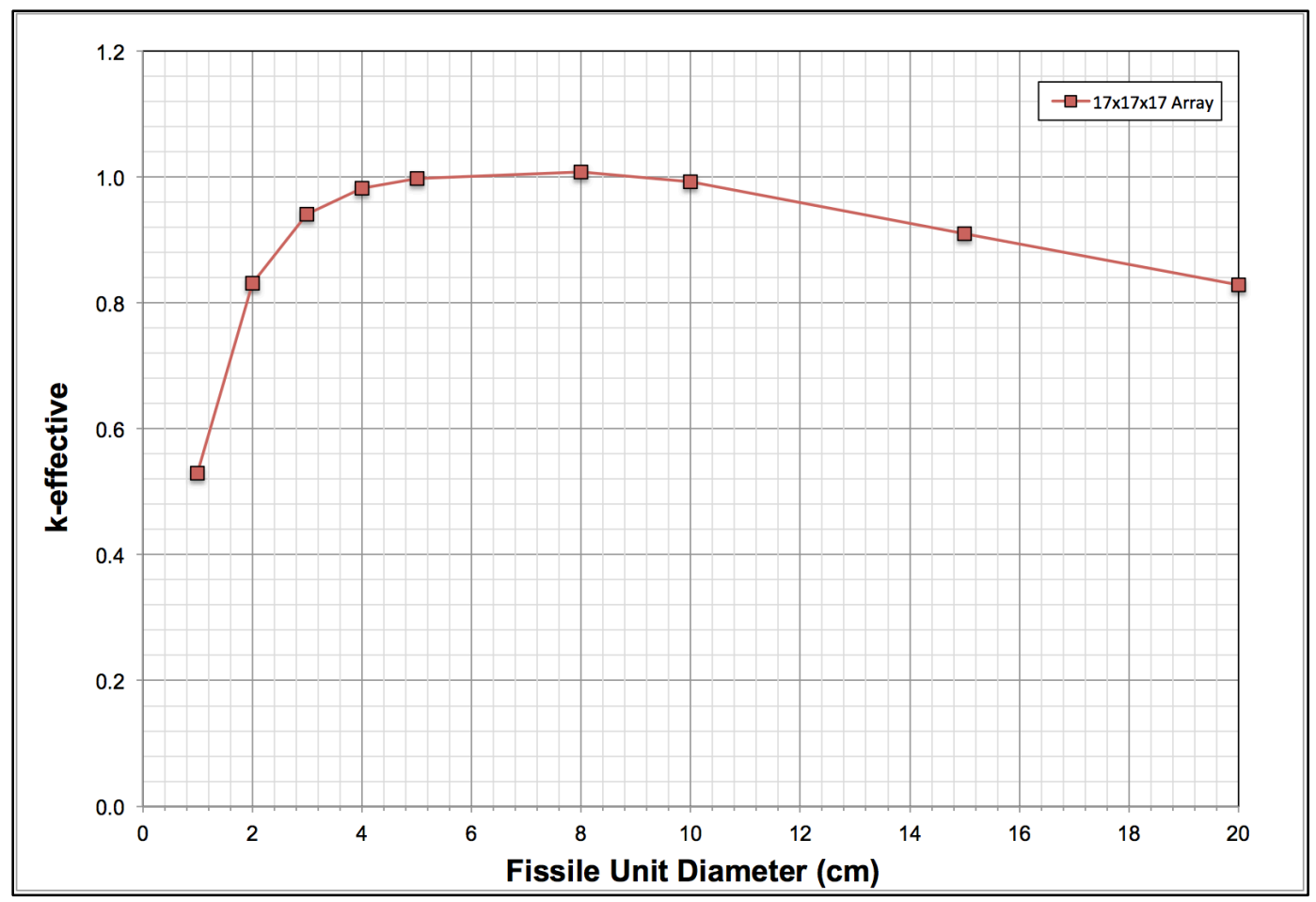

Figure $617 \times 17 \times 17$ Array of U(0.995)-Metal Units Immersed in Water

\subsubsection{CFR 71.15(e): Liquid Solutions of Uranyl Nitrate Enriched in ${ }^{235} \mathrm{U}$ to a Maximum of 2 Percent}

71.15(e) - Liquid solutions of uranyl nitrate enriched in uranium-235 to a maximum of 2 percent by mass, with a total plutonium and uranium-233 content not exceeding 0.002 percent of the mass of uranium, and with a minimum nitrogen to uranium atomic ratio $(N / U)$ of 2 . The material must be contained in at least a DOT Type A package.

The intent of this exemption is to allow shipment of uranyl nitrate solutions with uranium enrichments below $2 \mathrm{wt} \%{ }^{235} \mathrm{U}$. An intended application of the exemption includes uranyl nitrate solutions created from spent fuel reprocessing activities. The solution must be contained within a Type A package to ensure that the solution material will not convert to oxide form, combine with fissile material from other packages, mix with water, or form into an unfavorable geometry during normal conditions of transport. The total mass of the ${ }^{235} \mathrm{U}$ in the consignment is not controlled for criticality safety purposes; however, the mass of uranium in the uranyl nitrate solution is required to be known if there is plutonium or ${ }^{233} \mathrm{U}$ present because the mass of plutonium and ${ }^{233} \mathrm{U}$ is limited to $0.002 \%$ of the mass of uranium. For example, if there is $100 \mathrm{~g}$ of uranium in a package of uranyl nitrate solution, the ${ }^{233} \mathrm{U}$ or plutonium content in the package cannot exceed $0.002 \mathrm{~g}$. The ratio of atomic nitrogen to uranium $(\mathrm{N} / \mathrm{U})$ ratio must be greater than 2 to ensure a minimum level of neutron absorption by nitrogen is present in the fissile material package to prevent criticality.

The technical basis of the fissile exemption for uranyl nitrate solutions $\left[\mathrm{UO}_{2}\left(\mathrm{NO}_{3}\right)_{2}+6 \mathrm{H}_{2} \mathrm{O}\right]$ is based on the critical enrichment limits and parasitic neutron absorption from nitrogen. The 
subcritical enrichment limit for low-enriched $\mathrm{UO}_{2}\left(\mathrm{NO}_{3}\right)_{2}$ solutions ${ }^{5}$ with a thick water reflector is $2.88 \mathrm{wt} \%{ }^{235} \mathrm{U}$ (Refs. 22 and 23 ) and shows that the $k_{\text {inf }}$ for a $\mathrm{UO}_{2}\left(\mathrm{NO}_{3}\right)_{2}$-water system for $1.95 \mathrm{wt} \%{ }^{235} \mathrm{U}$ enrichment and thick water reflection is less than 1.0, (Ref. 24) which means that criticality is not possible (Fig. 7). Furthermore, Ref. 3 provides the ${ }^{235} \mathrm{U}$ subcritical enrichment limit for $\mathrm{UO}_{2}\left(\mathrm{NO}_{3}\right)_{2}$ homogeneously mixed with water as $1.96 \mathrm{wt} \%{ }^{235} \mathrm{U}$ (assuming a margin of 0.02 in the $k_{\text {eff }}$. The exemption limit is set at $2 \mathrm{wt} \%$ enriched ${ }^{235} \mathrm{U}$, which is slightly larger than the uranium-water mixture limiting critical enrichment values. However, these limits provide a significant safety margin since the subcritical enrichment limit calculations assume optimum conditions (e.g., spherical geometry and thick, close-fitting water reflection). The fissile exemption also limits the quantity of other fissile nuclides to ensure that the enrichment limit for ${ }^{235} \mathrm{U}$ is valid (i.e., quantities of $\mathrm{Pu}$ and ${ }^{233} \mathrm{U}$ isotopes are inconsequential ${ }^{6}$ ).

The use of packages that meet Type A standards is sufficient to ensure that the uranyl nitrate solutions are protected from any adverse conditions encountered during normal conditions of transport that could affect nuclear criticality safety (e.g., loss of geometry). The exemption enrichment limit also accounts for the accumulation of ${ }^{235} \mathrm{U}$ during hypothetical accident conditions that involve the loss of packaging during transport since an infinite system is considered. There is also a limitation on the minimum nitrogen-to-uranium atomic ratio $(\mathrm{N} / \mathrm{U})$ of 2 . This requirement ensures that there is a minimum level of neutron absorption in nitrogen (a moderate thermal neutron absorber) to ensure the $k_{\text {inf }}$ is maintained less than 1.0.

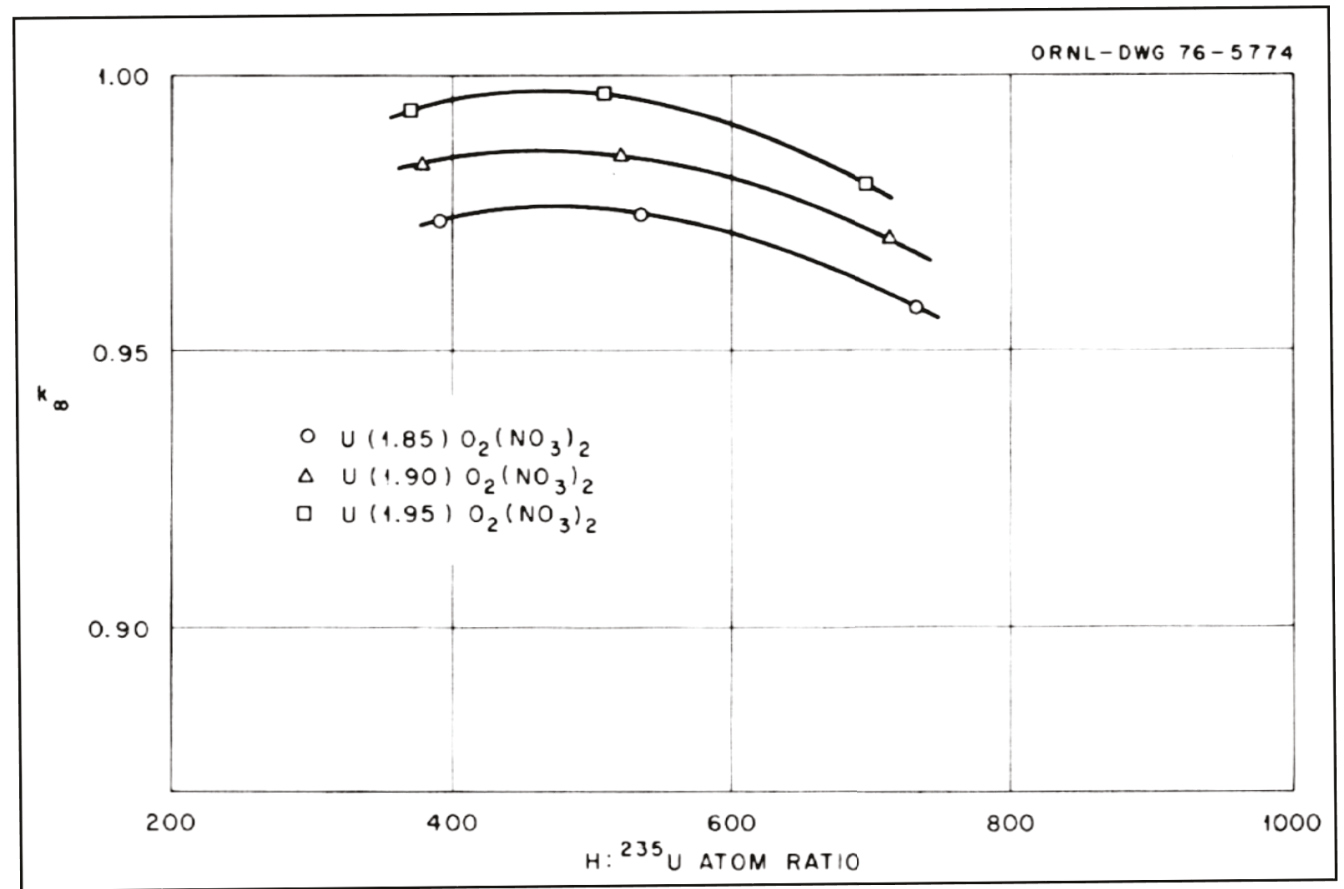

Figure $7 k_{\text {inf }}$ Calculated for $\mathrm{UO}_{2}\left(\mathrm{NO}_{3}\right)_{2}-\mathrm{H}_{2} \mathrm{O}$ Mixtures (Ref. 24, Fig. 2)

5 These subcritical values are valid for uniform homogeneous aqueous solutions of $\mathrm{UO}_{2}\left(\mathrm{NO}_{3}\right)_{2}$. The subcritical enrichment limit of $2.88 \mathrm{wt} \%{ }^{235} \mathrm{U}$ is the limit on ${ }^{235} \mathrm{U}$ content of uranium in a saturated $(2.5 \mathrm{M})$ aqueous solution of $\mathrm{UO}_{2}\left(\mathrm{NO}_{3}\right)_{2}$ to preserve subcriticality (Ref. 23).

6 The NRC amended this fissile exemption requirement in 2004 with the limitation on total Pu and ${ }^{233} \mathrm{U}\left(0.002 \%\right.$ of ${ }^{235} \mathrm{U}$ mass) to be consistent with international regulations. 


\subsubsection{CFR 71.15(f): Packages Containing Plutonium with a Large Percentage of ${ }^{238} \mathrm{Pu}$}

71.15(f) - Packages containing, individually, a total plutonium mass of not more than 1000 grams, of which not more than 20 percent by mass may consist of plutonium-239, plutonium-241, or any combination of these radionuclides.

This provision allows for the exemption of individual fissile packages containing plutonium with a mass of $1000 \mathrm{~g}$ or less provided not more than $20 \%$ of the total plutonium mass contains the fissile nuclides ${ }^{239} \mathrm{Pu},{ }^{241} \mathrm{Pu}$, or a combination of ${ }^{239} \mathrm{Pu}$ and ${ }^{241} \mathrm{Pu}$. This fissile exemption does not constrain the mass of commingled nonfissile material or low-neutron-absorbing special moderating materials. This particular exemption requirement is not applicable for uranium that may have trace amounts of plutonium present, or for packages with other fissile material. This exemption is intended primarily for shipment of low-assay plutonium, such as heat sources, with a high percentage of ${ }^{238} \mathrm{Pu}$ and a low percentage of fissile nuclides of plutonium.

The radiological nature of plutonium would require the quantity of material allowed by this exemption to be shipped in a Type B package design certified by the NRC to maintain integrity under hypothetical accident conditions. However, this exemption would eliminate the need for a criticality safety assessment as required under 10 CFR 71.55 and 71.59 . The amount of fissile plutonium nuclides $\left({ }^{239} \mathrm{Pu}\right.$ and ${ }^{241} \mathrm{Pu}$ ) allowed in such a shipment is $20 \%$ of the total plutonium mass, and the maximum fissile mass allowed would be $200 \mathrm{~g}$ in the limiting plutonium shipment of $1,000 \mathrm{~g}$.

The technical basis for this exemption is that the presence of the nonfissile plutonium isotopes will provide significant parasitic neutron absorption and will eliminate the potential for criticality. Fig. 8 illustrates that $200 \mathrm{~g}$ of ${ }^{239} \mathrm{Pu}$ corresponds to a $k_{\text {eff }}$ of 0.8 under optimal conditions of pure materials, spherical geometry, and thick water reflector. Furthermore, the subcritical limits for ${ }^{239} \mathrm{Pu}$ and ${ }^{241} \mathrm{Pu}$ are 450 and $200 \mathrm{~g}$, respectively (Ref. 25). It is not likely that ${ }^{241} \mathrm{Pu}$ would be present in greater quantities than ${ }^{239} \mathrm{Pu}$ (Ref. 26); however, to ensure that criticality is precluded, the exemption limitation of $20 \%$ of the $1,000 \mathrm{~g}$ of total plutonium is bounded for ${ }^{239} \mathrm{Pu}$ and combinations of ${ }^{239} \mathrm{Pu}$ and ${ }^{241} \mathrm{Pu}$ by the $200 \mathrm{~g}$ subcritical limit for ${ }^{241} \mathrm{Pu}$. Again, the presence of nonfissile plutonium isotopes would increase the safety margin by introducing a source of neutron absorption to the system. The mass required for criticality would tend to increase as a result. 


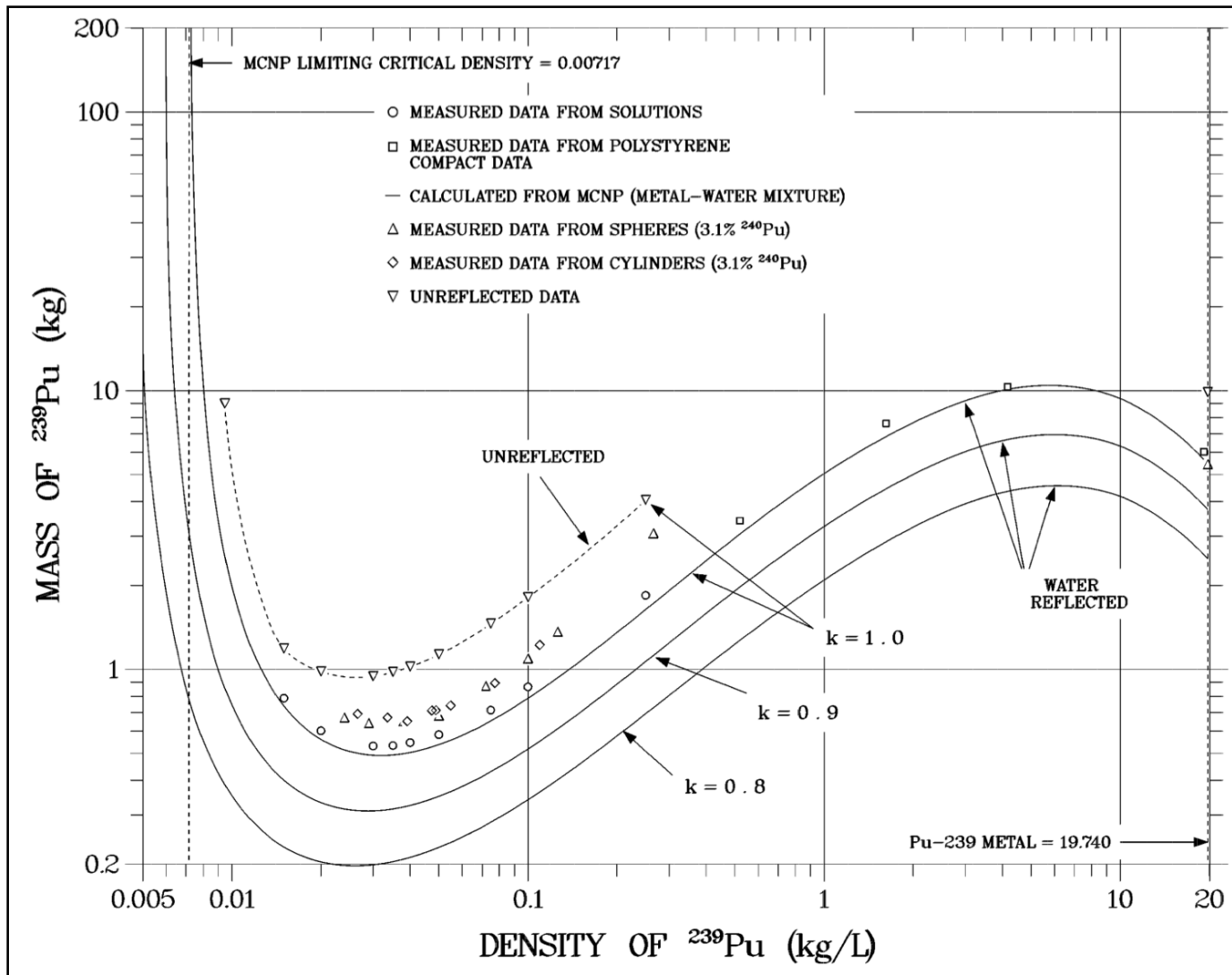

Fig. 10. Masses of spheres of homogeneous water-moderated ${ }^{239} \mathrm{Pu}$ as functions of ${ }^{239} \mathrm{Pu}$ density.

Figure 8 Masses of Spheres of Homogeneous Water-Moderated ${ }^{239} \mathrm{Pu}$ as Functions of ${ }^{239} \mathrm{Pu}$ Density (Ref. 22, Fig. 10)

\subsection{General License: Fissile Material}

The general license criteria in 10 CFR 71.22 (fissile material) are intended to allow NRC licensees to ship small quantities of fissile material in packages that have been assigned a CSI to ensure accumulation control for packages on a conveyance.

The current general license language from 10 CFR 71.22 is listed in the tables below. Table 2 provides the content of 10 CFR 71.22, "General license: fissile material." Table 3 provides mass limits for general license packages containing mixed quantities of fissile material or ${ }^{235} \mathrm{U}$ of unknown enrichment, and Table 4 provides mass limits for general license packages containing ${ }^{235} \mathrm{U}$ of known enrichment, which are needed to evaluate the equation in $71.22(\mathrm{e})(1)$. 


\section{Table 2 Content in 10 CFR 71.22, "General license: Fissile material”}

\subsection{General License: Fissile Material.}

(a) A general license is issued to any licensee of the Commission to transport fissile material, or to deliver fissile material to a carrier for transport, if the material is shipped in accordance with this section. The fissile material need not be contained in a package, which meets the standards of subparts $E$ and $F$ of this part; however, the material must be contained in a Type A package. The Type A package must also meet the DOT requirements of 49 CFR 173.417(a).

(b) The general license applies only to a licensee who has a quality assurance program approved by the Commission as satisfying the provisions of subpart $\mathrm{H}$ of this part.

(c) The general license applies only when a package's contents:

(1) Contain no more than a Type A quantity of radioactive material; and

(2) Contain less than 500 total grams of beryllium, graphite, or hydrogenous material enriched in deuterium.

(d) The general license applies only to packages containing fissile material that are labeled with a CSI which:

(1) Has been determined in accordance with paragraph (e) of this section;

(2) Has a value less than or equal to 10; and

(3) For a shipment of multiple packages containing fissile material, the sum of the CSIs must be less than or equal to 50 (for shipment on a nonexclusive use conveyance) and less than or equal to 100 (for shipment on an exclusive use conveyance).

(e)

(1) The value for the CSI must be greater than or equal to the number calculated by the following equation:

$$
\mathrm{CSI}=10\left[\frac{\text { grams of }{ }^{235} \mathrm{U}}{X}+\frac{\text { grams of }{ }^{233} \mathrm{U}}{Y}+\frac{\text { grams of } \mathrm{Pu}}{Z}\right]
$$

(2) The calculated CSI must be rounded up to the first decimal place;

(3) The values of $X, Y$, and $Z$ used in the CSI equation must be taken from Tables $71-1^{7}$ or $71-2^{8}$, as appropriate;

(4) If Table 71-2 is used to obtain the value of $X$, then the values for the terms in the equation for uranium-233 and plutonium must be assumed to be zero; and

(5) Table 71-1 values for $X, Y$, and Z must be used to determine the CSI if:

(i) Uranium-233 is present in the package;

(ii) The mass of plutonium exceeds 1 percent of the mass of uranium-235;

(iii) The uranium is of unknown uranium-235 enrichment or greater than 24 weight percent enrichment; or

(iv) Substances having a moderating effectiveness (i.e., an average hydrogen density greater than $\mathrm{H}_{2} \mathrm{O}$ ) (e.g., certain hydrocarbon oils or plastics) are present in any form, except as polyethylene used for packing or wrapping.

\footnotetext{
${ }^{7}$ See Table 3 in this report.

${ }^{8}$ See Table 4 in this report.
} 
Table 310 CFR 71.22 Table 71-1-Mass Limits for General License Packages Containing Mixed Quantities of Fissile Material or ${ }^{235} \mathrm{U}$ of Unknown Enrichment per 71.22(e)

\begin{tabular}{|l|c|c|}
\hline \multicolumn{1}{|c|}{ Fissile material } & $\begin{array}{c}\text { Fissile material mass mixed with } \\
\text { moderating substances having an } \\
\text { average hydrogen density less than or } \\
\text { equal to } \mathrm{H}_{2} \mathrm{O} \text { (grams) }\end{array}$ & $\begin{array}{c}\text { Fissile material mass mixed with } \\
\text { moderating substances having an } \\
\text { average hydrogen density greater } \\
\text { than } \mathrm{H}_{2} \mathrm{O}^{\text {a }} \text { (grams) }\end{array}$ \\
\hline${ }^{235} \mathrm{U}(\mathrm{X})$ & 60 & 38 \\
\hline${ }^{233} \mathrm{U}(\mathrm{Y})$ & 43 & 27 \\
\hline${ }^{239} \mathrm{Pu}$ or ${ }^{241} \mathrm{Pu}(\mathrm{Z})$ & 37 & 24 \\
\hline
\end{tabular}

a When mixtures of moderating substances are present, the lower mass limits shall be used if more than 15 percent of the moderating substance has an average hydrogen density greater than $\mathrm{H}_{2} \mathrm{O}$.

Table 410 CFR 71.22 Table 71-2-Mass Limits for General License Packages Containing ${ }^{235} \mathrm{U}$ of Known Enrichment per 71.22(e)

\begin{tabular}{|c|c|}
\hline $\begin{array}{l}\text { Uranium enrichment in weight percent } \\
\text { of }{ }^{235} \mathrm{U} \text { not exceeding }\end{array}$ & $\begin{array}{l}\text { Fissile material mass } \\
\text { of }{ }^{235} \mathrm{U}(\mathrm{X}) \text { (grams) }\end{array}$ \\
\hline 24 & 60 \\
\hline 20 & 63 \\
\hline 15 & 67 \\
\hline 11 & 72 \\
\hline 10 & 76 \\
\hline 9.5 & 78 \\
\hline 9 & 81 \\
\hline 8.5 & 82 \\
\hline 8 & 85 \\
\hline 7.5 & 88 \\
\hline 7 & 90 \\
\hline 6.5 & 93 \\
\hline 6 & 97 \\
\hline 5.5 & 102 \\
\hline 5 & 108 \\
\hline 4.5 & 114 \\
\hline 4 & 120 \\
\hline 3.5 & 132 \\
\hline 3 & 150 \\
\hline 2.5 & 180 \\
\hline 2 & 246 \\
\hline 1.5 & 408 \\
\hline 1.35 & 480 \\
\hline 1 & 1,020 \\
\hline 0.92 & 1,800 \\
\hline
\end{tabular}

The general license provisions are applicable to fissile materials in quantities and conditions that could potentially result in criticality if the provisions are not followed correctly. Therefore, the NRC requires that a licensee have a commission-approved quality assurance program to ensure that the general license criteria in this section are used appropriately and with the correct level of rigor for safety purposes. The general license criteria require that the user meet the requirements in 10 CFR 71 Subpart H, "Quality Assurance," (10 CFR 71.101-71.137) that apply to the design, purchase, fabrication, handling, shipping, storing, cleaning, assembly, inspection, testing, 
operation, maintenance, repair, and modification of components of the packaging that are important to safety (Ref. 1).

The technical bases for the general license mass limits used to calculate the CSI for packages are based on the subcritical mass values for the materials of interest. The first two provisions of 10 CFR 71.22, 71.22(a), and 71.22(b), require the fissile material to be present in a Type A package meeting the requirements of 49 CFR 173.417(a), and the general license criteria are applicable to NRC licensees with an NRC-approved quality assurance program satisfying the provisions of 10 CFR 71 Subpart $\mathrm{H}$. The packaging requirements for Type A packages are described in Sect. 2.5.

The general license criteria in 10 CFR 71.22 apply to fissile materials with Type A quantities of total radioactive material, mixed with limited quantities (less than $500 \mathrm{~g}$ ) of beryllium, graphite, or hydrogenous material enriched in deuterium. Provisions 10 CFR 71.22(d)(1)-(3) apply to the calculation of a CSI for a package. The CSI is calculated using the formula provided in 10 CFR 71.22(e)(1):

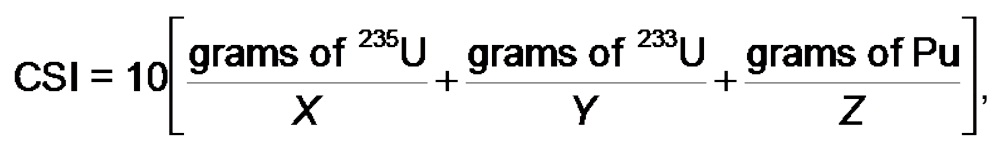

where $X, Y$ and $Z$ represent the quantities of ${ }^{235} \mathrm{U},{ }^{233} \mathrm{U}$, and $\mathrm{Pu}$ in the package, respectively. The value of the CSI for an individual package is limited to 10 . The accumulation of multiple packages is controlled by limiting the CSI to less than or equal to 50 (for shipment on a nonexclusive use conveyance) or less than or equal to 100 (for shipment on an exclusive use conveyance). In a nonexclusive use conveyance, a CSI of 50 corresponds to a fissile mass of about $50 \%$ of the acceptable subcritical mass limit. ${ }^{9}$ An exclusive-use conveyance with a CSI of 100 corresponds to the acceptable subcritical mass limit and requires additional control because of the larger quantity of fissile material that can be shipped.

The CSI for the package is calculated based on the fissile material contents in the package $\left({ }^{233} \mathrm{U}\right.$, ${ }^{235} \mathrm{U}$ and/or $\mathrm{Pu}$ ) and their corresponding mass limits, as specified in Tables $71-1$ and $71-2$. The fissile material mass limits are based upon the uranium enrichment and whether or not the fissile material is mixed with a moderating material with a hydrogen density less than or equal to water or with a hydrogen density greater than water. The mass limits in these tables were derived based on fissile material-water or fissile material-polyethylene systems, and they do not consider the presence of low-absorbing moderators. The CSI label is required to control the accumulation of packages on a conveyance (Ref. 6). To ensure that a conservative CSI is determined, the value of the CSI is rounded up to the first decimal place. As defined in $10 \mathrm{CFR} 71.4$, for an exclusive use conveyance, the conveyors and shippers must ensure that any loading or unloading is performed by personnel having radiological training and resources appropriate for safe handling of the consignment. Further, the consignor and shipper must issue specific instructions, in writing, for maintenance of exclusive use shipment controls, and include them with the shipping paper information provided to the shipper by the consignor.

9 The acceptable subcritical mass limit is the limiting value assigned to the mass of fissionable material that results in a subcritical system under certain conditions. This mass limit is set by considering a bias and bias uncertainty of the calculation method used to determine the subcritical value. 
Table 71-1 lists mass limits for general license packages containing mixed quantities of fissile material or ${ }^{235} \mathrm{U}$ of unknown enrichment, which were generated based on fully enriched ${ }^{235} \mathrm{U}$. The first column of Table $71-1$ applies for ${ }^{233} \mathrm{U},{ }^{235} \mathrm{U}$ or Pu systems that are mixed with moderating materials having an average hydrogen density less than or equal to water. The second column of Table 71-1 applies to these fissile nuclides when mixed with moderating materials having an average hydrogen density greater than water (e.g., hydrocarbon oils and high-density polyethylene). The mass limit data in the tables also require that if a package contains fissile materials mixed with both types of moderating materials that the lower mass limits (column 2 data) be used if more than $15 \%$ of the moderating substance has an average hydrogen density greater than water. Table $71-1$ must be used if ${ }^{233} \mathrm{U}$ is present in a package or if the mass of Pu in the package exceeds 1 percent of the mass of ${ }^{235} \mathrm{U}$.

The fissile mass limits in Tables 71-1 were derived based on calculations ${ }^{10}$ performed in Ref. 4 to determine the acceptable subcritical mass limit of ${ }^{235} \mathrm{U},{ }^{233} \mathrm{U}$, and ${ }^{239} \mathrm{Pu}$. The calculations considered water reflected and optimally moderated spheres of ${ }^{235} \mathrm{U},{ }^{233} \mathrm{U}$, and ${ }^{239} \mathrm{Pu}$. For Table $71-1$, column 1, the acceptable subcritical masses corresponding to a system $k_{\text {eff }}$ of less than 0.95 for ${ }^{235} \mathrm{U},{ }^{233} \mathrm{U}$, and ${ }^{239} \mathrm{Pu}$ are $614 \mathrm{~g}, 437 \mathrm{~g}$, and $379 \mathrm{~g}$, respectively. For each fissile isotope, the acceptable subcritical mass limit was reduced by a factor of 10 , corresponding to a package CSI of 10, and rounded down to the following values for ${ }^{235} \mathrm{U},{ }^{233} \mathrm{U}$, and ${ }^{239} \mathrm{Pu}: 60$, 43, and $37 \mathrm{~g}$, respectively. The Table 71-1, column 2 data are applicable for fissile materials mixed with moderating substances having an average hydrogen density greater than water, such as polyethylene (not used for packing or wrapping materials) or hydrocarbon oils. The mass limits are lower for these waste matrices because these systems provide better moderation due to the greater hydrogen density in the matrix. According to Ref. 4, Table 3-1, the minimum critical mass of ${ }^{235} \mathrm{U}$ homogeneously mixed with polyethylene is $527 \mathrm{~g}$. The mass limit values in the second column of Table 71-1 were derived by reducing the column 1 values by the ratio of the minimum critical mass for a ${ }^{235} \mathrm{U} /$ polyethylene system, $527 \mathrm{~g}$, to the minimum critical mass for a ${ }^{235} \mathrm{U} /$ water system, $820 \mathrm{~g}$, which is equal to about 0.64 (for ${ }^{235} \mathrm{U}$, the $60 \mathrm{~g}$ limit becomes $60 \times 0.64$ or $38 \mathrm{~g}$, for ${ }^{233} \mathrm{U}$, the $43 \mathrm{~g}$ limit is $43 \times 0.64$ or $27 \mathrm{~g}$, and for $\mathrm{Pu}$, the $37 \mathrm{~g}$ limit is $37 \times 0.64$ or $24 \mathrm{~g}$ ).

Table 71-2 lists mass limits for general license packages containing ${ }^{235} \mathrm{U}$ of known enrichment up to $24 \mathrm{wt} \%{ }^{235} \mathrm{U}$. If Table $71-2$ is used to obtain a value of $\mathrm{X}$ in the CSI equation, then the values for the terms in the equation for ${ }^{233} \mathrm{U}$ and Pu must be zero. The mass limits for known enrichments in Table 71-2 begin at $60 \mathrm{~g}$ at an enrichment of $24 \mathrm{wt} \%{ }^{235} \mathrm{U}$. This corresponds to the subcritical $\left(k_{\text {eff }}=0.95\right)$ fissile material mass for fully enriched ${ }^{235} U$ (Ref. 4 , Table $\left.3-1\right)$, which is approximately $600 \mathrm{~g}$ of ${ }^{235} \mathrm{U}$. This acceptable subcritical mass limit is divided by 10 to represent a package CSI limit of 10 . The mass limit value for $0.92 \mathrm{wt} \%$ enrichment is $1,800 \mathrm{~g}$ (with a package CSI limit of 10 ) and corresponds to a subcritical mass of $18,000 \mathrm{~g}^{235} \mathrm{U}$. These mass limit values were increased by $150 \%$ from the pre-2004 general license criteria, based on recommendations in Ref. 4. Per 10 CFR 71.22(e)(2), the calculated CSI values must be rounded up to the first decimal place; e.g., if a CSI were calculated to be 1.95, the actual value would be 2.0. Interpolating mass limit values in the tables is not permitted. The licensee must use the mass corresponding to the next highest enrichment value available in Table 71-2.

Above 24 wt $\%{ }^{235} \mathrm{U}$ enrichment, the mass limit is based on full enrichment (i.e., 100 wt $\%{ }^{235} \mathrm{U}$ ). If $\mathrm{Pu}$ is present in the package with a mass that exceeds $1 \%$ of the mass of ${ }^{235} \mathrm{U}$, then the data in

10 These criticality calculations were performed with the SCALE (Ref. 19) computer code system. Specifically, the minimum subcritical mass calculations were calculated with one-dimensional systems using the discrete ordinates transport theory code sequence CSAS1X using the 27-energy group library based on ENDF/B-IV data (Ref. 4). 
Table 71-1 must be used to ensure that the presence of any $\mathrm{Pu}$ in a package does not invalidate the mass limit data because ${ }^{239} \mathrm{Pu}$ and ${ }^{241} \mathrm{Pu}$ isotopes are more reactive than ${ }^{235} \mathrm{U}$ in moderated systems. If any quantity of ${ }^{233} \mathrm{U}$ is present in the package, then the data in Table $71-1$ must be used because ${ }^{233} \mathrm{U}$ is generally more reactive than ${ }^{235} \mathrm{U}$. The $\mathrm{NRC}$ recognizes that small quantities of ${ }^{233} \mathrm{U}$ may be present along with ${ }^{235} \mathrm{U}$ in some circumstances. Small quantities of ${ }^{233} \mathrm{U}$ should not adversely impact nuclear criticality safety for a package. Determining the quantity of ${ }^{23} U$ that may be allowed may be addressed in a future rulemaking to 10 CFR 71 .

Provision 10 CFR 71.22(c)(1) requires that each package contain no more than a Type A quantity, as specified in Table A-1, " $A_{1}$ and $A_{2}$ Values for Radionuclides." This provision ensures that radiological limitations are maintained within each package. For example, the maximum radiological limits $\left(A_{2}\right.$ value $)$ for ${ }^{239} \mathrm{Pu}$ in Table $\mathrm{A}-1$ can be used to calculate the maximum quantity of ${ }^{239} \mathrm{Pu}$ allowed in a package, $0.435 \mathrm{~g}$. The general license mass value from Table $71-1$ is $39 \mathrm{~g}$. Thus, this example illustrates that the radiological limitations (no more than a Type A quantity of radioactive in a Type A package) for the fissile nuclides will limit the quantity of fissile material present rather than the criticality safety limitations for some of the fissile isotopes of interest. The provisions preclude the use of a Type B package, which the NRC recognizes is inconsistent with the allowed plutonium mass values in Table 71-1. This issue may be addressed in a future rulemaking to $10 \mathrm{CFR} 71$.

This provision also limits the quantity of low absorbing materials (beryllium, graphite, or hydrogenous materials enriched in deuterium) that can be present inside a package with fissile material to $500 \mathrm{~g}$ or less (total). The limitation on these low absorbing materials precludes forming a reflector that could be more effective than water around the optimally moderated system, which could reduce the subcritical mass for ${ }^{235} \mathrm{U},{ }^{233} \mathrm{U}$, and ${ }^{239} \mathrm{Pu}$ (Ref. 4).

\subsection{General License: Plutonium-Beryllium Special Form Material}

The general license criteria in 10 CFR 71.23 (Pu-Be special form material) is intended to allow NRC licensees to ship small quantities of fissile material in packages that have been assigned a $\mathrm{CSI}$ to ensure accumulation control for packages on a conveyance. The general license criterion in 10 CFR 71.23 applies to Pu-Be materials which meet the special form requirements of 10 CFR 71.75, ensuring that the material itself will maintain its integrity and will not disperse during normal conditions of transport or under hypothetical accident conditions into an unfavorable geometry. Table 5 lists the content of 10 CFR 71.23, "General license: Plutonium-beryllium special form material."

As stated in 10 CFR 71.23(b), the general licenses are applicable to licensees that have a quality assurance program approved by NRC. 10 CFR 71 Subpart H, "Quality Assurance," (10 CFR 71.101-71.137) provides requirements for an acceptable quality assurance (QA) program to apply the general license criteria. This Subpart defines the QA requirements, organization, program, package design/procurement control, document control, test control, and other criteria relevant to ensuring the criteria in 10 CFR 71.23 can be applied by a licensee without NRC approval.

The general license criteria for Pu-Be special form materials are similar to those in the fissile material general license requirements with respect to having to calculate a CSI based on the quantity of fissile material present, specifically the quantities of the fissile isotopes ${ }^{239} \mathrm{Pu}$ and ${ }^{241} \mathrm{Pu}$. For the general license to apply, the package containing Pu-Be special form sources cannot contain more than a Type A quantity of total radioactive material, and it is limited to 1,000 g plutonium with up to $240 \mathrm{~g}$ being the fissile isotopes ${ }^{239} \mathrm{Pu}$ and/or ${ }^{241} \mathrm{Pu}$ as required by $10 \mathrm{CFR} 71.23$ (c). There are 
no provisions in 10 CFR 71.23 to limit the quantity of low neutron absorbing moderators because of the nature of the Pu-Be sources (small sealed capsules with a fixed geometry, and low mass limits). A CSI equation is provided in 10 CFR 71.23(e)(1) to allow the consignor to calculate the CSI for the package based on the mass of ${ }^{239} \mathrm{Pu}$ and ${ }^{241} \mathrm{Pu}$ in the package:

$$
\mathrm{CSI}=10\left[\frac{\text { grams of }{ }^{239} \mathrm{Pu}+\text { grams of }{ }^{241} \mathrm{Pu}}{24}\right] .
$$

\section{Table 5 Content in 10 CFR 71.23 “General License: Plutonium-Beryllium Special Form Material"}

\subsection{General License: Plutonium-beryllium special form material.}

(a) A general license is issued to any licensee of the Commission to transport fissile material in the form of plutoniumberyllium (Pu-Be) special form sealed sources, or to deliver Pu-Be sealed sources to a carrier for transport, if the material is shipped in accordance with this section. This material need not be contained in a package which meets the standards of subparts $E$ and $F$ of this part; however, the material must be contained in a Type A package. The Type A package must also meet the DOT requirements of 49 CFR 173.417(a).

(b) The general license applies only to a licensee who has a quality assurance program approved by the Commission as satisfying the provisions of subpart $\mathrm{H}$ of this part.

(c) The general license applies only when a package's contents:

(1) Contain no more than a Type A quantity of radioactive material; and

(2) Contain less than $1000 \mathrm{~g}$ of plutonium, provided that: plutonium-239, plutonium-241, or any combination of these radionuclides, constitutes less than $240 \mathrm{~g}$ of the total quantity of plutonium in the package.

(d) The general license applies only to packages labeled with a CSI which:

(1) Has been determined in accordance with paragraph (e) of this section;

(2) Has a value less than or equal to 100; and

(3) For a shipment of multiple packages containing Pu-Be sealed sources, the sum of the CSls must be less than or equal to 50 (for shipment on a nonexclusive use conveyance) and less than or equal to 100 (for shipment on an exclusive use conveyance).

(e)

(1) The value for the CSI must be greater than or equal to the number calculated by the following equation:

$$
\mathrm{CSI}=10\left[\frac{\text { grams of }{ }^{299} \mathrm{Pu}+\text { grams of }{ }^{241} \mathrm{Pu}}{24}\right] \text {, and }
$$

(2) The calculated CSI must be rounded up to the first decimal place.

This general license provision requires calculating the CSI for special form Pu-Be sources with the equation in 10 CFR 71.23(e)(1), which requires the consignor to know the quantity (grams) of total plutonium, including ${ }^{239} \mathrm{Pu}$ and/or ${ }^{241} \mathrm{Pu}$, in the sources being packaged. The CSI limits for single and multiple packages containing fissile material based on the CSI equation and criteria in 10 CFR 71.23(e) are meant to control the accumulation of fissile material in special form Pu-Be source packages on a conveyance (Ref. 6). For a single package, the CSI for these sources can be as high as 100 . For shipment on a nonexclusive use conveyance, the CSI limit is smaller (50) and corresponds to half of the allowed $240 \mathrm{~g}$ mass limit for ${ }^{239} \mathrm{Pu},{ }^{241} \mathrm{Pu}$, or mixtures of the two nuclides in the package. For shipment on an exclusive use conveyance, a higher CSI limit of 100 is permitted due to the increased control on the shipment. A CSI limit of 100 corresponds to a total ${ }^{239} \mathrm{Pu}$ and ${ }^{241} \mathrm{Pu}$ mass equal to the subcritical mass limit of $240 \mathrm{~g}$. The general license criteria in 
10 CFR 71.23(d)(3) allow for a larger CSI for a single package $(C S I=100)$ than the general license criteria in 10 CFR 71.22(d)(2) $(\mathrm{CSI}=10)$ because of the lower likelihood of special form fissile material escaping and reconfiguring into an unfavorable geometry during an exclusive use conveyance hypothetical accident.

The mass limits in 10 CFR 71.23(c) limit the quantity of plutonium in the Pu-Be special form sources to $1,000 \mathrm{~g}$ or less to ensure that there is sufficient criticality safety margin. This provision also requires that less than $240 \mathrm{~g}$ of the total plutonium quantity in the package is ${ }^{239} \mathrm{Pu}$, ${ }^{241} \mathrm{Pu}$, or a combination of ${ }^{239} \mathrm{Pu}$ and ${ }^{241} \mathrm{Pu}$. To illustrate the difference between the fissile material exemption for Pu in 10 CFR 71.15(f) and the general license for special form Pu-Be sources, the $240 \mathrm{~g}$ fissile Pu limit for $10 \mathrm{CFR} 71.23$ does not require a certain percentage of nonfissile material mixed with the fissile material (Pu), whereas 10 CFR $71.15(\mathrm{f})$ requires more than $80 \%$ of the Pu in the package to be nonfissile material.

Provision 10 CFR 71.23(c)(1) requires that each package contain no more than a Type A quantity, as specified in Table A-1, " $A_{1}$ and $A_{2}$ Values for Radionuclides." This provision ensures that radiological limitations are maintained within each package. For example, the maximum radiological limits $\left(A_{1}\right.$ value for special form material) for ${ }^{239} \mathrm{Pu}$ and ${ }^{241} \mathrm{Pu}$ in Table $\mathrm{A}-1$ can be used to calculate the maximum quantity of these fissile nuclides allowed in a package, $4.35 \mathrm{~kg}$ and $11 \mathrm{~g}$, respectively. The Pu-Be general license allows for up to $1,000 \mathrm{~g}$ or less of $\mathrm{Pu}$ (up to $240 \mathrm{~g}$ total of ${ }^{239} \mathrm{Pu}$ and ${ }^{241} \mathrm{Pu}$ ) to be present in a Type A package. Up to $760 \mathrm{~g}$ of other $\mathrm{Pu}$ isotopes is permitted in the package along with the fissile isotopes. The maximum radiological limits for special form material for each isotope $\left({ }^{236} \mathrm{Pu}, 1.52 \mathrm{~g} ;{ }^{237} \mathrm{Pu}, 0.045 \mathrm{~g} ;{ }^{238} \mathrm{Pu}, 15.8 \mathrm{~g} ;{ }^{242} \mathrm{Pu}, 69,230 \mathrm{~g}\right.$; and ${ }^{244} \mathrm{Pu}, 61,111 \mathrm{~g}$ ) can be present in the package along with the two fissile forms of $\mathrm{Pu}$, up to the $1000 \mathrm{~g}$ limit. Thus, the consignor must ensure that no more than a Type A quantity of fissile material is present in a package but also that the package complies with the limitations of 10 CFR 71.23. Also, the 10 CFR 71.23 provisions currently do not allow the use of Type B packages for shipping Pu-Be source materials. This issue may be addressed in a future rulemaking to 10 CFR 71.

Provision 10 CFR 71.23(c)(2) limits the quantity of total plutonium present in the form of special form sources to $1,000 \mathrm{~g}$ or less. The fissile isotopes of plutonium, ${ }^{239} \mathrm{Pu}$ and ${ }^{241} \mathrm{Pu}$, are those of significance to nuclear criticality safety. Thus, ${ }^{239} \mathrm{Pu},{ }^{241} \mathrm{Pu}$, or combinations of these two isotopes are limited to $240 \mathrm{~g}$ or less of the total plutonium mass. For comparison, the acceptable subcritical mass limits of ${ }^{239} \mathrm{Pu}$ and ${ }^{241} \mathrm{Pu}$ are $370 \mathrm{~g}$ (Ref. 4) and $200 \mathrm{~g}$ (Ref. 26) respectively. The allowance for $240 \mathrm{~g}$ of fissile plutonium per package compared to the maximum general license allowance of $37 \mathrm{~g}$ of fissile plutonium per package has been made because of the increased confidence that the fissile plutonium in the special form capsules would not escape during an accident and reconfigure into an unfavorable geometry (Ref. 16). Ref. 4 provides a technical basis for the $240 \mathrm{~g}$ ${ }^{239} \mathrm{Pu}+{ }^{241} \mathrm{Pu}$ mass limit in the package that is based on the acceptable subcritical mass of $379 \mathrm{~g}$ for ${ }^{239} \mathrm{Pu}\left(k_{\text {eff }}=0.95\right)$ for a thick water reflected fissile material-water moderated system. Using the same basis as the fissile material general licenses for moderators with a hydrogen density greater than water, the fissile Pu mass limit is equal to $64 \%$ of the critical mass value of $379 \mathrm{~g}$ and is rounded down to $240 \mathrm{~g}$. The amount of fissile plutonium nuclides $\left({ }^{239} \mathrm{Pu}\right.$ and ${ }^{241} \mathrm{Pu}$ ) allowed in such a shipment is $24 \%$ of the total plutonium mass. Although typically limited in Pu-Be sources, the presence of the nonfissile plutonium isotopes will provide significant parasitic neutron absorption and will eliminate the potential for criticality. 


\section{EXAMPLE PROBLEMS}

This section provides hypothetical examples for the fissile exemption provisions in 10 CFR 71.15 and general license provisions 10 CFR 71.22 and 71.23. Each example problem was chosen based upon transportation scenarios that could illustrate how the provisions might be applied and justified.

\subsection{Fissile Material Exemption Examples}

\subsubsection{Small Samples}

A variety of small samples that have contamination-level quantities of fissile material present are required to be shipped for disposition purposes. The fissile material samples present were generated from plutonium-bearing processes. These samples are contaminated metal, swipes, laundry, condensate from various fissile processes, environmental liquids, etc. The environmental samples contain fissile material at very low concentrations (milligrams or micrograms of fissile material per liter). The total measured fissile material mass plus two times the measurement uncertainty (total quantity of ${ }^{239} \mathrm{Pu}$ and ${ }^{241} \mathrm{Pu}$ ) is significantly less than the $2 \mathrm{~g}$ fissile material exemption limit. Based on the measured quantity of fissile material present, these small samples can be shipped in an individual package within the $2 \mathrm{~g}$ exemption limit per individual package.

The $2 \mathrm{~g}$ fissile exemption in 10 CFR 71.15(a) was an obvious choice for this problem. This problem assumed that fissile mass was well known, but the content of the nonfissile materials present with the fissile material was not quantified. The need to quantify the amount of nonfissile material present along with the fissile material makes it difficult to comply with the requirements in 10 CFR 71.15(b) or 10 CFR 71.15(c). The requirements of 10 CFR 71.15(d) and 71.15(e) also do not apply due to the presence of plutonium in the samples. The samples contain both ${ }^{239} \mathrm{Pu}$ and

${ }^{241} \mathrm{Pu}$ with less than $200 \mathrm{~g}$ of ${ }^{239} \mathrm{Pu}$ and ${ }^{241} \mathrm{Pu}$ present; however, there is not enough information in the problem description to determine the quantity of nonfissile Pu present. Without knowing the quantity of nonfissile material present, the ratio of fissile Pu to nonfissile Pu cannot be calculated and compared to the $20 \%$ fissile Pu to nonfissile Pu limitation. These samples cannot be shipped using the requirements in 10 CFR 71.15(f).

These samples can also be handled in greater quantities under the general license regulations in 10 CFR 71.22 for licensees with an NRC-approved quality assurance program and no more than a Type A quantity of radioactive material in a Type A package. The need to quantify the amount of nonfissile material present along with the fissile material may make it difficult for a consignor to comply with the general license requirements to ship these sample materials under the fissile exemption provisions (10 CFR 71.15[b] and 71.15[c]).

\subsubsection{Plutonium-Contaminated Glove Box}

To support the decontamination and decommissioning of a plutonium processing facility, a glove box has been removed that contains $10 \mathrm{~g}$ of total $\mathrm{Pu}$ (including two times the measurement uncertainty) distributed uniformly on its interior surfaces. This is easily verified based on visual inspections of the interior surfaces. The glove box will be disassembled and packaged in a standard waste box for shipment to a waste repository. The glove box (mass of $300 \mathrm{~kg}$ ) is made of stainless steel and contains no other moderating substances except a clear plastic cover held in place with duct tape. The total Pu mass can be assumed to be the fissile isotope ${ }^{239} \mathrm{Pu}$ because it was used for weapons-grade plutonium processing operations. The quantity of ${ }^{239} \mathrm{Pu}$ clearly meets the $15 \mathrm{~g}$ fissile material limit. The solid nonfissile mass of the glove box is $300 \mathrm{~kg}$, which is much larger than required by the $200: 1$ ratio. The plastic bag mass is a negligible contribution to 
the nonfissile mass. Thus, the glove box can be shipped as fissile exempt material under 71.15(b).

Other fissile exemption regulations could have been applied to this example to determine if they could be used to ship the Pu-contaminated glove box. The exemption criteria from 10 CFR 71.15(c) do not apply to this example problem. Because 71.15(c) states the exemption applies only when there is, essentially, a homogeneous mixture of fissile and nonfissile material (diluent), this provision cannot be applied to surface contaminated items since the fissile and nonfissile materials are not mixed together in a homogeneous matrix.

The exemption regulation in 10 CFR 71.15(f) does not apply for this example problem. The contaminated glove box contains $10 \mathrm{~g}$ of total Pu based on physical measurements, which is assumed to be ${ }^{239} \mathrm{Pu}$. There is no information provided on the content of nonfissile Pu that could also be present to calculate the ratio of fissile Pu to nonfissile Pu to compare to the limit provided in the exemption. Thus, the 71.15(f) provision cannot be applied to this example problem.

The general license regulations in 10 CFR 71.22 can be considered for this example problem for licensees with an NRC-approved quality assurance program. In this case, there is a small quantity of plastic (negligible quantity) and a $300 \mathrm{~kg}$ stainless steel glove box present with $10 \mathrm{~g}$ of ${ }^{239} \mathrm{Pu}$. A Type A package is required by the general license provisions for the shipment, and there is no beryllium, graphite, or hydrogenous materials enriched in deuterium present. The general license provisions in 10 CFR 71.22 appear to be applicable to this problem; however, the use of a Type A package also involves radiological limitations based on the characteristics of the materials being shipped, in this case plutonium isotopes. The radiological limitations are provided in $10 \mathrm{CFR} 71$, Appendix A. Specifically, Table A-1 provides the $A_{1}$ and $A_{2}$ values for various radionuclides. The maximum mass of ${ }^{239} \mathrm{Pu}$ permitted in a Type $A$ package can be calculated by dividing the $\mathrm{A}_{2}$ value, $0.027 \mathrm{Ci}$, by the specific activity of ${ }^{239} \mathrm{Pu}, 0.062 \mathrm{Ci} / \mathrm{g}$. The quantity of ${ }^{239} \mathrm{Pu}$ permitted in a Type A package is $0.435 \mathrm{~g}$, which is far less than the $10 \mathrm{~g}$ of total Pu needing to be shipped. Thus, the fissile material general license cannot be used to ship this material.

\subsubsection{Uranium Contaminated Sludge}

Low-level waste (LLW) streams from various sites are contaminated with small concentrations of uranium. This LLW can be treated in a process to concentrate the wastes as sludge and place them into a $55 \mathrm{gal}(208 \mathrm{~L})$ drum that is filled with concrete for shipment to a disposal facility. Assume the density of the sludge is bounded by a value of $0.8 \mathrm{~g} / \mathrm{cm}^{3}$ and the density of the concrete is $2.3 \mathrm{~g} / \mathrm{cm}^{3}$. The sludge and concrete are mixed together and the fissile material present is essentially homogeneously distributed in the sludge/concrete mixture. The only fissile isotope present is ${ }^{235} \mathrm{U}$, and there is no beryllium, graphite, or hydrogenous substances enriched in deuterium present in the package. The volume of the sludge is approximately $100 \mathrm{~L}$, and the remainder of the drum volume, $108 \mathrm{~L}$, is filled with concrete. This example considers ${ }^{235} \mathrm{U}$-contaminated sludge with a concentration of $150 \mathrm{nCi} / \mathrm{L}$, based on sampling results. The sampling error for the ${ }^{235} \mathrm{U}$ data is $\pm 50 \%$. Based on the uncertainty in the sampling data, the total ${ }^{235} \mathrm{U}$ concentration in the sludge with two times the measurement uncertainty is equal to $300 \mathrm{nCi} / \mathrm{L}$ $(150 \mathrm{nCi} / \mathrm{L}+[2 \times 0.50 \times 150 \mathrm{nCi} / \mathrm{L}])$. Based on the ${ }^{235} \mathrm{U}$ concentration of $300 \mathrm{nCi} / \mathrm{L}$, the specific activity for ${ }^{235} \mathrm{U}, 2.2 \times 10^{-6} \mathrm{Ci} / \mathrm{g}^{1}$, and the sludge volume, $100 \mathrm{~L}$, the total ${ }^{235} \mathrm{U}$ mass can be calculated to be about $13.6 \mathrm{~g}\left(\left[300 \mathrm{nCi} / \mathrm{L} \div\left[10^{9} \mathrm{nCi} / \mathrm{Ci} \times 2.2 \times 10^{-6} \mathrm{Ci} / \mathrm{g}\right] \times 100 \mathrm{~L}\right)\right.$. The total sludge mass is $80,000 \mathrm{~g}\left(100 \mathrm{~L} \times 1,000 \mathrm{~cm}^{3} / \mathrm{L} \times 0.8 \mathrm{~g} / \mathrm{cm}^{3}\right)$, and the total concrete mass is $248,400 \mathrm{~g}$

\footnotetext{
${ }^{1}$ The ${ }^{235} \mathrm{U}$ Specific Activity is referenced from 10 CFR 71, Table A-1, "A $A_{1}$ and $A_{2}$ Values for Radionuclides."
} 
$\left([208 \mathrm{~L}-100 \mathrm{~L}] \times 1,000 \mathrm{~cm}^{3} / \mathrm{L} \times 2.3 \mathrm{~g} / \mathrm{cm}^{3}\right)$ for a total solid nonfissile mass of $328,400 \mathrm{~g}(80,000 \mathrm{~g}$ of sludge $+248,400 \mathrm{~g}$ of concrete). Thus, this waste stream can be transported as fissile exempt waste using the exemption in 10 CFR 71.15(b) because the total fissile material content is less than $15 \mathrm{~g}$, and the total solid nonfissile content exceeds that required by the 200:1 ratio. If lead, beryllium, graphite, or hydrogenous substances enriched in deuterium were present in the LLW drum, it would be allowed, but the quantity of these moderating substances could not be counted toward the total quantity of solid nonfissile material.

Other fissile exemption regulations could have been used to ship the uranium-contaminated sludge. The exemption criteria from 10 CFR 71.15(c) applies to this example as well. This example states that the material consists of low concentrations of solid fissile material commingled with solid nonfissile material. Based on the calculations above, there is more than $24,000 \mathrm{~g}$ of nonfissile material for every gram of ${ }^{235} \mathrm{U}$ present in the package, which meets the 2,000-to-1 nonfissile -to-fissile ratio specified in 10 CFR 71.15(c)(1)(i). The fissile material is dilute, with $13.6 \mathrm{~g}$ of ${ }^{235} \mathrm{U}$ distributed in about $328,400 \mathrm{~g}$ of nonfissile material, which is far less than the allowed fissile concentration of $180 \mathrm{~g}$ of ${ }^{235} \mathrm{U}$ distributed within $360 \mathrm{~kg}$ of contiguous nonfissile material.

The general license regulations in 10 CFR 71.22 can be applied to this problem for licensees with an NRC-approved quality assurance program as long as the material is shipped in a Type A package. Based on the information in the example problem, there is no beryllium, graphite, or hydrogenous materials enriched in deuterium present. The CSI can be calculated using the formula in 10 CFR 71.22(e)(1)-(5). The uranium enrichment is not provided in the example problem description, so the mass limits from Table 71-1 must be used. There are no moderating substances having an average hydrogen density greater than water present in the waste container, so the mass limits in column 1 in Table $71-1$ can be used (60 $\mathrm{g}$ for ${ }^{235} \mathrm{U}$ ). The CSI for this example is 2.3 [CSI $=10 \times\left(13.6 \mathrm{~g}\right.$ of ${ }^{235} \mathrm{U} \div 60 \mathrm{~g}$ of $\left.\left.{ }^{235} \mathrm{U}\right)\right]$. The calculated CSI for the package is less than 50 , which qualifies the package to be shipped on a nonexclusive use conveyance.

\subsubsection{Uranium-Contaminated Graphite}

A large quantity of uranium-contaminated graphite has been discovered during decommissioning activities. The graphite was exposed to uranium during critical experiments in the past and NonDestructive Assay (NDA) measurements indicate that less than $10 \mathrm{~g}$ of ${ }^{235} \mathrm{U}$ (including two times the measurement uncertainty) is present in a mass of graphite of approximately $2.5 \mathrm{~kg}$ consisting of "chunks" of graphite material. The uranium present is in the form of surface contamination. Based on the NDA measurement results and the mass of graphite present, a ratio of fissile material to nonfissile material present can be made. This ratio is calculated to be approximately $1 \mathrm{~g}$ of ${ }^{235} \mathrm{U}$ for $250 \mathrm{~g}$ of graphite present $\left(10 \mathrm{~g}^{235} \mathrm{U} \div 2500 \mathrm{~g}\right.$ graphite). The uranium is diluted with graphite material such that the fissile-to-nonfissile ratio $(1 / 250)$ is lesser than the ratio required by 10 CFR 71.15(b) (1/200). However, the provision requires that the solid nonfissile materials not contain graphite, a low-absorbing moderating material. Thus, the graphite cannot be shipped as fissile exempt material.

It is possible to use 10 CFR 71.15(c) to ship the uranium-contaminated graphite, provided nonfissile materials other than lead, beryllium, graphite, and hydrogenous material enriched in deuterium are present. These low neutron absorbing moderator and reflector materials cannot be included in the determination of the quantity of solid nonfissile material present. Thus, a solid nonfissile material (e.g., concrete or soil) can be added to the shipment in the required nonfissileto-fissile material ratio ( $2,000 \mathrm{~g}$ nonfissile material for every gram of fissile material) to be shipped 
as exempt from the requirements for fissile material, provided the material is mixed sufficiently to be considered commingled.

With some redistribution and repackaging, the general license regulations in 10 CFR 71.22 can also be used for NRC licensees with an NRC-approved quality assurance program. The quantity of ${ }^{235} \mathrm{U}$ present is compliant with the tabulated mass limits; however, the regulations only allow up to $500 \mathrm{~g}$ of graphite to be present in the shipment. The uranium-contaminated graphite can be shipped using this provision if less than $500 \mathrm{~g}$ graphite is present. Clearly, the quantity of ${ }^{235} \mathrm{U}$ present would remain under the Table 71-1 mass limit. The material would have to be shipped in a Type A package.

\subsubsection{Soils Contaminated with Fissile Material}

A particular site has an area with $5 \mathrm{~m}^{3}\left(5,000,000 \mathrm{~cm}^{3}\right)$ of soil homogeneously contaminated with uranium from numerous past experiments. The experiments were known to use uranium with maximum enrichment of $3 \mathrm{wt} \%{ }^{235} \mathrm{U}$. The soil density has been determined to be conservatively assessed as $1.33 \mathrm{~g} / \mathrm{cm}^{3}$, based on physical measurements of the medium textured soil present in the area. The quantity of uranium based on soil sample data is approximately $3 \times 10^{-3} \mathrm{~g} \mathrm{U} / \mathrm{g}$ soil (value represents the mean uranium value plus two times the measurement uncertainty). The total soil mass is approximately $6,650,000 \mathrm{~g}\left(5,000,000 \mathrm{~cm}^{3} \times 1.33 \mathrm{~g} / \mathrm{cm}^{3}\right)$, and, based on this quantity of soil, the quantity of uranium in the soil is about $19,950 \mathrm{~g}\left(6,650,000 \mathrm{~g}\right.$ soil $\times 3 \times 10^{-3} \mathrm{~g} \mathrm{U} / \mathrm{g}$ soil). This corresponds to about $599 \mathrm{~g}$ of ${ }^{235} \mathrm{U}$ contamination in the soil with uranium enriched to $3 \mathrm{wt} \%$ ${ }^{235} \mathrm{U}\left(19,950 \mathrm{~g} \mathrm{U} \times 0.03 \mathrm{~g}{ }^{235} \mathrm{U} / \mathrm{g} \mathrm{U}\right)$. To satisfy the exemption criteria of $10 \mathrm{CFR} 71.15(\mathrm{c})$, there has to be at least $2,000 \mathrm{~g}$ of solid nonfissile material (soil in this case) per gram of ${ }^{235} \mathrm{U}$ and no more than $180 \mathrm{~g}$ of ${ }^{235} \mathrm{U}$ distributed within $360 \mathrm{~kg}$ of contiguous nonfissile material. The results of this example show that there is $6,650,000 \mathrm{~g}$ of soil mixed uniformly with $599 \mathrm{~g}$ of ${ }^{235} \mathrm{U}$, a ratio of $11,102: 1$. This clearly meets the $2,000: 1$ ratio required by the exemption in addition to the concentration limit. Low neutron-absorbing moderators can be included in the package, but their mass cannot count toward the quantity of solid nonfissile material present.

The provision of 10 CFR 71.15(b) is applicable assuming it is practical for the uraniumcontaminated soil to be broken into smaller shipments to comply with the $15 \mathrm{~g}$ fissile material mass limit and the required $200 \mathrm{~g}$ solid nonfissile material for each gram of fissile material ratio. This is likely to be an impractical option with respect to the quantity of contaminated soil needing to be shipped.

The general license criteria in 10 CFR 71.22 can be used to ship the contaminated soil if the soil were significantly reduced in volume to comply with the shipping and packaging requirements. Each Type A package of uranium-contaminated soil would have to be measured for ${ }^{235} \mathrm{U}$ content and would need to satisfy the Table 71-1 mass limits to generate a CSI for the package. This provision would tend to be impractical compared with the option to use 10 CFR 71.15(c) because control over the shipment would be required, including mass limits, packaging, and labeling requirements.

\subsubsection{Contaminated Uranium Alumina Trap Contents}

At a gaseous diffusion plant, a 55 gal drum $(208 \mathrm{~L})$ contains used alumina $\left(\mathrm{Al}_{2} \mathrm{O}_{3}\right)$ trap mix $\left(\rho=0.8 \mathrm{~g} / \mathrm{cm}^{3}\right)$ used to filter out $\mathrm{UF}_{6}$ from a particular gas stream. The $\mathrm{UF}_{6}$ reacts with the water loaded on the alumina to form uranyl fluoride dihydrate $\left(\mathrm{UO}_{2} \mathrm{~F}_{2} \cdot 2 \mathrm{H}_{2} \mathrm{O}\right)$. Grab sample results of the spent alumina trap mix material have verified that the uranium enrichment is less than $2.0 \mathrm{wt} \%{ }^{235} \mathrm{U}$. These sampling results conservatively factor in two times the measurement uncertainties. 
Furthermore, the alumina was removed from a trap that had good gas flow, which ensures the alumina has a uniform quantity of uranium present throughout the trap (i.e., the mixture is homogeneous). This satisfies the 10 CFR 71.15(c) requirement that the fissile material is commingled with solid nonfissile material. Recent sampling data have confirmed previous sample results for the quantity of uranium present in the alumina and include two times the measurement uncertainty. There is approximately $8,000 \mathrm{~g}$ of uranium in the uranyl fluoride dihydrate present in the drum, which corresponds to about $160 \mathrm{~g}$ of ${ }^{235} \mathrm{U}$ based on a uranium enrichment of $2.0 \mathrm{wt} \%{ }^{235} \mathrm{U}$ $\left(8,000 \mathrm{~g} \mathrm{U} \times 0.02 \mathrm{~g}^{235} \mathrm{U} / \mathrm{g} \mathrm{U}\right)$. Based on the density of the alumina $\left(0.8 \mathrm{~g} / \mathrm{cm}^{3}\right)$ and the volume of the $55 \mathrm{gal}$ drum $(208 \mathrm{~L})$, the total mass of alumina is $166,400 \mathrm{~g}\left(0.8 \mathrm{~g} / \mathrm{cm}^{3} \times 208,000 \mathrm{~cm}^{3}\right)$. To meet the exemption criteria in $10 \mathrm{CFR} 71.15$ (c), there must be at least $2,000 \mathrm{~g}$ of solid nonfissile material per gram of fissile material. The nonfissile-to-fissile mass ratio for this example is 1,040:1, so the fissile exemption criterion cannot be met. For this exemption provision to be valid, based on the quantity of solid nonfissile material in the drum and the drum volume, less than about $83 \mathrm{~g}$ of ${ }^{235} \mathrm{U}(4,160 \mathrm{~g} \mathrm{U})$ can be present to meet the dilution criteria. The uranium-contaminated alumina in the drum could be split into multiple drums, and fresh alumina or other nonfissile material could be added and mixed to reduce the ratio of fissile material to nonfissile material.

The requirements in 10 CFR 71.15(b) could also be used to ship the uranium-contaminated alumina. Because the enrichment of the uranium contamination $\left(2 \mathrm{wt} \%{ }^{235} \mathrm{U}\right)$ and the total quantity of uranium $(8,000 \mathrm{~g})$ are known, the alumina can be split into multiple packages to comply with the $15 \mathrm{~g}$ fissile mass limit. Assuming the uranium is homogeneously distributed throughout the alumina, this requires more than eleven packages with $728 \mathrm{~g}$ of uranium per package ( $14.5 \mathrm{~g}$ of ${ }^{235} \mathrm{U}$ ) to comply with the requirements. To increase the nonfissile-to-fissile mass ratio, at least 2,900 $\mathrm{g}$ of fresh or clean alumina, or other solid nonfissile material, would need to be added to the existing fissile material mixture.

The 10 CFR 71.22 general license regulations can be applied to this example to generate a package CSI limit based on the contents. Using these regulations would require the licensee to have an NRC-approved QA program and the shipment would have to be made in a Type A package. There are no special moderating materials present in the waste materials. The CSI can be calculated based on the ${ }^{235} \mathrm{U}$ mass limits in Table $71-2$ for an enrichment of 2 wt \% ${ }^{235} \mathrm{U}, 246 \mathrm{~g}$ ${ }^{235} \mathrm{U}$. Assuming a Type A package can accept the volume of the contaminated alumina, the CSI for this package is 6.504 [CSI $=10 \times\left(8,000 \mathrm{~g}\right.$ uranium $\times 0.02 \mathrm{wt} \%{ }^{235} \mathrm{U}$ per gram of uranium

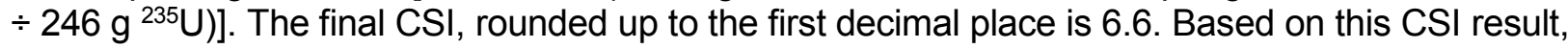
the package can be shipped with a CSI of less than 50 , which qualifies the package to be shipped on a nonexclusive use conveyance.

\subsubsection{Uranium-Contaminated Process Equipment}

Legacy equipment in a nuclear facility may contain fissile material in small quantities. For example, a converter from a gaseous diffusion plant may contain fissile material even following significant efforts to decontaminate the equipment non-destructively. Assume a converter from a gaseous diffusion plant processes uranium hexafluoride gas with uranium enrichment of $1.75 \mathrm{wt} \%{ }^{235} \mathrm{U}$. It is known that fissile material is present mainly as internal surface contamination. The interior portions cannot be visually inspected, and the equipment is known to contain less than $95 \mathrm{~g}$ of ${ }^{235} \mathrm{U}$, a value that contains at least two times the uncertainty of the NDA measurement. The site would like to ship this large item intact using fissile material exemption 10 CFR 71.15(c) because it contains significantly more fissile material than allowed by 10 CFR $71.15(a)$ and $71.15(\mathrm{~b})$, and the 2,000:1 ratio of nonfissile material to fissile material is clearly met based on the quantity of ${ }^{235} \mathrm{U}$ present and the large mass of the converter casing (nonfissile material). Based on operating experience, the consignor must assume that the fissile 
material present could redistribute during transportation operations, which is not consistent with the intent of 10 CFR 71.15(c) with respect to the fissile material being uniformly distributed within the nonfissile material, in this case the converter casing. Therefore, the converter cannot be shipped using the 10 CFR 71.15(c) fissile material exemption.

The size of the uranium-contaminated process equipment makes shipping options difficult. As discussed above, the fissile exemption regulations are not applicable to this situation. The general license requirements are an option; however, these requirements require an NRC-approved QA program and the use of a Type A package that meets the DOT requirements in 49 CFR 173.417(a). If a Type A package can be designed or is available to ship the converter, the general license requirements can be used for the equipment. The uranium enrichment for this problem, $1.75 \mathrm{wt} \%{ }^{235} \mathrm{U}$, is well within the enrichment data shown in Table 71-2, "Mass Limits for General License Packages Containing Uranium-235 of Known Enrichment per 71.22(e)." The CSI based on the ${ }^{235} \mathrm{U}$ present, $95 \mathrm{~g}$, and the mass limit for a ${ }^{235} \mathrm{U}$ enrichment of $1.75 \mathrm{wt} \%, 246 \mathrm{~g}$ for $2 \mathrm{wt} \%$ enrichment material (interpolation is not permitted and the next-highest enrichment value must be used), is $3.9(\mathrm{CSI}=10 \times[95 \div 246])$. Based on this CSI result, and assuming the converter can be shipped in a Type A package, a single or multiple converters can be shipped with a CSI of less than 50 , which qualifies the package to be shipped on a nonexclusive use conveyance.

\subsubsection{Shipment of Multiple Drums}

A temporary waste burial site that was used to bury metal drums of various kinds of wastes (e.g., uranium-contaminated piping, motors, tools, personnel protective equipment, etc.) has been exhumed for disposition to a permanent waste disposal site. During the excavation, operations personnel noticed that most of the metal drums had rusted sufficiently that the surrounding soil is suspected of being contaminated with radiological material, most of which is low-enriched uranium, greater than $1 \mathrm{wt} \%{ }^{235} \mathrm{U}$ enriched, based on historical records of the buried materials. The material was exhumed, including the contaminated soil, and repackaged into numerous steel drums with the fissile material carefully distributed throughout the nonfissile materials present. No lead, beryllium, graphite, or hydrogenous material enriched in deuterium was present in the loaded drums. Sample analysis results for the packaged drums indicate that all drums, except one, comply with the requirement in 10 CFR 71.15(c)(1) that there be at least $2,000 \mathrm{~g}$ of solid nonfissile material for every gram of fissile material present. The consignor noted that if all the drum ratio sample results were averaged together, all the drums would meet the 2,000:1 fissile material to nonfissile material ratio. However, the option to average the results of multiple drums to one result across multiple packages does not meet the intent of 10 CFR 71.15(c), which is that the material must be "commingled." The outlier drum should be separated from the rest of the drums to allow the other compliant drums to be shipped under this exemption.

The outlier drum could not be shipped as exempt from the definition of fissile material because the nonfissile-to-fissile material ratio was not greater than the 2,000-to-1 ratio required by 10 CFR 71.15(c)(1). A simple option would be to repack the drum into two or more drums with a nonfissile diluent added and properly commingled such that it effectively reduces the nonfissile-tofissile ratio above the 2,000:1. The fissile exemption requirements in $10 \mathrm{CFR} 71.15$ (b) could be applicable if less than $15 \mathrm{~g}$ of ${ }^{235} \mathrm{U}$ were present along with greater than a 200:1 ratio of nonfissile material to fissile material, excluding lead, graphite, beryllium, or hydrogenous materials enriched in deuterium. The example problem does not provide sufficient information to determine whether or not 10 CFR $71.15(b)$ is applicable. 
The general license requirements in 10 CFR 71.22 may be applicable to the outlier drum, depending upon the quantity of fissile material present and the characteristics of the nonfissile material in the drum. The general license requires an NRC-approved QA program and the use of a Type A package that meets the DOT requirements in 49 CFR 173.417(a).

\subsubsection{Uranium-Contaminated Oil}

This particular waste stream is prevalent in uranium enrichment operations where lubricating oils can become contaminated with uranium during operations. For this operation, the uranium is uniformly distributed throughout the oil based on the equipment in which the uranium and oil were mixed. The presence of uranium in hydrocarbon oil tends to significantly thicken the oil to the point that it will not flow freely, and operations personnel have to scoop the contaminated oil out of the equipment. The U-contaminated oil has been removed from the contaminated equipment and put into a 5.5 gal package for shipment to a disposal facility. This oil was sampled for enrichment but not for uranium mass. It is common for enrichment sample results to be reported with three times the measurement uncertainty at this particular site. For this case, the enrichment results for the oil are reported to be $0.92 \mathrm{wt} \%{ }^{235} \mathrm{U}$ meaning that the uranium present in the drum has been slightly enriched during diffusion plant operations. There is no ${ }^{233} \mathrm{U}$ or Pu present, nor are low neutronabsorbing moderators such as lead, beryllium, graphite, or hydrogenous materials enriched in deuterium. Based on these results, the drum can be shipped as exempt from fissile classification based on the criteria in 10 CFR 71.15(d) because of the enrichment and distribution of the uranium in the drum.

The ${ }^{235} \mathrm{U}$ mass is not provided in the example problem although it could be estimated based on the viscosity of the oil and uranium mixture and historical sample results that consider uranium loading as a function of viscosity. However, this step is not required if the enrichment is known to be less than $1 \mathrm{wt} \%{ }^{235} \mathrm{U}$. The $10 \mathrm{CFR} 71.15(\mathrm{a})$ fissile exemption may apply to this situation, but it may be more difficult to demonstrate compliance with the regulation for these provisions. Because the oil and uranium mixture is not a solid material, the fissile exemptions in 10 CFR 71.15(b) and 71.15(c) do not apply. The regulations for the general license in 10 CFR 71.22 could be applied to this example; however, it is far more practical and economical to use the fissile exemption in 10 CFR 71.15(d) based on the information provided in the example problem.

\subsubsection{Low-Enriched Uranium Waste}

A waste process designed to chemically extract uranium from low-enriched solutions produces a filtrate that is solidified and ground into powder for storage. A package of this powder is to be shipped to another location and contains $400 \mathrm{~g}$ of ${ }^{235} \mathrm{U}$ with an enrichment of $0.8 \mathrm{wt} \%{ }^{235} \mathrm{U}$. Confirmatory samples show that there are $3.4 \mathrm{~g}$ of ${ }^{233} \mathrm{U}$ and $0.4 \mathrm{~g}$ of ${ }^{239} \mathrm{Pu}$ also present. These values include the sample analysis measurement uncertainty. The three fissile isotopes are distributed homogeneously in the powder. These quantities meet the exemption criteria in $10 \mathrm{CFR}$ $71.15(\mathrm{~d})$ because the total mass of ${ }^{233} \mathrm{U}$ and $\mathrm{Pu}$ (all assumed to be ${ }^{239} \mathrm{Pu}$ ) is less than $1 \%$ of the mass of ${ }^{235} \mathrm{U}\left[\left(3.4 \mathrm{~g}\right.\right.$ of ${ }^{233} \mathrm{U}+0.4 \mathrm{~g}$ of $\left.{ }^{239} \mathrm{Pu}\right) \div\left(400 \mathrm{~g}\right.$ of $\left.{ }^{235} \mathrm{U}\right)=0.95 \%$ ]. There were no moderating substances present in the waste material, so the criterion involving the presence of the low neutron-absorbing moderators is met.

The fissile exemption regulations in 10 CFR 71.15(c) may be applicable to this example if a nonfissile diluent was added in a sufficient quantity and comingled with the fissile material present ([400 g of ${ }^{235} \mathrm{U}+3.4 \mathrm{~g}$ of ${ }^{233} \mathrm{U}+0.4 \mathrm{~g}$ of $\left.{ }^{239} \mathrm{Pu}\right] \times 2000 \mathrm{~g}$ nonfissile per gram of fissile $]=807,600 \mathrm{~g}$ nonfissile) to meet the $2,000 \mathrm{~g}$ of nonfissile per gram of fissile material ratio. Furthermore, the distribution of fissile material in the nonfissile material must be assured to preclude more than 
$180 \mathrm{~g}$ of fissile material per $360 \mathrm{~kg}$ of contiguous nonfissile material. The low-absorbing moderator materials cannot be included in the determination of the quantity of the nonfissile material present. The general license requirements in 10 CFR 71.22 may be used as well to ship the uranium powder with more rigorous justification and packaging requirements. Based on the information available in this situation, it is more economical and practical to use the fissile exemption criteria in 10 CFR 71.15(d).

\subsubsection{Uranium Metal Ingots}

Uranium metal ingots with an enrichment of about $0.995 \mathrm{wt} \%{ }^{235} \mathrm{U}$ are produced as part of a fissionable material process. The metal ingots are cylindrical in shape, have a total uranium metal mass of $500 \mathrm{~g}$ (final density of about $18 \mathrm{~g} / \mathrm{cm}^{3}$ ) each, and have the diameter and height of approximately $3.3 \mathrm{~cm}$ (height-to-diameter ratio of 1.0). Sixty-four ingots are stored in a fixture made of stainless steel to preclude their rearrangement during shipping operations, and the individual ingots have an average edge-to-edge spacing of approximately $2 \mathrm{~cm}$. The fixture has a configuration similar to a cubic array with four units in each dimension $(4 \times 4 \times 4)$. The total ${ }^{235} \mathrm{U}$ mass in the array of metal units is approximately $318 \mathrm{~g}(64$ units $\times 500 \mathrm{~g} \mathrm{U} / \mathrm{unit} \times 0.00995 \mathrm{~g}$ $\left.{ }^{235} \mathrm{U} / \mathrm{g} \mathrm{U}\right)$. The consignor would like to transport this package as exempt from the classification as fissile based on 10 CFR 71.15(d), valid for fissile material with a uranium enrichment of less than $1 \mathrm{wt} \%{ }^{235} \mathrm{U}$. The uranium metal has been purified and does not contain any plutonium isotopes or ${ }^{233} \mathrm{U}$, and there is no beryllium, graphite, or hydrogenous material enriched in deuterium present. The fissile exemption in 10 CFR 71.15(d) cannot be applied to fissile material in heterogeneous arrangements (i.e., a fixed, repeating array of fissile material lumps or distinct uranium metal units). It has been discussed previously that heterogeneous arrangement of low-enriched uranium can potentially be more reactive than homogeneous arrangements of the same material. Thus, these items cannot be shipped using 10 CFR 71.15(d).

The fissile material exemptions do not apply to this situation based on the information provided. However, the 10 CFR 71.22 general license regulations appear to apply. The site would need an approved Type A package and an NRC-approved QA program. There are no requirements in the general license criteria regarding the homogeneity of the fissionable material being shipped. The general license requirements are applied to this example in Sect. 5.2.3.

\subsubsection{Uranyl Nitrate Solution from Spent Fuel Reprocessing}

Uranyl nitrate solution that has been stored in $2 \mathrm{~L}$ bottles needs to be shipped to another site for research purposes. The facility is interested in using fissile exemption 10 CFR 71.15(e) for shipping these bottles. Each bottle contains $2 \mathrm{~L}$ of uranyl nitrate solution and no ${ }^{233} \mathrm{U}$ is present in the solution. The solution has an enrichment of $1.5 \mathrm{wt} \%{ }^{235} \mathrm{U}$ based on sampling data that, with measurement uncertainties factored in, clearly satisfies the enrichment limitation of $2 \mathrm{wt} \%{ }^{235} \mathrm{U}$ or less for the exemption in 10 CFR 71.15(e). The uranyl nitrate solution being shipped was the product of spent fuel reprocessing and has very small concentrations of plutonium present. According to sampling data taken at the time the uranyl nitrate solution was produced, the quantity of Pu present is approximately $10 \mu \mathrm{g}$ (measurement uncertainties included) and the Pu in the uranyl nitrate is expected to be uniformly distributed throughout all the uranyl nitrate solution stored in the 2 $L$ bottles. The sampling records indicate that the $N / U$ ratio is 3.7 , which satisfies the exemption criterion for minimum N/U ratio. To ensure the limit on plutonium content, which must be less than $0.002 \%$ of the mass of the total uranium present, the quantity of uranium in the $2 \mathrm{~L}$ bottle is determined from sampling data. According to the data logs, the uranium concentration is $200 \mathrm{~g} \mathrm{U} / \mathrm{L}$ (measurement uncertainty has already been factored into the concentration value). Thus, the uranium mass in the $2 \mathrm{~L}$ bottle of $400 \mathrm{~g}(200 \mathrm{~g} \mathrm{U} / \mathrm{L} \times 2 \mathrm{~L})$. Based on this uranium concentration, the 
maximum quantity of plutonium permitted in the $2 \mathrm{~L}$ bottle with uranyl nitrate solution is $0.008 \mathrm{~g} \mathrm{Pu}$ (400 $\mathrm{g} \mathrm{U} \times 0.002 \%$ ) and the total amount of Pu present in each $2 \mathrm{~L}$ bottle of solution is approximately $10 \mu \mathrm{g} \mathrm{Pu}\left(1 \times 10^{-5} \mathrm{~g} \mathrm{Pu}\right)$. Multiple $2 \mathrm{~L}$ bottles of uranyl nitrate solution can be transported using $10 \mathrm{CFR} 71.15(\mathrm{e})$ with these assumptions as long as the total amount of Pu in the Type A package is less than $0.008 \mathrm{~g} \mathrm{Pu}$. Based on the quantity of Pu in the $2 \mathrm{~L}$ bottle, $10 \mathrm{\mu g} \mathrm{Pu}$ $\left(1 \times 10^{-5} \mathrm{~g} \mathrm{Pu}\right)$, the requirements in $10 \mathrm{CFR} 71.15$ (e) can be used to ship the uranyl nitrate solution, a single bottle of uranyl nitrate can be shipped as fissile exempt inside a Type A package.

The only fissile material exemption specifically applicable to uranyl nitrate solutions is 10 CFR 71.15(e). The general license regulations in 10 CFR 71.22 can be applied to this shipping scenario assuming the site has an NRC-approved QA program. These regulations also require the use of a Type A package. Beryllium, graphite, or hydrogenous materials enriched in deuterium are not present with the fissile material. Each $2 \mathrm{~L}$ bottle of uranyl nitrate solution contains $400 \mathrm{~g}$ of Uranium at a ${ }^{235} \mathrm{U}$ enrichment of $1.5 \mathrm{wt}$. \%. The total mass of ${ }^{235} \mathrm{U}$ in each bottle is then $(400 \mathrm{~g} \mathrm{U} \times$ $0.015 \mathrm{~g}^{235} \mathrm{U}$ per $\left.\mathrm{g} \mathrm{U}\right)$ about $6 \mathrm{~g}^{235} \mathrm{U}$. The quantity of Pu present $(0.008 \mathrm{~g}$ of $\mathrm{Pu})$ is less than $1 \mathrm{wt} \%$ of the ${ }^{235} \mathrm{U}$ mass present in each bottle $\left(0.06 \mathrm{~g}\right.$ of $\left.{ }^{235} \mathrm{U}\right)$, which allows use of mass limits for 2 wt $\%{ }^{235} \mathrm{U}$ enrichment from Table $71-2\left(408 \mathrm{~g}\right.$ of $\left.{ }^{235} \mathrm{U}\right)$. The $\mathrm{CSI}$, rounded up to the nearest tenth, is $0.1 \mathrm{for}$ the uranyl nitrate $\left(\mathrm{CSI}=10 \times\left[6 \mathrm{~g}\right.\right.$ of ${ }^{235} \mathrm{U} \div 408 \mathrm{~g}$ of $\left.\left.{ }^{235} \mathrm{U}\right]=0.0147\right)$, which is less than the single package CSI limit of 10 . Single or multiple bottles of uranyl nitrate solution can be shipped up to the CSI limit of 50 for shipment on a nonexclusive use conveyance or the CSI limit of 100 for a shipment on an exclusive use conveyance.

For this example, the provisions of 10 CFR 71.15(e) or 10 CFR 71.22 appear to be applicable to the shipment of multiple $2 \mathrm{~L}$ bottles of uranyl nitrate solution in a single Type A package, assuming the radiological requirements are not exceeded.

\subsubsection{Uranyl Nitrate Solution Laboratory Experiments}

Uranyl nitrate solutions were used for various experiments at a site that processes uranium. The uranyl nitrate solutions are being shipped off-site to be converted to uranium oxide at another site. The solutions are stored in polyethylene $2 \mathrm{~L}$ bottles. Approximately $45 \mathrm{~g}$ of ${ }^{235} \mathrm{U}$ in uranyl nitrate is present in each bottle. The uranyl nitrate solution was generated from dissolving essentially pure uranium dioxide in nitric acid; thus, no other fissile isotopes are present. The solution was known to contain low-enriched uranium; however, sample and historical records had to be found to determine the enrichment of the solution. After this review was completed, the solution was determined to have an enrichment of $3.0 \mathrm{wt} \%{ }^{235} \mathrm{U}$. Thus, the bottles of uranyl nitrate solution cannot be shipped as fissile exempt material per 10 CFR 71.15(e) because the enrichment limit is 2.0 wt $\%{ }^{235} \mathrm{U}$ or less.

The only fissile material exemption specifically applicable to uranyl nitrate solutions is 10 CFR 71.15(e). The general license regulations in 10 CFR 71.22 can be applied to this shipping scenario assuming the site has an NRC-approved QA program. These regulations also require the use of a Type A package. There is no beryllium, graphite, or hydrogenous materials enriched in deuterium present with the fissile material. There is no ${ }^{233} \mathrm{U}$ or Pu present, so the mass limits for 3 wt $\%{ }^{235} \mathrm{U}$ enrichment from Table $71-2\left(150 \mathrm{~g}\right.$ of $\left.{ }^{235} \mathrm{U}\right)$ can be used. The CSI is calculated to be 3.0 for the uranyl nitrate $\left(\mathrm{CSI}=10 \times\left[45 \mathrm{~g}\right.\right.$ of ${ }^{235} \mathrm{U} \div 150 \mathrm{~g}$ of $\left.{ }^{235} \mathrm{U}\right]$ ), which is less than the single package CSI limit of 10 . Single or multiple bottles of uranyl nitrate solution can be shipped up to the CSI limit of 50 for shipment on a nonexclusive use conveyance. 


\subsubsection{Plutonium Oxalate Material}

Nitric acid dissolution operations are performed at a plutonium processing facility to capture plutonium from scrap plutonium-contaminated items such as glass, graphite casting molds, incinerator ash, etc. The resulting plutonium solutions are passed through a column packed with anion-exchange resin to capture the plutonium in the solution. This plutonium is then precipitated out of the solution and passed through a filter. The filtrate is then dried under vacuum and placed into a sealed container and put into a vault for storage. This material is now in the form of plutonium oxalate, which can be converted to plutonium oxide by calcination at high temperature. The oxalate contains $150 \mathrm{~g}$ of weapons-grade plutonium that consists of 5 at. $\%{ }^{240} \mathrm{Pu}(5.02 \mathrm{wt} \%$ $\left.{ }^{240} \mathrm{Pu}\right)$ and 95 at. $\%{ }^{239} \mathrm{Pu}\left(94.98 \mathrm{wt} \%{ }^{239} \mathrm{Pu}\right)$. No other plutonium isotopes are present in the plutonium oxalate. The quantity of ${ }^{239} \mathrm{Pu}$ in the container is $142.5 \mathrm{~g}$, which is significantly less than the maximum amount of fissile plutonium that could be shipped under 10 CFR 71.15(f); i.e., $200 \mathrm{~g}$ of fissile plutonium if the remainder up to the $1,000 \mathrm{~g}$ total is nonfissile plutonium. However, 10 CFR 71.15(f) cannot be used for shipping the package of plutonium oxalate because the ratio of nonfissile plutonium $\left({ }^{240} \mathrm{Pu}\right.$ ) to fissile plutonium $\left({ }^{239} \mathrm{Pu}\right)$ does not exceed $80 \%$ ( $800 \mathrm{~g}$ nonfissile mass to $1000 \mathrm{~g}$ fissile mass). In this case, the ratio of ${ }^{240} \mathrm{Pu}$-to- ${ }^{239} \mathrm{Pu}$ mass is much less than the required $80 \%$; thus, the package of plutonium oxalate cannot be shipped individually under 10 CFR 71.15(f). Furthermore, the quantity of ${ }^{239} \mathrm{Pu}$ needing to be shipped in this example problem would require a Type $B$ package because the quantity of ${ }^{239} \mathrm{Pu}$ present would exceed a Type A quantity of radioactive material.

The other fissile exemption regulations in 10 CFR 71.15 do not apply to this example. The 10 CFR 71.15(a) and 71.15(b) requirements are applicable for Pu systems; however, the quantity of $\mathrm{Pu}$ in this example exceeds the 10 CFR 71.15(a) and 71.15(b) mass limits $2 \mathrm{~g}$ and $15 \mathrm{~g}$, respectively.

The general license regulations in 10 CFR 71.22 do not apply to this example problem. The quantity of ${ }^{239} \mathrm{Pu}$ in this example, $142.5 \mathrm{~g}$, exceeds the ${ }^{239} \mathrm{Pu}$ mass limits in Table 71-1 (37 and 24 for moderating substances having an average hydrogen density less than or equal to water or greater than water, respectively). For this example, the plutonium could be sub-divided amongst multiple containers; however, a Type B container would be required to comply with radiological requirements.

\subsubsection{Plutonium-Contaminated Graphite Molds}

There are fissile processes at some sites that use graphite molds to cast plutonium metal parts. After the plutonium metal in the mold cools, it is removed from the mold and the mold pieces are crushed and placed into containers. The molds from multiple casting operations are combined into a single container with a volume of 5 gal (about $18.9 \mathrm{~L}$ ). Small quantities of plutonium remain in the molds. After the molds are crushed into a fine powder, the plutonium contamination is essentially homogeneously distributed in the graphite matrix. The 5 gal container holds the remains of 20 graphite molds that each contained approximately $4 \mathrm{~g}$ of ${ }^{239} \mathrm{Pu}$ and $40 \mathrm{~g}$ of ${ }^{240} \mathrm{Pu}$ of contamination (assume only ${ }^{239} \mathrm{Pu}$ and ${ }^{240} \mathrm{Pu}$ isotopes are present), based on a mass-balance after casting operations were completed. Thus, there is approximately $80 \mathrm{~g}$ of ${ }^{239} \mathrm{Pu}$ and $800 \mathrm{~g}$ of ${ }^{240} \mathrm{Pu}$ present. In this case, there is less than $1000 \mathrm{~g}$ total of Pu present $(880 \mathrm{~g})$ with less than $20 \%$ of the total ${ }^{239} \mathrm{Pu}(\sim 9 \%)$. Thus, the plutonium-contaminated graphite molds can be shipped using the exemption in 10 CFR 71.15(f). This exemption applies to the quantities of fissile and nonfissile $\mathrm{Pu}$ isotopes present and does not restrict the presence of graphite with the fissile material. 
The other fissile exemption regulations in 10 CFR 71.15 do not apply to this example. 10 CFR 71.15(a) and 71.15(b) are applicable for Pu systems; however, the quantity of Pu in this example exceeds the 10 CFR 71.15(a) and 71.15(b) mass limits of $2 \mathrm{~g}$ and $15 \mathrm{~g}$, respectively.

The general license regulations in 10 CFR 71.22 cannot be applied to this example problem. The quantity of ${ }^{239} \mathrm{Pu}$ in this example, $80 \mathrm{~g}$, exceeds the ${ }^{239} \mathrm{Pu}$ mass limits in Table 71-1 (37 and 24 for moderating substances having an average hydrogen density less than or equal to water or greater than water, respectively). For this example, the plutonium could be sub-divided amongst multiple containers; however, a Type B container would be required to comply with radiological requirements.

\subsection{General License Criteria Examples}

\subsubsection{Uranyl Nitrate Solution Laboratory Experiments}

In Section 5.1.13, the example for 10 CFR 71.15(e) regarding uranyl nitrate solutions is reconsidered as an example to meet the general license requirements in 10 CFR 71.22. This example could not be used to demonstrate meeting the requirements of $10 \mathrm{CFR} 71.15(\mathrm{e})$ because the enrichment of the ${ }^{235} \mathrm{U}$ in the uranyl nitrate was too high, $3.0 \mathrm{wt} \%{ }^{235} \mathrm{U}$. As previously stated, uranyl nitrate solutions were used for various experiments at a site that processes uranium. Some of these uranyl nitrate solutions are converted to uranium oxide at another facility. The solutions are stored in $2 \mathrm{~L}$ polyethylene bottles. Approximately $45 \mathrm{~g}$ of ${ }^{235} \mathrm{U}$ of uranyl nitrate is present in each bottle. The uranyl nitrate solution was generated by dissolving essentially pure uranium dioxide in nitric acid; thus, no other fissile isotopes are present. The solution was known to contain low-enriched uranium; however, sample and historical records had to be found to determine the enrichment of the solution. After this review was completed, the solution was determined to have an enrichment of $3.0 \mathrm{wt} \%{ }^{235} \mathrm{U}$, including measurement uncertainties.

The contents will be contained within a Type A package, with no more than a Type A quantity of total radioactive material present. There is no beryllium, graphite, or hydrogenous material enriched in deuterium present in the package. Furthermore, the licensee that will ship the package has an NRC-approved QA program meeting 10 CFR 71 Subpart $H$.

The CSI can be calculated by using the quantity of ${ }^{235} \mathrm{U}$ present in the $2 \mathrm{~L}$ bottle of uranyl nitrate solution, $45 \mathrm{~g}$. This mass quantity has already factored in uncertainties in the sampled data. The CSI equation with the mass of ${ }^{235} \mathrm{U}$ and the mass limit referenced from Table 71-2 for uranium of known enrichment ( 3 wt \% enriched in this case) is as follows:

$$
\begin{gathered}
C S I=10\left[\frac{\text { grams of }{ }^{235} \mathrm{U}}{\mathrm{X}}\right] \\
\mathrm{CSI}=10\left[\frac{45 \mathrm{~g}}{150 \mathrm{~g}}\right]=3.0
\end{gathered}
$$

The calculated CSI for the single package is less than the limit of 10 . The package will be shipped on a nonexclusive use conveyance, which has a total CSI limit of 50 based on the CSI of the package. The consignor can ship up to 16 bottles if desired on the nonexclusive use conveyance. 


\subsubsection{Uranium-Graphite Waste}

A particular fissile material operation generates wastes that contain a mixture of uranium, graphite, and other nonfissile solids after dissolution and precipitation operations. The enrichment of the uranium in the waste material is $20 \mathrm{wt} \%{ }^{235} \mathrm{U}$. The solids are transferred to a 5 gal drum $(18.9 \mathrm{~L})$ and placed in a Type A package after the operations are completed. The solids have an average uranium concentration of about $7.5 \mathrm{~g} \mathrm{U} / \mathrm{L}$. At $20 \mathrm{wt} \%{ }^{235} \mathrm{U}$, the concentration of ${ }^{235} \mathrm{U}$ is about $1.5 \mathrm{~g}^{235} \mathrm{U} / \mathrm{L}$. The quantity of ${ }^{235} \mathrm{U}$ in the $5 \mathrm{gal}$ drum is about $28.4 \mathrm{~g}\left(1.5 \mathrm{~g}^{235} \mathrm{U} / \mathrm{L} \times 18.9 \mathrm{~L}\right)$. Approximately $300 \mathrm{~g}$ of graphite (bulk density of $0.0159 \mathrm{~g} / \mathrm{cm}^{3}$ ) is present in the $5 \mathrm{gal}$ drum.

The contents will be contained within a Type A package, and no more than a Type A quantity of additional radioactive material is present in the container. Again, approximately $300 \mathrm{~g}$ of graphite is present inside the package and mixed with the fissile material, which is within the $500 \mathrm{~g}$ limitation. Furthermore, the licensee that will ship the package has an NRC-approved QA program as required by $10 \mathrm{CFR} 71$ Subpart $\mathrm{H}$.

The CSI can be calculated by using the quantity of ${ }^{235} \mathrm{U}$ present in the 5 gal drum, $28.4 \mathrm{~g}$, and the enrichment of the uranium, $20 \mathrm{wt} \%{ }^{235} \mathrm{U}$. This mass quantity has already factored in two times the measurement uncertainties in the sampled data. The CSI equation, with the mass of ${ }^{235} \mathrm{U}$ and the mass limit referenced from Table 71-2 for uranium of known enrichment, is as follows:

$$
\begin{aligned}
& C S I=10\left[\frac{\text { grams of }{ }^{235} \mathrm{U}}{\mathrm{X}}\right] \\
& \mathrm{CSI}=10\left[\frac{28.4 \mathrm{~g}}{63 \mathrm{~g}}\right]=4.507
\end{aligned}
$$

The final CSI is 4.6, rounded up to the next decimal place. The calculated CSI for the single package is less than the limit of 10 . The package will be shipped on a nonexclusive use conveyance which has a total CSI limit of 50. The consignor can ship multiple Type A packages if desired based on the calculated CSI.

If a general license is not desired for shipping the drum of uranium graphite waste, the fissile exemption criteria in 10 CFR 71.15(c) can be used for this example if nonfissile diluent is added to the package to ensure a nonfissile-to-fissile mass ratio is greater than 2,000-to- 1 . This regulation allows graphite to be present in the package along with the fissile material and diluent material but the graphite cannot be used to determine the required mass of solid nonfissile material in the package. Because there is less than $30 \mathrm{~g}$ of ${ }^{235} \mathrm{U}$ present in the package, the package will contain less than $180 \mathrm{~g}$ of fissile material distributed within the nonfissile matrix.

\subsubsection{Uranium Metal Ingots}

The uranium metal ingots from Sect. 5.1.11 cannot be shipped using the fissile material exemptions in 10 CFR 71.15. The consignor is now considering the requirements for a fissile material general license to ship the uranium metal ingots to another facility. As previously stated, the uranium metal units have an enrichment of about $0.995 \mathrm{wt} \%{ }^{235} \mathrm{U}$, including measurement uncertainties. The metal ingots are cylindrical in shape, have a total uranium metal mass of $500 \mathrm{~g}$ each (final density of about $18 \mathrm{~g} / \mathrm{cm}^{3}$ ), and have a diameter and a height of approximately $3.3 \mathrm{~cm}$ (height-to-diameter ratio of 1.0). Sixty-four ingots are stored in a fixture made of stainless steel to preclude their rearrangement during shipping operations, and the individual ingots have an 
average edge-to-edge spacing of approximately $2 \mathrm{~cm}$. The fixture has a configuration similar to a cubic array with four units in each dimension $(4 \times 4 \times 4)$. The total ${ }^{235} \mathrm{U}$ mass in the array of metal units is approximately $318 \mathrm{~g}$ (64 units $\left.\times 500 \mathrm{~g} \mathrm{U} / \mathrm{unit} \times 0.00995 \mathrm{~g}^{235} \mathrm{U} / \mathrm{g} \mathrm{U}\right)$. The consignor has an NRC-approved QA program, and the consignor can ship the uranium fixture and units in a Type A package. The $A_{1}$ and $A_{2}$ values are unlimited for ${ }^{235} \mathrm{U}$ and ${ }^{238} \mathrm{U}$, and there is no beryllium, graphite or hydrogenous materials enriched in deuterium present in the package. The consignor calculates the CSI based on the requirements in 71.22(e). The CSI equation from 71.22(e)(1) is used for the calculation. The ${ }^{235} \mathrm{U}$ mass for the calculation is the total ${ }^{235} \mathrm{U}$ present, $318 \mathrm{~g}$, and the value of the $\mathrm{X}$ for ${ }^{235} \mathrm{U}$ from Table $71-2$ is $1,020 \mathrm{~g}$ (rounded up to an enrichment of $1 \mathrm{wt} \%$ ).

$$
\begin{aligned}
& \text { CSI }=10\left[\frac{\text { grams of U-235 }}{X}\right] \\
& C S I=10\left[\frac{318 \mathrm{~g}}{1020 \mathrm{~g}}\right]=3.12(3.2)
\end{aligned}
$$

The CSI calculation resulted in a CSI of 3.2 (rounded up to the first decimal place). The value of the CSI is less than 10, which is the CSI limit for a single package. If other fissile items are to be shipped using a fissile material general license, the sum of the CSls must be less than or equal to 50 for shipment on a nonexclusive use conveyance or less than or equal to 100 for an exclusive use conveyance.

\subsubsection{Sealed Sources for Gamma-Ray Measurements}

A facility plans to ship a spherical sealed source containing depleted and highly enriched uranium (HEU) using the fissile material general license requirements in 10 CFR 71.22. The spherical source consists of four spherical shells with an HEU core. The core region contains a $53.76 \mathrm{~g}$ sphere of HEU (93 wt \% ${ }^{235} \mathrm{U}$ ) metal with a density of $19.05 \mathrm{~g} / \mathrm{cm}^{3}$ and a radius of approximately $0.86 \mathrm{~cm}$. The shell around the core region is a 5.14-cm-thick spherical shell of aluminum metal $\left(\rho=2.7 \mathrm{~g} / \mathrm{cm}^{3}\right)$, the third shell is a 2-cm-thick spherical shell of polyethylene $\left(\rho=0.92 \mathrm{~g} / \mathrm{cm}^{3}\right)$, and the last shell is a $0.5-\mathrm{cm}$-thick spherical shell of depleted uranium $\left(\rho=19.05 \mathrm{~g} / \mathrm{cm}^{3}\right)$. The depleted uranium (DU) is $0.3 \mathrm{wt} \%$ enriched ${ }^{235} \mathrm{U}$. The sealed source is shown in Fig. 9. The consignor would need to consider the total ${ }^{235} \mathrm{U}$ content present, as well as the mass of the polyethylene shell. Polyethylene has a larger hydrogen density than water; thus, the mass limits from Table 71-1, column 2, would apply ( $\leq 38 \mathrm{~g}$ of ${ }^{235} \mathrm{U}$ ). The total mass of ${ }^{235} \mathrm{U}$ present can be calculated based on volume. The mass of the HEU core is $53.76 \mathrm{~g}$, with an enrichment of $93 \mathrm{wt} \%{ }^{235} \mathrm{U}$. The ${ }^{235} \mathrm{U}$ mass in the core region is $50.0 \mathrm{~g}$ (53.76 $\mathrm{g} \mathrm{HEU} \times\left[0.93 \mathrm{~g}^{235} \mathrm{U} \div\right.$ gram HEU]). This exceeds the ${ }^{235} \mathrm{U}$ mass limit for a fissile material general license, and 10 CFR 71.22 does not apply.

If the polyethylene shell were not present, or was replaced with a material with a hydrogen density less than that of water, the larger ${ }^{235} \mathrm{U}$ mass limit would apply. In this case, the ${ }^{235} \mathrm{U}$ mass in the core, $46.5 \mathrm{~g}$, would be less than the mass limit in Table 71-1 for fissile material mixed or present with materials with a hydrogen density less than that of water. However, the calculation is not complete because the ${ }^{235} \mathrm{U}$ content in the DU has not been factored into the ${ }^{235} \mathrm{U}$ mass value. The $\mathrm{DU}$ is enriched to $0.3 \mathrm{wt} \%{ }^{235} \mathrm{U}$. The volume of the DU shell is $427.8 \mathrm{~cm}^{3}\left(4 \pi / 3 \times\left[\mathrm{r}_{\text {outer }} \mathrm{DU}\right.\right.$ shell ${ }^{3}-$ $\left.\left.r_{\text {inner DU shell }}{ }^{3}\right]=4 \pi / 3 \times\left[(8.5 \mathrm{~cm})^{3}-(8 \mathrm{~cm})^{3}\right]\right)$, and the density is $19.05 \mathrm{~g} / \mathrm{cm}^{3}$. The total ${ }^{235} \mathrm{U}$ mass in the depleted uranium shell is the volume of the DU shell multiplied by the density of the material $\left(19.05 \mathrm{~g} / \mathrm{cm}^{3}\right)$ and the ${ }^{235} \mathrm{U}$ enrichment $\left(0.3 \mathrm{wt} \%{ }^{235} \mathrm{U}\right)$, which is equal to approximately $24.4 \mathrm{~g}$ 
${ }^{235} \mathrm{U}$. The total ${ }^{235} \mathrm{U}$ in the sealed source is then the sum of the HEU core and the DU core, $74.4 \mathrm{~g}$ $\left(50.0 \mathrm{~g}^{235} \mathrm{U}\right.$ in HEU $+24.4 \mathrm{~g}^{235} \mathrm{U}$ in DU). Thus, even if the polyethylene shell was missing or replaced with another material, a fissile material general license could not be used to ship this sealed source.

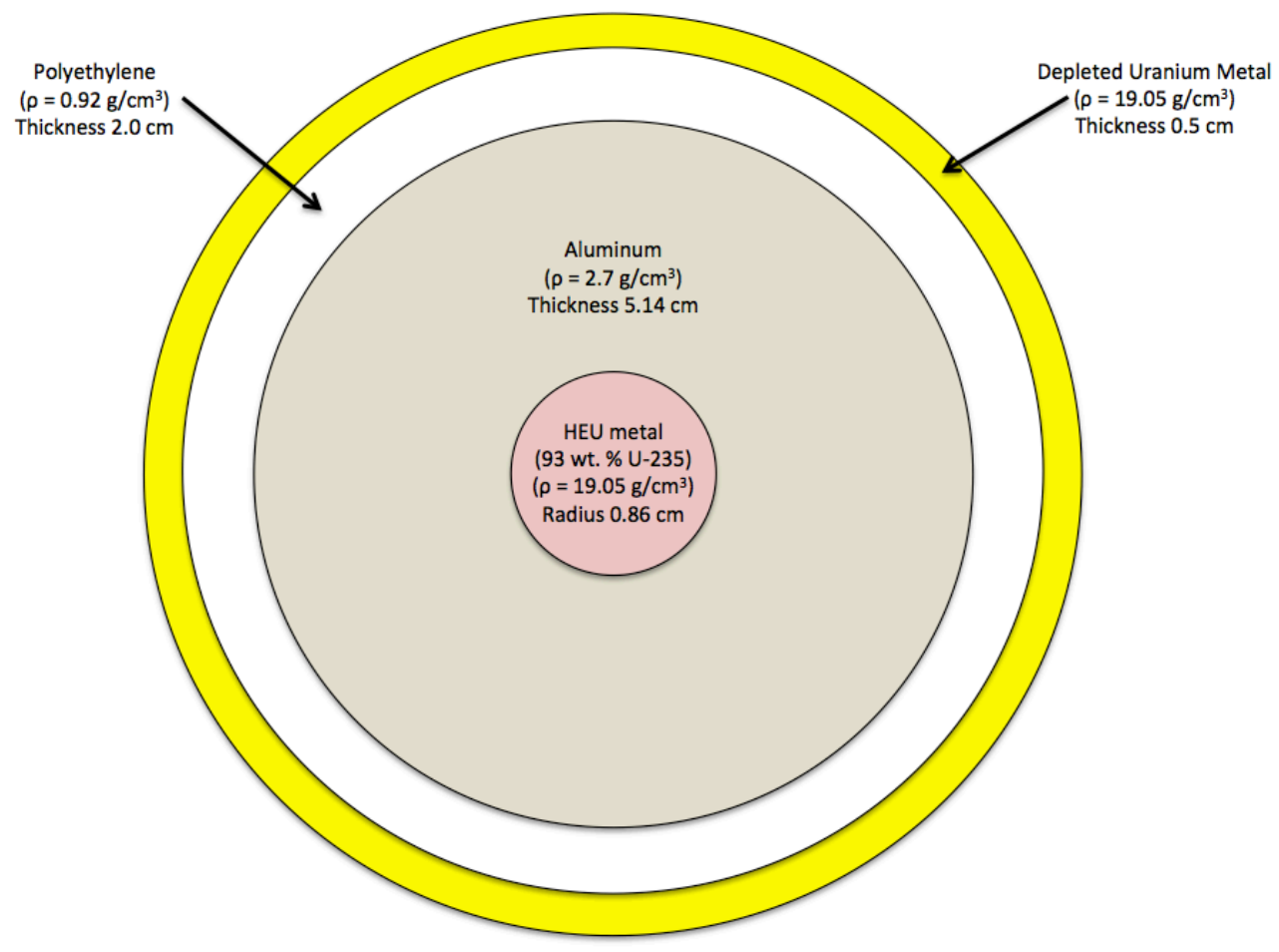

Figure 9 Illustration of the HEU Sealed Source in 10 CFR 71.22 Example 4 (Figure Not to Scale)

\subsubsection{Plutonium-Beryllium Sources}

Three plutonium-beryllium sources are to be shipped in a Type A package from one licensee to another to extract the plutonium from the sources for recycling purposes. The fissile content of the three sources is listed in Table 6. The licensee that will ship the package has an NRC-approved QA program as required by 10 CFR 71 Subpart $\mathrm{H}$. 
Table 6 Isotopic Breakdown of Pu-Be Sources for 10 CFR 71.23 Example Problem

\begin{tabular}{|l|c|c|c|}
\hline \multirow{2}{*}{ Source Number } & \multicolumn{2}{|c|}{ Fissile Content $\mathbf{( g )}$} & \multirow{2}{*}{ Total (g) } \\
\cline { 2 - 3 } & ${ }^{239} \mathrm{Pu}$ & ${ }^{241} \mathbf{P u}$ & \\
\hline $01-X Y Z 42$ & 1.50 & 0.75 & $\mathbf{2 . 2 5}$ \\
\hline $02-X Y Z 43$ & 4.20 & 0.13 & $\mathbf{4 . 3 3}$ \\
\hline $03-X Y Z 44$ & 3.00 & 0.62 & $\mathbf{3 . 6 2}$ \\
\hline \multicolumn{1}{|c|}{ Total (grams) } & $\mathbf{8 . 7 0}$ & $\mathbf{1 . 5 0}$ & $\mathbf{1 0 . 2 0}$ \\
\hline Specific Activity (Ci/g) & $6.20 \times 10^{-2}$ & $1.0 \times 10^{2}$ & - \\
\hline Activity Present (Ci) & 0.54 & 150.00 & - \\
\hline A $_{1}$ Special Form Limit & 270.00 & $1,100.00$ & - \\
\hline
\end{tabular}

The CSI can be calculated by using the total quantities for each fissile isotope, $8.7 \mathrm{~g}^{239} \mathrm{Pu}$ and $1.5 \mathrm{~g}^{241} \mathrm{Pu}$, from Table 6 . These mass values have measurement uncertainties conservatively factored into them.

$$
\begin{aligned}
& \mathrm{CSI}=10\left[\frac{\text { grams of }{ }^{239} \mathrm{Pu}+\text { grams of }{ }^{24} \mathrm{Pu}}{24}\right] \\
& \mathrm{CSI}=10\left[\frac{8.7 \text { grams }{ }^{239} \mathrm{Pu}+1.5 \text { grams }{ }^{24} \mathrm{Pu}}{24 \text { grams }}\right]=4.3
\end{aligned}
$$

The calculated CSI for the single package is less than the limit of 100 . The package can be shipped on a nonexclusive use conveyance, which has a total CSI limit of 50 . The consignor can ship up to 11 Type A packages if desired based on the results of the CSI calculation. To ensure the package meets the requirement in 10 CFR 71.23(c)(1) that it contain no more than a Type A quantity of radioactive material, the total activity is calculated based on the specific activity and $A_{1} / A_{2}$ values from 10 CFR 71, Table $A-1$, " $A_{1}$ and $A_{2}$ Values for Radionuclides." The special form limits apply to the Pu-Be sources, which are sealed capsules that meet the definition for special form radioactive materials in 10 CFR 71.4. The specific activity, $A_{1}$ values from Table $A-1$, and activities for ${ }^{239} \mathrm{Pu}$ and ${ }^{241} \mathrm{Pu}$ are provided in Table 6 . The $\mathrm{A}_{1}$ special form limit is also provided in Table 6 to compare the activity result to the special form limit. The results in Table 6 show that the quantities of ${ }^{239} \mathrm{Pu}$ and ${ }^{241} \mathrm{Pu}$ present are within the $\mathrm{A}_{1}$ special form limits for a Type $A$ package; thus, these Pu-Be sources can be shipped with the CSI limit of 4.3 in a Type A package.

Based on the quantities of fissile material present, $8.7 \mathrm{~g}$ of ${ }^{239} \mathrm{Pu}$ and $1.5 \mathrm{~g}$ of ${ }^{241} \mathrm{Pu}$, it is possible to apply the fissile material exemptions, 10 CFR 71.15(f), to this problem only if there is greater than about $40.8 \mathrm{~g}$ of nonfissile plutonium $\left(10.2 \mathrm{~g}{ }^{239} \mathrm{Pu}+{ }^{241} \mathrm{Pu} \div 0.2\right)$. The total amount of plutonium present is less than $1000 \mathrm{~g}\left(10.2 \mathrm{~g}-\right.$ sum of ${ }^{239} \mathrm{Pu}$ and $\left.{ }^{241} \mathrm{Pu}\right)$, which is required by $71.15(\mathrm{f})$, and less than $20 \%$ of the total plutonium present comprises fissile isotopes. However, there is no information in the example problem about the content of the nonfissile isotopes of plutonium present. Thus, the provisions of 10 CFR 71.15(f) cannot be applied to this situation. 



\section{CONCLUSIONS AND FUTURE WORK}

Title 10 of the United States (U.S.) Code of Federal Regulations (CFR), Part 71 (Ref. 26), Packaging and Transportation of Radioactive Material, contains requirements for exemption from classification as fissile material (10 CFR 71.15) and requirements for the general licenses for fissile material and plutonium-beryllium special form sources (10 CFR 71.22 and 71.23 , respectively). The U.S. regulations in 10 CFR 71 have undergone significant evolution throughout the years. An overview of the history, technical basis, and intent of each of the fissile material exemptions and general licenses has been provided in this document, along with examples of their use, to assist fissile materials licensees and NRC review staff in understanding the requirements to transport fissile material.

As this work was being completed, there were some potential opportunities for improvement compiled to improve the general licenses for fissile material in 10 CFR 71. Specifically, the provision for no ${ }^{233} \mathrm{U}$ in $10 \mathrm{CFR} 71.22(\mathrm{e})(5)(\mathrm{i})$ is overly restrictive given that small quantities of ${ }^{233} \mathrm{U}$ may be present along with ${ }^{235} \mathrm{U}$ in some circumstances, but those small quantities should not adversely impact nuclear criticality safety for a package. This issue could be resolved by modifying the provision to be similar to 10 CFR 71.22(e)(5)(ii), which limits plutonium to a mass percentage of the ${ }^{235} \mathrm{U}$. Additionally, there is a discrepancy between the limitation to a Type $A$ quantity of radiological material in 10 CFR 71.22(c)(1) and the mass limits for plutonium in Table 71-1. The mass limits in this table are significantly larger than the Type A radiological limit of $0.435 \mathrm{~g}{ }^{239} \mathrm{Pu}$ or $0.016 \mathrm{~g}{ }^{241} \mathrm{Pu}$. There are no nuclear criticality safety issues with using a Type $\mathrm{B}$ package for the amount of fissile material in Table 71-1 provided the package is certified for the radiological content. Therefore, the NRC may consider revising the general license provisions to allow for shipment in a Type B package. These issues may be addressed in a future rulemaking to 10 CFR 71.

The IAEA has regulations in SSR-6 that cover the packaging and transport of fissile material. These regulations have been historically similar to those in 10 CFR 71. With the 2012 Edition of the Regulations, the IAEA has significantly revised the approach used to provide exceptions for transport of fissile material in packages other than those certified for such transport (see Appendix $B$ for more detailed information). These regulations are not consistent with the exemptions from classification as fissile material and fissile material general licenses in 10 CFR 71. As in the past, the NRC will continue to monitor changes to the IAEA regulations and will seek compatibility wherever possible. 



\section{REFERENCES}

1 Title 10 of the Code of Federal Regulations Part 71, Energy, Office of the Federal Register National Archives and Records Administration, February 18, 2016.

2 International Atomic Energy Agency, Safety Standards Series No. SSR-6, Regulations for the Safe Transport of Radioactive Material, 2009 Edition, International Atomic Energy Agency, Vienna, 2012.

3 ANSI/ANS-8.1-2014, "Nuclear Criticality Safety in Operations with Fissionable Material Outside Reactors," American Nuclear Society, 2014.

4 C. V. Parks, C. M. Hopper, and J.L. Lichtenwalter, Assessment and Recommendations for Fissile-Material Packaging Exemptions and General Licenses Within 10 CFR 71, NUREG/CR-5342, (ORNL/TM-13607), U.S. Nuclear Regulatory Commission, Oak Ridge National Laboratory, July 1998.

D. M. Willaford, Radioactive Materials Packaging and Transportation Primer, United States Department of Energy, Oak Ridge Office, October 2011.

6 A. Barto, J. Smith, and C. V. Parks, "Bases for the General Licenses for Fissile Material and Exemptions from Classification as Fissile Material in 10 CFR 71, 'Packaging and Transportation of Radioactive Material'," Sixteenth International Symposium on the Packaging and Transportation of Radioactive Materials, October 3-8, 2010, London, United Kingdom.

$7 \quad$ Federal Register /, Vol. 62, No. 27, Monday, February 10, 1997 / Rules and Regulations 10 CFR 71, Fissile Material Shipments and Exemptions.

8 Green, R. "Nuclear Criticality Safety Concerns Related to Transport of U-BEO Waste," Trans. Am. Nucl. Soc., 76, pp. 256-257, Orlando, Fla., June 1-5, 1997.

$9 \quad$ NRC Information Notice 96-63. Potential Safety Issue Regarding the Shipment of Fissile Material, U.S. Nuclear Regulatory Commission, Washington, D.C., December 5, 1996.

10 International Atomic Energy Agency, Safety Standards Series No. TS-R-1, Regulations for the Safe Transport of Radioactive Material, 1996 Edition (As Amended 2003), International Atomic Energy Agency, Vienna, 2003.

11 Title 10 of the Code of Federal Regulations Part 71, Energy, Office of the Federal Register National Archives and Records Administration, January 1, 1998.

12 Federal Register / Vol. 67, No. 83, Tuesday, April 30, 2002 / Compatibility with IAEA Transportation Safety Standards (TS-R-1) and Other Transportation Safety Amendments.

13 D. Hammer, K. Blake, L. Massar, S. Matheson, E. Piendak, Summary and Categorization of Public Comments on the Major Revision of 10 CFR 71, U.S. Nuclear Regulatory Commission, NUREG/CR-6712, Apr. 2002.

14 Federal Register / Vol. 64, No. 207, Wednesday, October 27, 1999 / Fissile Material Shipments and Exemptions; Response to Comments and Request for Information.

15 International Atomic Energy Agency, "Consultant Services Meeting (CS-41) Development of Exceptions from the Regulations for Transport Packages Containing Fissile Material - Discussion of Fissile Exemption Criteria Proposed by the United States," Paris, France, March 15-17, 2004. 
16 Federal Register / Vol. 69, No. 16, Monday, January 26, 2004 / Compatibility with IAEA Transportation Safety Standards (TS-R-1) and Other Transportation Safety Amendments.

17 International Atomic Energy Agency, Safety Standards Series No. TS-R-1, Regulations for the Safe Transport of Radioactive Material, 1996 Edition (As Amended 2003), International Atomic Energy Agency, Vienna, 2003.

18 Title 10 of the Code of Federal Regulations Part 71, Energy, Office of the Federal Register National Archives and Records Administration, June 12, 2015.

19 SCALE: A Modular Code System for Performing Standardized Computer Analyses for Licensing Evaluation, ORNL/TM-2005/39, Version 6, Vols. I-III, January 2009. (Available from Radiation Safety Information Computational Center at Oak Ridge National Laboratory as CCC-750.)

20 K. R. Elam, C. M. Hopper, C. V. Parks and T. E. Harris, Emplacement Considerations for Criticality Safety in Low-Level-Waste Disposal, ORNL/TM-13765, Oak Ridge National Laboratory, 2001.

21 N. L. Pruvost and H. C. Paxton, Critical Dimensions of Systems Containing ${ }^{235} \mathrm{U},{ }^{239} \mathrm{Pu}$, and ${ }^{233}$ U, 1986 Revision, LA-10860-MS, Los Alamos National Laboratory (1986).

22 N. L. Pruvost and H. C. Paxton, Nuclear Criticality Safety Guide, LA-12808, Los Alamos National Laboratory (1996).

23 H. K. Clark, "Subcritical Limits for Uranium-235 Systems," Nucl. Sci. Eng., 81, 351-378, (1982).

24 D. W. Magnuson, Calculated Limiting Critical Concentrations of Plutonium in Natural Uranium and Water, Oak Ridge National Laboratory, ORNL/TM-5443 (1976).

25 American National Standards Institute, American Nuclear Society, Nuclear Criticality Control of Special Actinide Elements, ANSI/ANS-8.15-1981(R2005).

26 Title 10 of the Code of Federal Regulations Part 71, Energy, Office of the Federal Register National Archives and Records Administration, January 1, 2012. 


\section{APPENDIX A}

\section{BRIEF HISTORY OF 10 CFR 71 AND IAEA REGULATIONS FOR SAFE TRANSPORT OF RADIOACTIVE MATERIAL}

The early history of the regulations governing the transportation of fissile and other radioactive material has been previously discussed, in part, by Smith and Thomas (Ref. A1). Their paper provides chronological highlights of regulation development along with a brief discussion of the drivers of changes from 1936 to 1978. The brief history from that paper is provided below.

- United States post office issued an order banning "radium, thorium, or radioactive substances, or any material containing radioactive substances" due to mail shipments of radium occasionally fogging photographic film. Because of sensitive radiological detection instrumentation and strict interpretations of this order by some (radiation could be detected on or in most mail packages), an exemption was issued a few months later that allowed limited quantities of radium paint to be shipped when properly packaged (1936).

- The National Cancer Institute convened a conference to consider the safe transport of radium and resulted in criteria for the compatible transport of radium and film (1939).

- The Subcommittee on Shipment of Radioactive Substances of the Committee of Nuclear Science of the Division of Mathematical and Physical Sciences of the National Research Council developed a report (Ref. A2) that was a consistent and functional body of regulations that provided some twenty years of safety transport of radioactive materials, along with the bases behind them. These regulations introduced the concepts of exempt quantities of fissile material, of low specific activity material and of the isolation of radioactive materials and explosives that were transported together on rail cars (1951).

- The U.S. Atomic Energy Commission (AEC) adopted 10 CFR 71 regulations for the protection of inadvertent criticality in the shipment of special nuclear materials (1958). These regulations were replaced after a memorandum of understanding between the AEC and the Interstate Commerce Commission (ICC) was written in 1966 that stated the responsibility for regulation of carriers and consignors of radioactive materials belongs to the ICC but with the AEC establishing packaging standards for fissile materials and large quantities of radioactive material.

- The IAEA issued the first version of "Regulations for the Safe Transport of Radioactive Materials ${ }^{1}$," which at this stage mainly consisted of recommendations and not regulations (1961). This version of the regulations defined Fissile Classes I, II and III. Fissile I was defined such that an unlimited number of undamaged packages would be subcritical in any arrangement, or up to 250 would be subcritical in a damaged configuration. For Fissile II packages, an acceptable number of packages from a criticality safety standpoint was to be derived (five times the undamaged number of packages $\left\{N_{U}\right\}$ or two times the damaged number of packages $\left\{\mathrm{N}_{D}\right\}$ would be subcritical in a close-packed water-reflected array configuration). The smaller of the two numbers (i.e., $\mathrm{N}_{\cup}$ and $\mathrm{N}_{\mathrm{D}}$ ) would be divided into 50 to determine the minimum transport index for criticality safety purposes. The aggregate of package transport indexes was limited to a value of 50 for a single shipment.

\footnotetext{
${ }^{1}$ This document is now designated SSR-6, "Regulations for the Safe Transport of Radioactive Materials."
} 
It should be noted that the damaged package criteria were not added to the regulations until 1964. Fissile Class III shipments were those that required special arrangements for criticality safety control during transport and could have an aggregate of package minimum transport indexes no more than 100.

- The IAEA revised its regulations document (1964) with packaging test specifications and expanded the number of radiotoxicity groups to eight, and revised the document again (1967) to reduce the number of groups to seven and provided design principles for large radioactive source packages.

- The IAEA revised its regulations document again to eliminate the seven radiotoxicity groups and replaced them with two numerical limits, $A_{1}$ and $A_{2}$. Type $A$ packages are limited to $A_{1}$ curies in special form or $A_{2}$ curies in normal form (1973). According to Ref. $A 3, A_{1}$ is defined as the maximum activity of special form radioactive material permitted in a Type $A$ package, and $A_{2}$ is defined as the maximum activity of radioactive material, other than special form material, Low Specific Activity ${ }^{2}$, and Surface Contaminated Object ${ }^{3}$ material, permitted in a Type A package.

- The ICC regulations were superseded by regulations promulgated by the new Department of Transportation (DOT). The revised regulations were consistent with the 1967 version of the IAEA regulations. This led to two sets of criteria $\left(A_{1} / A_{2}\right.$ for IAEA or Groups I through VII for the DOT) and many in the United States wanted to revise the DOT regulations to be consistent with the IAEA regulations; however, this was not done until 1983 when both the DOT and NRC adopted regulations that essentially conformed (certain minor exceptions and differences remained) with the 1973 IAEA requirements (Safety Series 6).

Prior to 1996, fissile exemption and general license criteria in the regulations were based on criticality safety principles for fixed, well-known systems with common reflectors and moderators, such as water (Ref. A4). In 1996, the IAEA revised TS-R-1 regulations to limit the fissile mass per consignment $^{4}$ and to restrict the presence of certain low-neutron-absorbing moderators ${ }^{5}$ (e.g., beryllium, carbon and deuterium).

2 Per Ref. A3, Low Specific Activity (LSA) material means radioactive material with limited specific activity which is nonfissile or is excepted under 10 CFR 71.15, and which satisfies the descriptions and limits set forth below.

3 Per Ref. A3, a Surface Contaminated Object (SCO) means a solid object that is not itself classed as radioactive material, but which has radioactive material distributed on any of its surfaces.

4 A consignment is defined in the regulations as any package or packages, or load of radioactive material, presented by a consignor for transport.

5 A "special" moderator is one that is effective in slowing down neutrons without the characteristic of absorbing neutrons that is a characteristic of hydrogen in water. In some conservative situations, the critical concentration and minimum critical mass of fissile material can be lower than similar configurations that contain water. 


\section{REFERENCES}

A1 D. R. Smith and J. T. Thomas, Review of the Bases for Regulations Governing the Transport of Fissile and Other Radioactive Material, LA-UR-78-1296, Fifth International Symposium on Packaging and Transportation of Radioactive Materials, May 7-12, 1978, Las Vegas, Nevada.

A2 R. D. Evans, Physical, Biological, and Administrative Problems Associated with the Transportation of Radioactive Substances, National Academy of Sciences, National Research Council, Washington, D.C., 1951.

A3 Title 10 of the Code of Federal Regulations Part 71, Energy, Office of the Federal Register National Archives and Records Administration, February 18, 2016.

A4 C. V. Parks, "Technical Basis for Proposed Fissile Exemption Criteria for Transport Packages, Presentation for the $14^{\text {th }}$ International Symposium on the Packaging and Transportation of Radioactive Materials," Berlin, Germany, Sept. 24, 2004. 



\section{APPENDIX B}

\section{DISCUSSION OF IAEA REGULATIONS}

\section{B.1 Background}

The IAEA Regulations for the Safe Transport of Radioactive Material have, for over a 50-year period, provided specific requirements for packages certified for transport of fissile material. With the 2012 Edition of the Regulations (hereafter referred to as the 2012 Edition), the IAEA has significantly revised the approach used to provide exceptions (the IAEA uses the term "exceptions," whereas in the United States the term "exemptions" is used) for transport of fissile material in packages other than those certified for such transport. Prior to the 1996 Edition of the Regulations (hereafter referred to as the 1996 Edition), the criteria for exception from transport in certified packages indicated criticality safety would be assured regardless of packaging and without the need to control accumulations of packages or material. The adequacy of many of these criteria was challenged, particularly with regard to unintended accumulation of material and assurance of continued adherence to the criterion under accident conditions of transport. Thus, with the introduction of the 1996 Edition, many of the exception criteria were constrained by an imposed limit on the total mass of fissile material that could be shipped in a consignment.

Rather than resolve the discussion on exceptions for transport of fissile material, the 1996 Edition seemed to motivate further concerns, and by 2009 the IAEA had accumulated over 100 proposals recommending changes to the criteria that allow exceptions from requirements to transport fissile material in certified packages. The 2012 Edition of the Regulations provides a significant modification to the approach implemented for exceptions to the requirements for transport of fissile material. This Appendix provides a simplified overview of the requirements for packages certified for transport of fissile material and the categories of exceptions from these requirements that are allowed in the 2012 Edition.

\section{B.2 Packages Certified for Transport of Fissile Material}

Before discussing exceptions, it is beneficial to review the "standard" from which exceptions are allowed. Package designs certified for transport of fissile material must adhere to the requirements and provisions specified in paragraphs 676-686 of the 2012 Edition of the Regulations. These paragraphs provide the expectations that an applicant must demonstrate relative to subcriticality of individual packages and arrays of packages under normal conditions of transport and hypothetical accident conditions. Key requirements are:

1) " 5 times $\mathrm{N}$ packages shall be subcritical for the arrangement and package conditions that provide the maximum neutron multiplication" $\left(k_{\text {eff }}\right)$ consistent with normal conditions of transport, and

2) "2 times $\mathrm{N}$ packages shall be subcritical for the arrangement and package conditions that provide the maximum neutron multiplication" under hypothetical accident conditions.

For each requirement, the "package conditions" must assume the range of specified contents for the package, and unknown values associated with the contents must be assumed such that the 
highest value of $k_{\text {eff }}$ is obtained. Based on the assessment of these key requirements, the Criticality Safety Index (CSI) for each package is established to be

$$
\mathrm{CSI}=50 / \mathrm{N}
$$

where $\mathrm{N}$ is selected to be the smaller of the two values determined from the subcriticality assessments for normal conditions of transport and hypothetical accident conditions.

The CSI value is included in the package certificate issued by the competent authority and is used to provide a means of control over the accumulation of packages during transport. For example, if $\mathrm{N}=5$ for the purpose of determining the CSI per Eq. 1, then the CSI = 10 for the package. The CSI for a conveyance of packages must be limited to 50 unless the package is loaded, transported, and unloaded by a single consignor under exclusive use (in which case a CSI up to 100 is allowed subject to approval by the governing regulatory agency of the IAEA Member State).

Finally, packages certified by a competent authority will have an " $F$ " as part of the type code on the certificate and must be shipped with a label that identifies the contents have been classified as "FISSILE" consistent with shipping names and descriptions established by the United Nations. The label also must include the CSI value consistent with the certificate issued by the regulatory body of the IAEA Member State.

\section{B.3 Transport of Fissile Material in Packages Not Certified by the Regulatory Agency}

The IAEA Regulations provide the general expectation that all fissile material be transported so as to maintain subcriticality, but they also provide for exceptions that allow fissile material to be transported in packages not certified by the governing regulatory agency. Fundamentally, the IAEA provides two types of exceptions, where the fissile material is classified as "FISSILE" and subject to CSI control and exceptions where the fissile material is not classified as "FISSILE" and the transport is not subject to CSI control.

The exceptions that require CSI control are very similar to those of the general licenses in 10 CFR 71.22. The criticality safety during transport is assured largely on the fact that the respective mass of fissile material is controlled per the CSI to assure that $5 \mathrm{~N}$ packages are subcritical under normal conditions of transport and $2 \mathrm{~N}$ packages are subcritical under hypothetical accident conditions. The use of CSI control requires that each package must be classified as "FISSILE" and labeled with the proper CSI to control accumulation below the limiting safe mass values.

The IAEA Regulations have a provision very similar to 10 CFR $71.15(\mathrm{f})$ whereby up to $1 \mathrm{~kg}$ of plutonium need not be shipped in a package certified for transport of fissile material provided not more than $20 \%$ of the plutonium mass consists of fissile nuclides of plutonium (e.g., ${ }^{239} \mathrm{Pu}$ and ${ }^{241} \mathrm{Pu}$ ). This historic exception has been included in the 2012 Edition, but with the new requirement that the package be classified as "FISSILE" and a CSI be provided on the package label to assure accumulation control.

The second type of exception within the 2012 Edition are those where the fissile material is not classified as "FISSILE." However, unlike the approach used for the exemptions of 10 CFR 71.15(a)-(c), the 2012 Edition limits the quantity of fissile nuclides per package and combines that with a mass limit on the consignment. The mass of fissile material allowed per package is $2 \mathrm{~g}$ with a consignment limit of $15 \mathrm{~g}$. For uranium with enrichments less than $5 \mathrm{wt} \%$ ${ }^{235} \mathrm{U}, 3.5 \mathrm{~g}$ per package is allowed, provided the consignment is limited to $45 \mathrm{~g}$. Additionally, paragraph $417(\mathrm{e})$ allows shipment of up to $45 \mathrm{~g}$ fissile material, packaged or unpackaged, 
provided the shipment is made under exclusive use (i.e., the conveyance is limited to $45 \mathrm{~g}$ fissile material). The exemptions of 10 CFR 71.15 (d)-(e) are also included within the 2012 Edition.

\section{B.4 Exception from Definition as Fissile Material}

The 2012 Edition of the Regulations defines fissile material to be material containing fissile nuclides defined as ${ }^{233} \mathrm{U},{ }^{235} \mathrm{U},{ }^{239} \mathrm{Pu}$, and ${ }^{241} \mathrm{Pu}$. Excluded from the definition of fissile material is natural uranium or depleted uranium that is unirradiated or that has been depleted in thermal reactors only. With the 2012 Edition, the definition was expanded to exclude material with less than $0.25 \mathrm{~g}$ of fissile nuclides. This exclusion was added in recognition that many materials have trace quantities of fissile nuclides and the intent of the Regulations is not to have such materials governed under the requirements set forth for fissile material. 



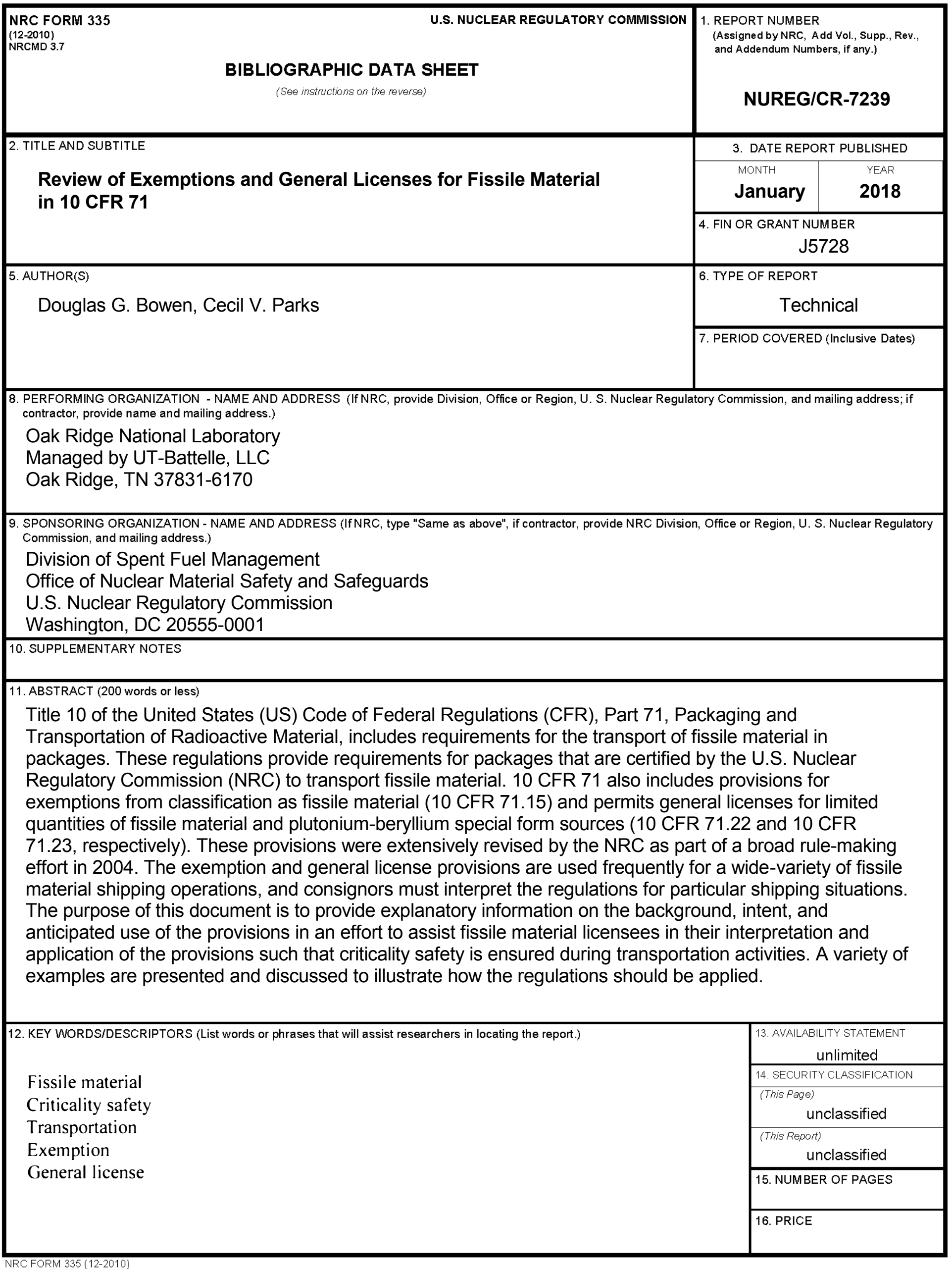


$\theta$ 



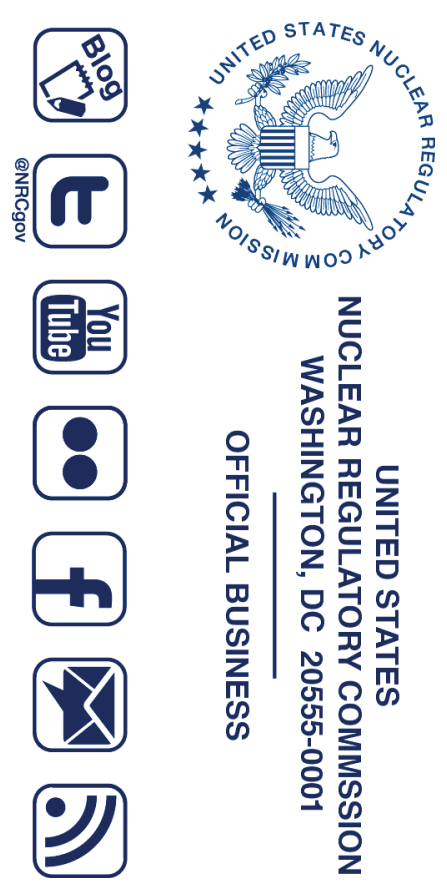



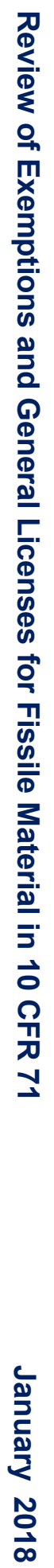